Portland State University

PDXScholar

$1-1-1987$

\title{
Interregional Competition in the Wood Products Industry: An Econometric Spatial Equilibrium Approach
}

M. Hossein Haeri

Portland State University

Follow this and additional works at: https://pdxscholar.library.pdx.edu/open_access_etds Let us know how access to this document benefits you.

\section{Recommended Citation}

Haeri, M. Hossein, "Interregional Competition in the Wood Products Industry: An Econometric Spatial Equilibrium Approach" (1987). Dissertations and Theses. Paper 539.

https://doi.org/10.15760/etd.539

This Dissertation is brought to you for free and open access. It has been accepted for inclusion in Dissertations and Theses by an authorized administrator of PDXScholar. Please contact us if we can make this document more accessible: pdxscholar@pdx.edu. 
INTERREGIONAL COMPETITION IN THE WOOD PRODUCTS INDUSTRY: AN ECONOMETRIC SPATIAL EQUILIBRIUM APPROACH

\section{by}

M. HOSSEIN HAERI

A dissertation submitted in partial fulfillment of the requirements for the degree of

DOCTOR OF PHILOSOPHY
in
URBAN STUDIES:
REGIONAL SCIENCE

Portland State University 1987 
TO THE OFFICE OF GRADUATE STUDIES AND RESEARCH

The members of the committee approved the dissertation of M. Hossein Haeri presented May 2I, 1987.

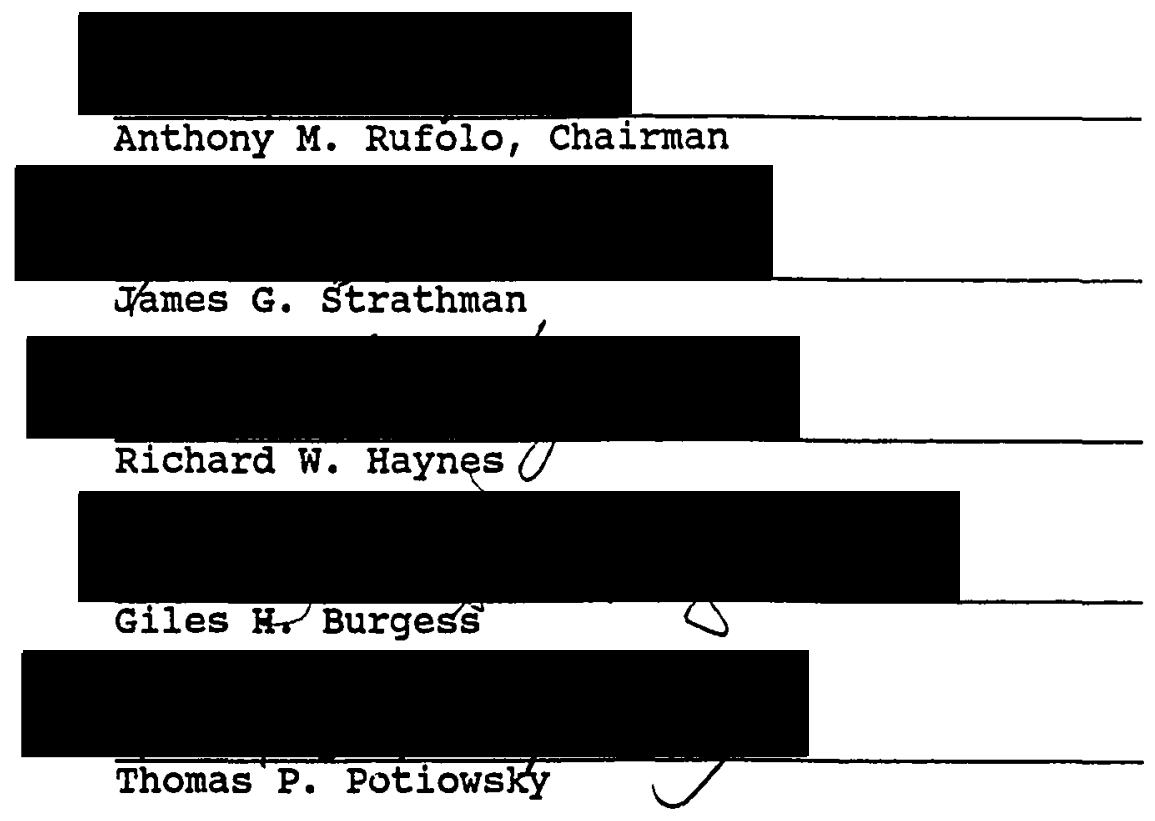

APPROVED:

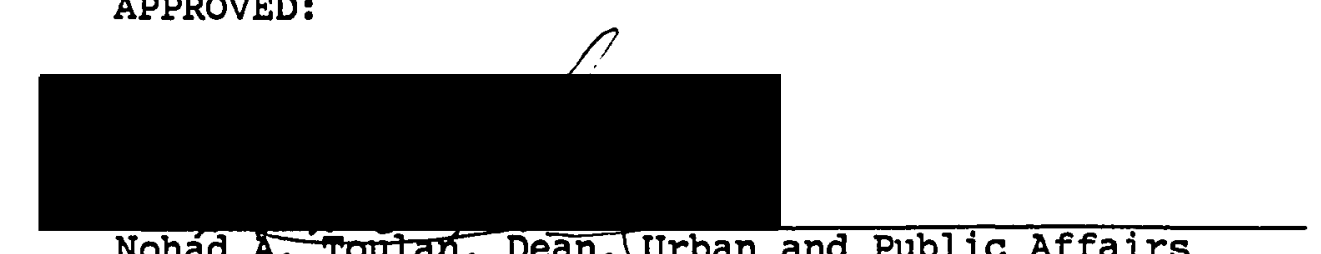

Nohád A. Toưlan, Dean, Urban and Public Affairs

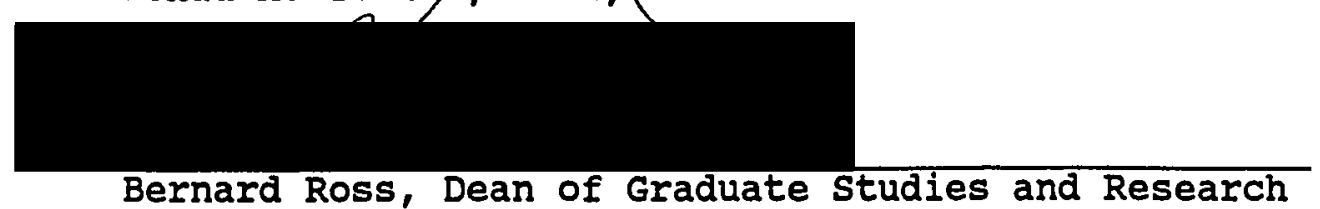


AN ABSTRACT OF THE DISSERTATION OF M. Hossein Haeri for the Doctor of Philosophy in Urban Studies: Regional Science presented May 21, 1987.

Title: Interregional competition in the wood Products Industry: An Econometric Spatial Equilibrium Approach .

APPROVED BY MEMBERS OF THE DISSERTATION COMMITTEE:

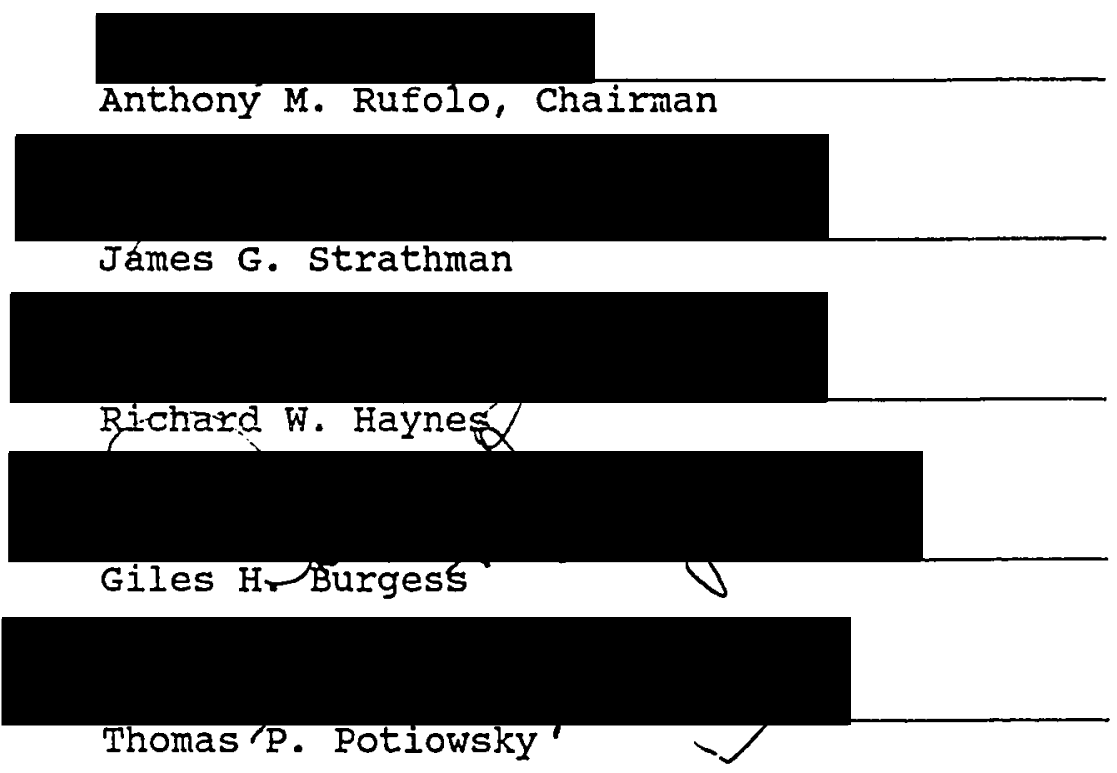

This study presents a multiregional model of the softwood forest products industry in the United States, designed to describe the dynamics of interregional competition in the industry and to provide a means for policy experimentation and short-term projection of regional market shares. Two 
products (softwood lumber and plywood), five product supply regions (including Canada), and six product demand regions are recognized. The design of the model is based on a combined top-down/bottom-up approach and consists of three interdependent components: 1) the aggregate product market, 2) regional product markets, and 3) regional factor markets. Model solutions are obtained by the simultaneous determination of national level product prices and quantities and allocation of equilibrium quantities across producing regions on the basis of their relative prices and locational advantage.

The model is evaluated in an historical simulation using data for 1950-84. Graphical analysis of simulated series suggests that the model replicates short-run trends as well as cyclical movements in aggregate demand and regional market shares. The results indicate that the shortrun impacts of relative prices and locational advantage on regional market shares are generally small. Price responsiveness of regional market shares for lumber appear to be considerably lower than that of plywood, indicating greater degrees of regional substitution in the plywood market.

The forecasting application of the model is demonstrated by extrapolating the complete structure for two years beyond the sample period. The projected trend during this two-year period is one of increasing demand for both lumber and plywood. Domestic producers' shares of the lumber market are expected to remain relatively stable. The results show 
that nearly all increases in demand for lumber in this period will be satisfied by Canadian imports. 


\section{ACKNOWLEDGEMENTS}

All credit for this work is shared in equal proportions with my wife Mary and my daughter Mana. Without their affectionate support and unyielding patience, I could have never completed this work.

I am indebted to professors Anthony Rufolo and James Strathman, teachers and friends, who inspired and guided me throughout my graduate studies at Portland state University. They helped me overcome my ignorance in many areas of regional economics without compromising my self confidence.

My enduring gratitude goes to Dr. Richard Haynes of the Pacific Northwest Forest and Range Experiment station in Portland for giving me so much of his valuable time whenever I needed it; and for his many scholarly works that lit my way through the deep forests of the wood products economy.

Professors Tom Potiowsky and Giles Burgess of the Economics Department at Portland State University provided many valuable comments on earlier drafts of this document.

I also acknowledge with gratitude the receipt of financial assistance from the school of Urban and Public Affairs during the course of my graduate studies at Portland State University. 
TABLE OF CONTENTS

PAGE

ACKNOWLEDGEMENTS $\ldots \ldots \ldots \ldots \ldots \ldots \ldots \ldots \ldots \ldots \ldots \ldots \ldots \ldots$ ii

LIST OF TABLES $\ldots \ldots \ldots \ldots \ldots \ldots \ldots \ldots \ldots \ldots \ldots \ldots \ldots \ldots \ldots \ldots$

LIST OF FIGURES $\ldots \ldots \ldots \ldots \ldots \ldots \ldots \ldots \ldots \ldots \ldots \ldots$ viii

CHAPTER

I INTRODUCTION $\ldots \ldots \ldots \ldots \ldots \ldots \ldots \ldots \ldots \ldots \ldots \ldots$

The Methodological Perspective ........ 4

The Theoretical Framework $\ldots \ldots \ldots \ldots \ldots \ldots$. 7

Product Demand

Demand for Regional Products

Regional Product Supply

Regional Factor Markets

The Complete Model

II THE INDUSTRY $\ldots \ldots \ldots \ldots \ldots \ldots \ldots \ldots \ldots \ldots \ldots \ldots . \ldots . \ldots . \ldots . \ldots$

The structure of the Industry ........ 25

The Market Process ................ 27

The Spatial Dimension ............. 32

Regional Market Shares ............. 35

Regional Timber Resources............ 42

III THE EMPIRICAL MODEL ................. 52

The Model, Its structure, and Components . 55

Model Estimation ................ 58 
Model Components ...................

The Aggregate Product Market

Regional Stumpage Markets

Regional Product Markets

Regional Market Shares

IV MODEL VALIDATION ................... 89

Validation in Parameter Estimates ....... 89

Validation in Simulation and Forecasting . 97

Concluding Remarks ................ 115

IITERATURE CITED $\ldots \ldots \ldots \ldots \ldots \ldots \ldots \ldots \ldots \ldots \ldots \ldots \ldots \ldots$

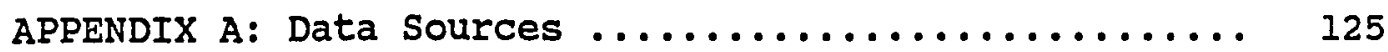

APPENDIX B: Average Hourly Earnings in Manufacturing and Lumber \& Wood Products ........... 127

APPENDIX c: Labor Productivity in Lumber and Plywood Production ....................... 128

APPENDIX D: Producer Price Indexes for Transportation Services and Lumber \& Wood Products

Freight ......................... 


\section{LIST OF TABIES}

I Domestic Lumber Consumption by End Use

Category (Percent of Total Consumption) ...... 28

II Lumber and Plywood Production Processes ...... 30

III Regional Lumber Market Shares

(\% Total Consumption) ................ 36

IV Regional Plywood Market Shares

(\% Total Consumption) ................. 39

$\mathrm{V}$ Distribution of Timberlands by Region and

Ownership in 1977 (MM Acres) ............ 44

VI Annual Harvest of Softwood Timber by Region and Ownership $(1950-1984) \ldots \ldots \ldots \ldots \ldots \ldots . \ldots . \ldots$

VII Volume of Softwood Sawtimber by Region and Ownership 1977 (MM BFt.) ................... 50

VIII Parameter Estimates of the Model ........... 60

IX Description of Variables Used in the Model .... 64

X Estimation Results for Regional stumpage Price

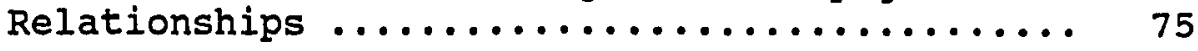

XI Estimates of Regional Elasticities of Private Stumpage Supply ................... 77

XII Interregional Transport Costs for Lumber 1977 ( $\$$ per MBFt. Deflated) .............. 87

XIII Interregional Trapsport Costs for Plywood 1977 ( $\$$ per MBFt. ${ }^{2}$ Deflated) ............ 87

XIV Regional Indexes of Accessibility Lumber and Plywood ................... 88

XV Impact Multipliers for selected Explanatory Variables: Regional Lumber Output (Measured as

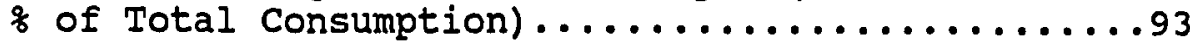


XVI Impact Multipliers for selected Explanatory Variables: Regional Lumber Market Shares........95

XVII Projected Values for Major Softwood Lumber and Plywood Market Variables ............... 112

XVIrI Average Hourly Earnings in Manufacturing and Lumber \& Wood Products ........... 127

XIX Labor Productivity in Lumber and Plywood

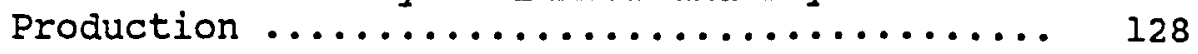

XX Producer Price Index: Transportation Services and Lumber \& Wood Products Freight ......... 129 


\section{LIST OF FIGURES}

1. Effects of Alternative Assumptions Regarding Elasticities of Supply ............... 16

2. Model Flow Schematic ................... 22

3. Major Products and stages in the Processing

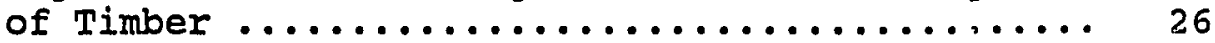

4. Product Supply Regions ................... 34

5. Product Demand Regions .................. 34

6. Regional Market Shares in Lumber as Percent of Apparent Consumption $(1950-1984) \ldots \ldots \ldots \ldots . . .40$

7. Regional Plywood Market Shares as Percent of Apparent Consumption $(1950-1984) \ldots \ldots \ldots \ldots . . .40$

8. Canadian Lumber Production, Consumption and Exports .......................... 41

9. Model structure and Its Main Interactions ..... 57

10. Historical Simulation Total Lumber Consumption - 98

11. Historical Simulation Average Lumber Price ..... 98

12. Historical Simulation Total Plywood Consumption 99

13. Historical simulation PPI Softwood Plywood ..... 99

14. Historical simulation stumpage Price NW ....... 100

15. Historical Simulation Stumpage Price so ....... 100

16. Historical Simulation Stumpage Price SW ....... 101

17. Historical simulation stumpage Price IL ....... 101

18. Historical Simulation Lumber Price NW ........ 102

19. Historical Simulation Lumber Price so ........ 102 
20. Historical Simulation Lumber Price SW ........ 103

21. Historical Simulation Lumber Price IL ........ 103

22. Plywood Price Douglas Fir ................ 104

23. Plywood Price Southern pine ............... 104

24. Lumber Market Share Canada ............... 105

25. Lumber Market Share NW ................. 105

26. Lumber Market Share so ................. 106

27. Iumber Market Share sw ................ 106

28. Lumber Market Share II ................. 107

29. Plywood Market Share NW ................. 107

30. Plywood Market Share so ................. 108

31. Lumber Market Share North ............... 108 


\section{CHAPTER I}

\section{INTRODUCTION}

This is a study of competition among spatially separated markets. It concerns the development and estimation of a multiregional model of the softwood forest products industry in the United States, designed to describe the dynamics of interregional competition in the industry; and to provide a means for policy experimentation and short-term projection of regional market shares.

The study is motivated by an interest to find out, given information on the aggregate national demand for these products, how production would be allocated among spatially separate producers. Two products (softwood lumber and plywood), five product supply regions (including Canada), and six product demand regions are recognized. The design of the model is based on a combined top-down/bottom-up approach and consists of three interdependent components: 1) the aggregate product market, 2) regional product markets, and 3) regional factor markets.

Model solutions are obtained by the simultaneous determination of national level product prices and quantities; and allocation of equilibrium quantities across 
producing regions on the basis of their relative prices and locational advantage. For each producing region, "locational advantage" is measured in terms of the region's overall accessibility in the national market.

A thirty-five year period time series data from 1950 to 1984 is used to estimate the parameters of the model. Following an assessment of the performance of the model, the complete structure is then extrapolated for two years beyond the sample period.

The first step in an empirical investigation is to identify the perspective from which it originates, and to define explicitly the theoretical framework in which the results may be deciphered. The principal mode of analysis adopted here is general equilibrium. The approach can be best described as an eclectic one: we draw from various areas of economic thought bordering on the neo-classical orientation, in particular, international trade and location theory.

The perspective here is that of the analyst interested in the dynamics of interregional competition and short-term forecast of regional export performance. Since the approach adopted in this study recognizes the impacts of exogenous demand and local supply conditions simultaneously, it presents a suitable alternative to such naive devices as regional "shift-share" and, its counterpart in international trade, "constant market-share analysis" and serve 
as a versatile tool for policy simulation. 1

The organization of this thesis is in four parts. The first chapter begins by casting the research problem in the general theoretical framework of interregional competition. We will then proceed to explore the required methods and necessary ingredients for developing a multiregional industry model.

The second chapter is intended to serve as an introduction to the forest products industry. Here, various economic, spatial, and institutional aspects of the industry will be examined in some detail. Institutional factors will be discussed only to the extent that they contribute to behavioral variations in regional markets. We shall make no attempt to partake in the ongoing controversy that surrounds the issue of public policy in this area. In this part of the study we will also specify the spatial units of our analysis (regions), consider their characteristics and describe the qualitative and quantitative differences that prevail among them in terms of resource endowment and ability to grow, process, and market their products.

1 We do not purport to discuss these techniques at any length here or elsewhere in this document. Richardson (1978) contains an ample discussion on the theory and application of "shift-share" analysis in regional studies. See also Houston (1967) for a critical treatment of the concept. For an exposition of "constant market share" analysis in international trade and a bibliography of empirical applications of the approach the reader is referred to Leamer and Stern (1970) pp.171-82. 
Chapter III presents a summary review of previous attempts at modeling the timber industry and use whatever insight that can be drawn from them in developing estimating relationships for the empirical model. In this part of the study, after considering relevant statistical and methodological issues, the complete empirical model will be estimated. Chapter IV, the final part of the study, is devoted entirely to the analysis of results and evaluation of performance of the model.

\section{THE METHODOLOGICAL PERSPECTIVE}

The subject of this study bears a prima facie resemblance to the well-known Enke-Samuelson problem of equilibrium among spatially separated markets. It seems therefore helpful at this preliminary stage to distinguish between the purpose and method of the present study from those associated with theirs.

The problem of equilibrium among spatially separated markets was first set forth by Enke in 1951:

... There are several (originally three) regions
trading a homogenous good. Each region
constitutes a single and distinct market.. The
regions are separated but not isolated by a
transportation cost per unit which is indepen-
dent of volume. There are no legal restrictions
to limit the actions of the profit-seeking
traders in each region. For each region the
functions that relate local production and local
use to local prices are known, and consequently,
the magnitude of the difference which will be
exported or imported at each local price is also
known. Given these trade functions and transpor-
tation costs, we wish to ascertain: (1) the net


price in each region; (2) the quantity of imports or exports for each region; (3) which region exports, imports, or does neither; (4) the volume and direction of trade between each possible pair of regions." (Enke 1951)

Given linear regional production and demand functions, and no economies of scale in transportation, Enke conceived of a solution to this problem by means of an electric analogue. Samuelson (1952) proceeded with the above formulation and demonstrated how it can be cast mathematically into a maximum problem and solved via the Hitchcock-Koopmans minimum transport cost linear programming procedure. The procedure consists of an iterative procss of varying interregional flows towards increasing "net social payoff" (i.e. the algebraic sum of areas under local excess supply and demand functions minus total transportation cost of all possible flows) ${ }^{2}$

Consequent elaborations of the approach and development of new solution algorithms have helped extend its applications to a wide range of analytic situations concerning temporal, as well as spatial activity and

2 For a non-mathematical discussion of the theory and application of linear programming see Dorfman (1953). Isard (1960, PP. 413-88) contains a comprehensive presentation of the technique and solution procedures in mathematical programming. For a more elaborate presentation and alternative formulations of spatial allocation and distribution problems see Takayama and Judge (1971). 
allocation problems. ${ }^{3}$ Developments have been particularly remarkable in the direction of relaxing the stringent assumptions of the early formulations concerning quantities and prices, and especially, linearity of production and demand functions. Contributions of Takayama and Judge (1964a, 1964b, 1971) have lead to the development of operational programming models in which prices and quantities are determined endogenously within the model.

Despite their theoretical elegance and versatility, most variants of mathematical programming models, save the very simple single objective linear formulations, pose serious practical problems when applied to general equilibrium analysis where large numbers of inputs, commodities, and locations are involved. In fact applications of mathematical programming models in spatial contexts have invariably been cast in a partial equilibrium framework in which only one sector of the economy or a limited group of related commodities is considered while the demand for, and prices, of other goods are determined

3 The first application of linear programming in a spatial allocation setting was made by Fox (1953) in his study of the feed-livestock market in the United states. The method has since been applied to a myriad of agricultural products (see Labys 1975), various natural resource commodities (for example Kennedy 1974), the timber industry (Holley, et al. 1975, Haynes, et al. 1978), and the equilibrium analysis of international trade (Uzawa 1958, Ginsburgh and Waelbroeck 1981). 
exogenously. And yet, even in these situations the analysis is often hindered by the complexity of solution schemes.

The purpose of the present study is more modest and, at the same time, more basic than what most programming models propose to achieve. The objective of this study, though not completely at variance with what can be obtained in a programing approach, differs from it in several fundamental ways. These differences become more apparent in the subsequent discussion where we proceed with the development of our general theoretical model. For the time being it suffices to point out that this study intends to investigate optimization in a more simplified supply-demand framework which does not concern interregional "flows" as such.

\section{THE THEORETICAL FRAMEWORR}

Having defined our objective, we must now explore the means of achieving it. Again, as with the Enke formulation, the conceived economic environment is a competitive one in which several producers are engaged in the production of one or more homogeneous good(s). Production takes place in predetermined locations (regions) which are separated from each other and from consumers by an intervening transportation cost. There are no barriers to trade and local producers can compete freely in the national market. Given the level of national demand for a good, we like to find out: a) how regional output shares will be determined, and 
b) given any initial equilibrium condition, what the effect will be on regional output levels of changes in the aggregate demand or local production conditions. Any econometric model capable of identifying the unique impacts of these factors on the regional output shares, must feature several critical characteristics. As Engle (1979a) has pointed out --though in a slightly different context-- such a model must produce reliable estimates of the elasticity of demand for regional products, determine the impact of factors on the supply schedule, and estimate the elasticities of factor supplies.

The foregoing conceptual framework embodies several necessary relationships that must be explicitly specified in the operational model. These are:

a) aggregate national demand relationship;

b) regional product demand relationships that can determine regional allocations of output on the basis of each region's unique advantage (disadvantage) in relative cost and location vis-avis others:

c) regional product supply relationships;

d) regional factor-market relationships; and

e) an equilibrium condition that ensures the consistency between projections at the national level of aggregate demand and regional supplies.

It also implies certain interactions that prevail among these relationships at the interregional, as well as, regional-national level which are to be accounted for in the operational model. Under product market conditions with a sufficiently large number of agents and perfectly elastic supplies (as the case is often assumed to be in 
international trade analysis) we normally need not concern ourselves with these interactions. In national economies, however, any analysis advanced on the basis of these assumptions is likely to fall at the first fence. For one thing, the number of producing regions for most commodities is often small and their outputs constitute a large enough portion of total supply so that the assumption of perfectly elastic demand would not hold. The proper analytic framework is therefore a quasi-competitive one where the actions of any one producer will have definite repercussions for other producers (Henderson and Quandt 1980, p.200). For another, any a priori assumptions concerning regional supply elasticities may well prove unwarranted.

In sections that follow, we will specify these relationships separately, elaborate their conceptual content and theoretical foundations and explore the nature and direction of their interdependencies.

\section{Prouuct Demand}

Specification of demand relationships derives directly from the general theory of consumer behavior. In its basic form the theory explains demand as conditions that must be satisfied if the consumer is to get the most for his money. Given an index of consumer satisfaction (U), a set of goods $\left(x_{i}, i=1 \ldots n\right)$ and their corresponding prices $\left(p_{i}\right.$, $i=1 \ldots n)$, and a budget constraint (Y) for the consumer; the demand function for any $x_{i}$ can be determined by maximizing 
$\mathrm{U}=\mathrm{f}\left(\mathrm{x}_{1}, \mathrm{x}_{2}, \ldots, \mathrm{x}_{\mathrm{n}}\right)$ subject to $\mathrm{Y}=\mathrm{p}_{1} \mathrm{x}_{1}+\mathrm{p}_{2} \mathrm{x}_{2}+\ldots+\varepsilon_{\mathrm{n}} \mathrm{x}_{\mathrm{n}}$. Assuming that thie second order conditions are fulfilled, the first order conditions, together with the uudget constraint can produce consumer's $n$ demand functions:

$$
d_{Q_{i}}=f\left(x, p_{i}, p_{j}\right) \quad \text { for } j=1,2, \ldots n-1
$$

which relates the demand for a commodity $x_{i}$ to its own price $\mathrm{p}_{i}$, the prices of other commodities $\mathrm{p}_{j^{\prime}}$ and income (Henderson and Quandt, 1980, pp.18-22).

Equation (1.1) represents the general form of the aggregate national demand relationship in our model. Replacing $\mathrm{Y}$ with a vector of appropriate exogenous variables $\mathrm{Z}$; and letting $\mathrm{p}_{i}$ equal the weighted average national price of commodity $i$, we specify the aggregate national demand relationship in the following form:

$$
d_{Q_{i}}=f\left(p_{i}, p_{j}, z\right)
$$

\section{Demand For Regional Products}

Equation (1.2) represents the general formulation of commodity demand functions in a spaceless economy. The inclusion of a spatial dimension in the analysis will require certain modifications in this specification in order to account for distinctions among $x_{i}$ 's not only in terms of 
their kind, but also with respect to their places of production and consumption.

Let us suppose there are $n$ goods being produced in $r$ regions. The products of each and every region are partially consumed in the producing region itself and the rest, assuming the presence of some excess supply, is shipped to other regions. 4 Any complete model of the national economy, therefore, will have to account for rn distinct products and rn prices. That is, for each $r_{i}$ (where the first subscript represents the place of production) there will be $k$ different $r p_{i k}$ 's where each $r^{p_{i k}}$ i.e. the price in region $k$ of good $i$ produced in region $r$, equals the price of that product in the producing region plus its transfer cost to the consuming region. In equilibrium, as Samuelson (1952, p. 287) has shown, the unit price of the good in the consuming region cannot, however, exceed its price in the producing region plus the per unit transportation cost between the two regions i.e.:

$$
r^{P_{i k}} \leq r^{P_{i r}}+t_{r k}
$$

4 In order to avoid confusion, it is helpful at this point to add a slight refinement to our terminology. Here- after, following Armington (1969), we will use the term "goods" to distinguish between commodities in terms of their kind. Alternatively, the term "product" will be used to distinguish between commodities both in terms of kind and the geographic place of production or consumption. 
from which it follows that we can conceivably define a demand function for each region's output, $r d_{i}$, as:

$$
r^{d_{i k}}=f\left({ }_{r} p_{i}, t_{r k}, x\right) \quad(k=1 \ldots n)
$$

where $k$ and $r$ respectively represent locations of consumption and production; and the second term on the right hand side can be construed as a measure of the producing region's overall accessibility in the market. 5

The foregoing discussion suggests how the second set of relationships in our model, i.e. regional allocation of output, might be derived. The key structural relationship here is the demand for the regional output. We can expect the quantity demanded of a product to decrease as its local price rises. This occurs partly due to income and substitution effects. However in product markets with several regional sources of supply, a major effect can result from the shift to the same product from a different region (Engle 1979b). One simple formulation of the demand

5 In most models of location analysis it is assumed that transportation inputs are proportional to the quantities being shipped implying that there are no economies of scale in transportation. However, in our model, transport inputs will be measured in terms of average per unit transport costs between trading areas, which when available, is a more realistic measure of the friction of distance as compared to transport "rates". 
function facing a regional product is direct estimation of every producing region's market share in all demand regions as a function of its own price and prices of the same good from alternative sources of supply:

Let $r^{d}{ }_{i k}$ denote demand in region $k$ of good $i$ produced in region $r$; then for a system of $r$ producing regions and $k$ consuming regions we will have:

$$
\begin{aligned}
& { }_{1}^{d_{i 1}}=f\left(d_{i 1},{ }_{1} p_{i 1},{ }_{2} p_{i 1}{ }_{3} p_{i 1}, \ldots, r^{p_{i 1}}\right) \\
& { }_{1} d_{i 2}=f\left(d_{i 2},{ }_{2} p_{i 2},{ }_{1} p_{i 2},{ }_{3} p_{i 2}, \ldots, r^{p_{i 2}}\right) \\
& { }_{1} d_{i k}=f\left(d_{i k},{ }_{1} p_{i k}{ }_{2} p_{i k}{ }_{3} p_{i k}, \cdots, r^{p_{i k}}\right)
\end{aligned}
$$

$$
\begin{aligned}
& { }_{2} a_{i 1}=f\left(a_{i 1},{ }_{2} p_{i 1},{ }_{1} p_{i 1}{ }_{3} p_{i 1}, \ldots, r^{p_{i l}}\right) \\
& { }_{2} d_{i 2}=f\left(d_{12},{ }_{2} p_{i 2},{ }_{1} p_{i 2},{ }_{3} p_{12}, \ldots, r^{p_{i 2}}\right) \\
& \text { • } \\
& r^{d_{i k}}=f\left(d_{i k}, r^{p_{i 1}}, r^{p_{12}} r^{p_{i 3}}, \ldots, r^{p_{i k}}\right)
\end{aligned}
$$

which gives a set of $r k$ simultaneous equations in $r k$ endogenous variables for each commodity $i$. Estimation of these equations, however, poses serious practical problems. First, data on regional demands are virtually non-existent. Although regional consumption patterns may be derived indirectly from production and interregional shipments, the shipment data themselves are either scarce or irrevocably 
distorted due to intermediate storage and transshipment. 6 second, collinearity among the price variables will most likely reduce the efficiency of parameter estimates considerably.

One way to circumvent these problems is to modify the equations in (1.5) into a form that is compatible with available data and also more agreeable to the exigencies of estimation. A simple approach is aggregation of $r d_{i k}$ 's over all k's and replacing the price variables by an appropriate measure of comparative cost. Thus reducing (1.5) to only $r$ equations and adding transport costs from (1.4) we will have:

$$
\begin{aligned}
& { }_{1} D_{i}=f\left(d_{Q_{i}},\left(p_{i}-{ }_{1} p_{i}\right), \Sigma t_{1 k} / n\right) \\
& { }_{2} D_{i}=f\left(d_{Q_{i}},\left(p_{i}-{ }_{2} p_{i}\right), \Sigma t_{2 k} / n\right) \\
& r^{D_{i}}=f\left({ }_{Q_{i}},\left(p_{i}-r_{i}\right), \Sigma t_{r k} / n\right)
\end{aligned}
$$

6 For a detailed discussion of problems associated with data on inierregional flows see Garnick (1980). Adams, Haynes, et al. (1979) have estimated regional demands for lumber and plywood in six U.S. regions for 1950-76. Their method is, however, complex and difficult to replicate. Work on updating the data is presently underway at the Pacific Northwest Forest and Range Experiment Station in Portland, Oregon. 
where $r_{i}^{D_{i}}=\sum r^{d_{i k}} r^{p_{i}}$ is the regional price of $i$ as defined in (1.4) and $p_{i}$, as before, is the weighted average price of the same good in the national market.

Regional product demand relationships in our model follow the same form as in (1.6), which relates the demand for a region's output to the total demand for that product and the region's price competitiveness vis-a-vis the corresponding price of the same good in the national market. Note that the coefficients of ${ }^{d}{ }_{Q_{i}}$ 's measure the elasticity of regional output relative to the industry output and the price elasticities, i.e. the coefficients of the price terms in parentheses, measure the competitive component of the regional market shares. 7

\section{Regional Product Supply}

Regional product supply functions constitute another essential ingredient in our model. As we have already noted, any model of spatial competition pivots on two elements of locational advantage and local prices. If a region lowers

7 This coefficient is conceptually analogous to the "elasticity of import substitution", the measurement of which has been the subject of perennial interest --and controversy-- in the international trade literature (Tinbergen 1946, Polak 1950, Ginsburg and stern 1965). Several alternative formulations of the relationship between the two price terms have been suggested in the lierature. Two formulations that immediately come to mind are: a) to cast the relationship in ratio form, i.e., $\left(p_{1} / p_{i}\right)$, or b) presentation of the two prices separately in the equation. These possibilities will be explored further as we proceed to develop the exact estimating equations in the following sections. 
(raises) its price, the quantity demanded of its product will increase (decrease) due to the fact that other regions will sell less (more). The regional differences in price depend largely on relative elasticities of supply. The point is demonstrated graphically in Figure (1). The figure shows the markets for a homogeneous product in two regions a and b. Both markets are in equilibrium with equal market shares $\left(Q_{1 t 0}=Q_{2 t 0}\right)$. The demand schedules $D_{\text {to }}$ are sloped smoothly because due to the aforementioned "regional substitution effect" are expected to be more elastic than the industry demand (Engle 1979a). $S_{a}$ and $s_{b}$ are the supply schedules in the two regions. The only difference between the two markets is that the slopes of supply curves are not the same.
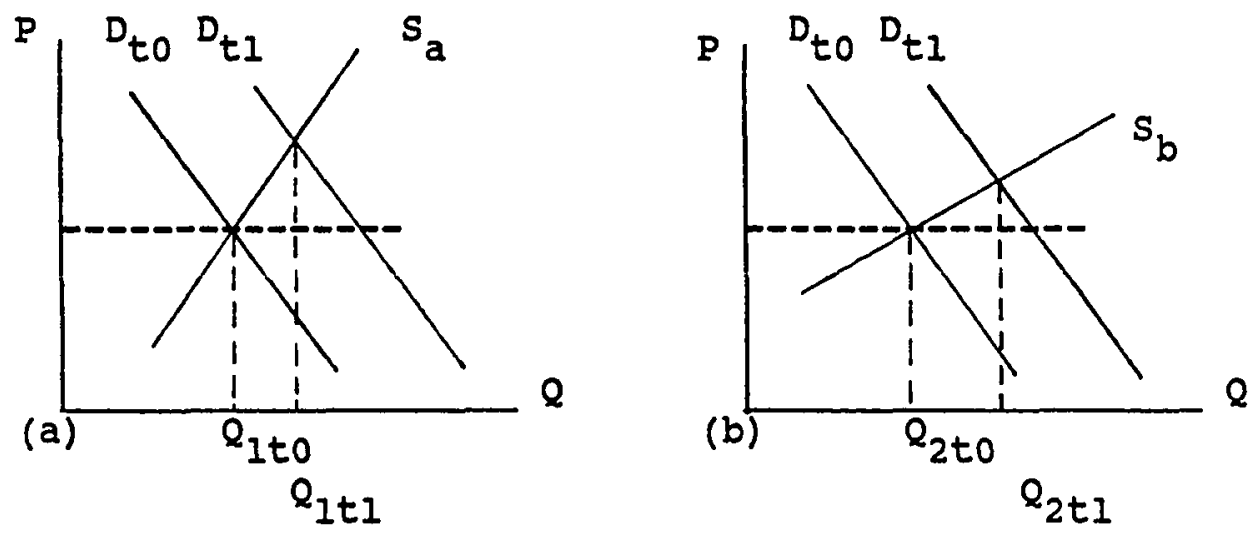

Figure 1. Effects of alternative assumptions regarding elasticities of supply.

Suppose that the demand schedule shifts from $D_{\text {to }}$ to $D_{t I}$. The subsequent results of the shift and its implications in terms of output and market share clearly are not the same for the two regions. This differential impact is quite evident in the difference between $\left(Q_{I t 0^{-}} Q_{I t I}\right)$ and 
$\left(Q_{2 t 0}-Q_{2 t 1}\right)$ which has resulted from unequal elasticities of supply in the two regions.

Supply functions are often much more diverse in nature than demand functions. They are derived in a fashion analogous to consumer utility maximization, that is, maximization of output by the producer subject to certain cost considerations (although this is not the only mode of optimizing behavior for the producer). Supply functions, as distinct from production functions that relate quantities of output to various inputs, describe the response of output to price, factor costs and other technological, institutional, or ecological factors (Labys 1973, ch.3). In the most general case a supply function may therefore be specified in the following form:

$$
s_{i}=f\left(p_{i}, w_{1} \ldots w_{n^{\prime}}\right)
$$

where $s_{i}$ is the quantity supplied of product $i, p_{i}$ is the price of $i, w_{i}$ to $w_{n}$ represent various input prices. Note that all variables carry regional subscripts that have been omitted for convenience.

\section{Regional Factor Markets}

Two factors have so far been identified that determine a region's market share in the national economy: location and price of outputs. Since locations are predetermined, competitiveness of a region is ultimately determined by the 
level of productivity in its industries and their cost performance relative to their competitors in other regions. It is apparent from equation (1.5) above that the level of output is in part determined by the price of inputs. If factor supplies are perfectly elastic, then we could assume their prices as fixed and need not worry about what goes on in the local factor markets. However, in reality (and consistent with economic theory), returns to a factor of production are market determined, i.e, in equilibrium they can be represented as the intersection of demand for and supply of the factor.

Factor markets are therefore inseparable from the product market. The key to a better understanding of the linkages between the two markets is to develop a conceptual framework in which the relationship between prices in the two markets can be explicitly defined.

The relationship between product price and input prices is straight forward and can be derived from producer's profit maximizing behavior. The producer's total revenue is determined by the quantity of output (q) multiplied by the unit market price (p). Producer's profit is defined as the difference between total revenue and total cost. Thus in a production process involving two factors, letting $x_{1}$ and $x_{2}$ be the levels of input of each factor 1 and 2 with $w_{1}$ and $w_{2}$ representing their respective unit prices, we have: 


$$
\text { Prof. }=p q-w_{1} x_{1}-w_{2} x_{2}
$$

where,

$$
q=f\left(x_{1}, x_{2}\right)
$$

The producer's demand function for each input can be derived directly from the profit unction by substituting for $q$ from (1.9), setting the partial derivatives of the new equation with respect to $x_{1}$ and $x_{2}$ equal to zero, and then solving for $x_{1}$ and $x_{2}$. See for example Intriligator (1971, p. 191) and Henderson and Quandt (1980, p. 80). Thus for a given production function, the demand for a factor may be expressed in terms of its own price, the price of other inputs, and price of output, i.e.:

$$
\begin{aligned}
& d_{F_{i}}=f\left(w_{i}, w_{j}, p_{i}\right) \quad \text { for } i=1 \ldots n \\
& \text { and } j=1 \ldots n-1
\end{aligned}
$$

This relationship implies that a producer's willingness to pay for factors is essentially constrained by the price he is able to obtain for his product. Validity of this conclusion is intuitively clear and consistent with the derived demand concept.

On the other side of the market are the suppliers of factors who, very much like all other producers, are also concerned with getting the most for their lot, that is, 
maximizing their profit (or present worth as in the case of natural resource commodities). Their behavior can therefore be explained within the framework of conventional static supply theory. In the case of natural resource commodities, however, the requisite for profit maximization is that the opportunity cost of holding reserves also be accounted for. one way of expressing the latter in a form amenable to empirical estimation is the use of proxies such as total available stocks or inventory. In our analysis we suggest to specify the factor supply relationships in the following form:

$$
s_{F_{i}}=f\left(w_{i}, x_{i}, x\right)
$$

Where $S_{F_{i}}$ is the quantity supply of factor $i$ in a given region, $w_{i}$ is the corresponding factor price, $x_{i}$ represents a measure of available stock of factors or inventory, and $\mathrm{X}$ is a vector of exogenous institutional, or otherwise noneconomic factors.

\section{The Complete Model}

If there are $r$ producing regions, $n$ commodities and $m$ factors, then relationships $(1.2),(1.6),(1.7),(1.10)$, and (1.11), constitute a system of $2 \mathrm{rn}+2 \mathrm{rm}+1$ equations in $2 r n+2 r m+1$ endogenous variables, namely, rn commodity prices $\left(p_{i}\right)$, rn regional supplies $\left(s_{i}\right)$, rm factor prices $\left(w_{i}\right)$, rm regional factor supplies $\left(s_{i}\right)$, and $D_{i} \cdot$ For 
convenience and ease of reference the complete system of equations developed so far is rewritten below:

Aggregate Demand:

Demand for Regional Products:

Regional Product Supplies:

Regional Mkt. Equilibrium:

Regional Factor Demands:

Regional Factor Supplies:

$$
\begin{aligned}
d_{Q_{i}}= & f\left(p_{i}, p_{j}, z\right) \\
r^{D_{i}}= & f\left(d_{Q_{i}},\left(p_{i}-p_{i}\right)\right. \\
& \left.\sum t_{r k} / n\right)
\end{aligned}
$$

$$
\begin{aligned}
& r_{i}=f\left(p_{i}, w_{1} \ldots w_{n^{\prime}}\right) \\
& r_{i}=r s_{i} \\
& d_{F_{i}}=f\left(w_{i}, w_{j}, p_{i}\right) \\
& s_{F_{i}}=f\left(w_{i}, x_{i}, x\right)
\end{aligned}
$$

The major elements and interactions of the model are given in Figure 2, which shows a schematic outline of the model structure. In addition to the behavioral relationships discussed above, the influence of imports on the product market and the impact of institutional factors on regional factor markets are also recognized.

The model developed here is intended to serve as a general framework for the analysis of interregional competition. In the jargon of econometric model building our approach here is commonly described as top-down modeling, as distinguished from the bottom-up approach (see Ballard, Glickman, and Gustely 1980; also Milne, Adams, and Glickman 1980). The model relies on the national economy to determine the overall level of sectoral activity which is then allocated across producing regions on the basis of their relative costs and locational characteristics. Our proposed 
formulation, however, departs from a purely top-down structure in that it allows for feed-backs from regional economies through price variables.

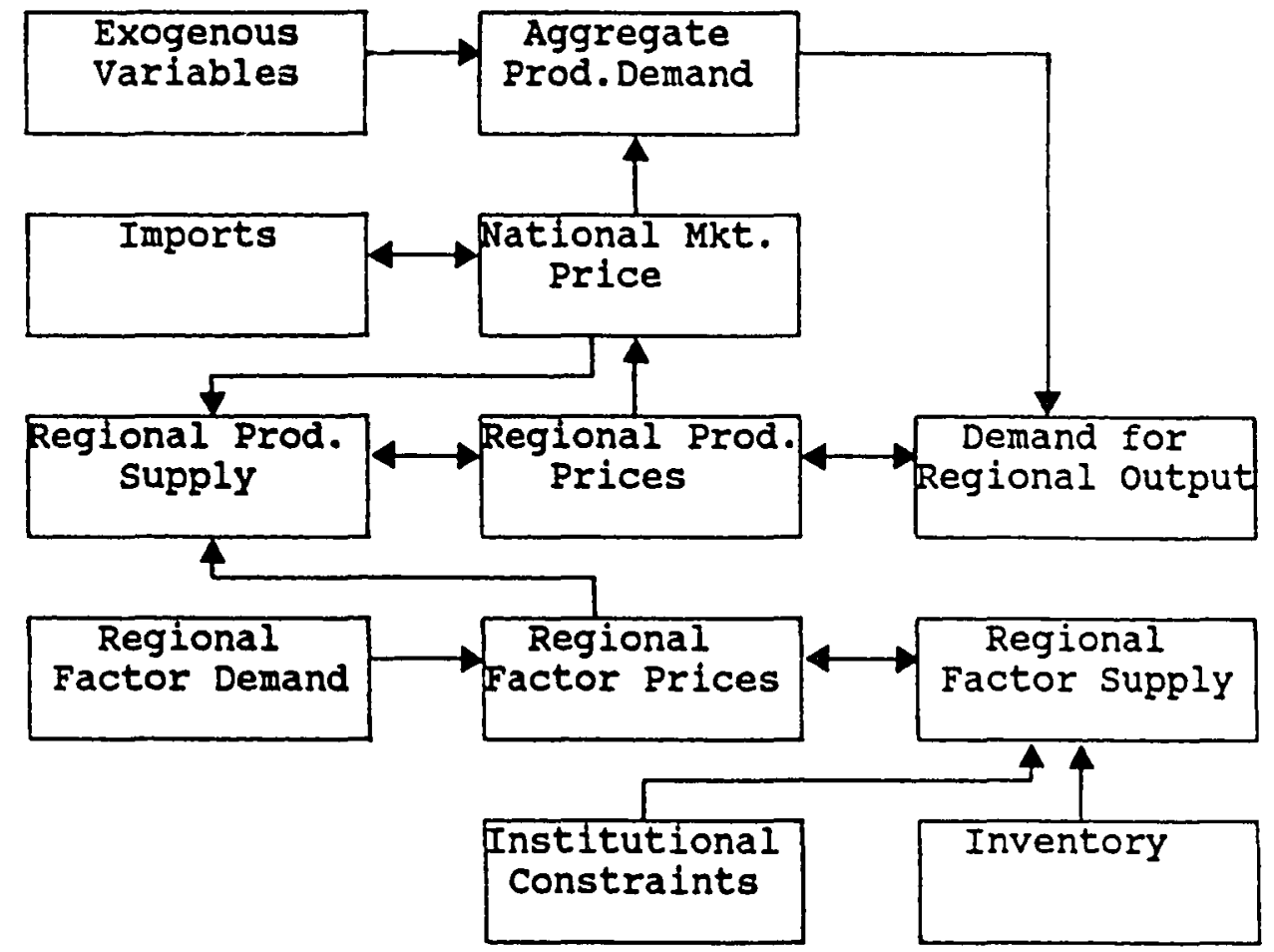

Figure 2. Model flow schematic

Before we proceed with the application of this model to actual data, the commodity dimension of the model must be fully developed. Therefore, this model can only serve as a prototype in the most general sense of the term. Furthermore, all relationships have been presented in their static forms. From an empirical point of view, no conclusions can be reached with regards to the appropriate functional forms or adjustment processes before the nature of the commodity under investigation is fully understood. A thorough 
discussion of these issues will be undertaken in the following sections where we will apply the model to the analysis of interregional competition in the wood products industry in the United states. 


\section{CHAPTER II}

THE INDUSTRY

The choice of the softwood forest products industry for the present study was motivated by the industry's several characteristics that render it suitable for the analysis of interregional competition. First, it is an important industry. In 1984, the lumber and wood products industry accounted for nearly four percent of total employment, and three percent of value added in manufacturing in the United states. The industry's contributions in terms of employment and income are particularly pronounced at the local and regional levels. In states such as oregon and Washington, for example, respectively forty and close to twenty percent of manufacturing employment originates in the timber related activities. ${ }^{1}$

second, it is a highly competitive industry characterized by a very large number of firms with relatively low

1 The Pacific Northwest states rank highest in their dependence on the forest products industries. In other major producing regions such as the south, local economies are much more diversified. Among the Southern states, Arkansas, where the forest products industries account for slightly over sixteen percent of basic employment, is the most timber dependent state in the region (Schallau and Maki, 1986). 
levels of concentration. In 1984, for example, there were over thirty thousand firms in the industry nationwide.

Third, the industry is also highly localized: roundwood is heavy, bulky, and the manufacturing processes for most products entail considerable losses in weight, as well as, in volume. The manufacturing facilities are, therefore, invariably located near the sources of timber supply concentrated in few distinct regions in the country. The forth and final factor in selecting this industry is product homogeneity; a condition (assumption) that is central to the analysis of interregional competition. Certain differences in grades and species notwithstanding, the main products of the industry such as lumber, plywood, and pulp, are sufficiently similar with respect to specific end uses to be considered homogenous.

\section{THE STRUCTURE OF THE INDUSTRY}

The softwood forest products industry is a complex and multi-faceted system that encompasses a wide range of activities extending from forest lands to the consumption of final products. This system is shaped and regulated by the confluence of many economic, biological, institutional, and spatial factors.

Broadly defined, the industry consists of wide a range of activities in which timber, in combination with other inputs (capital, labor, energy, etc.), is used to produce a myriad of consumer products. The most commonly accepted 
classification of these products is in terms of the stage of processing, and involves two categories of primary and secondary products. The main processing stages and major primary products of the forest products industry are shown in Figure 3.

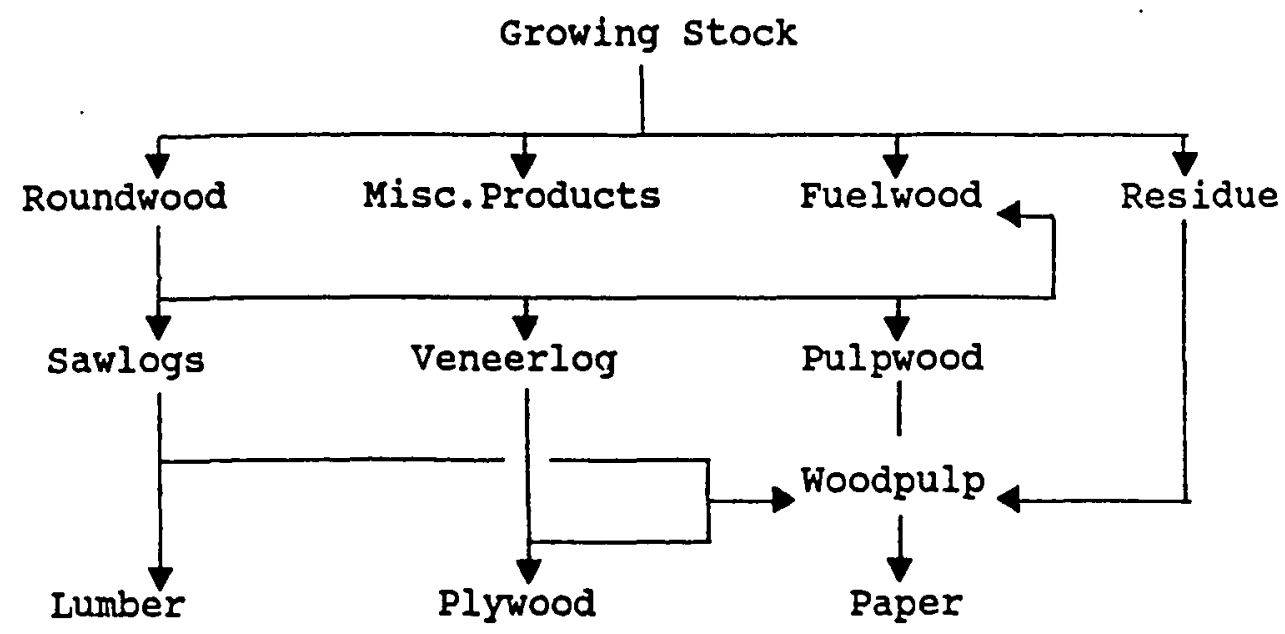

Fiqure 3. Major products and stages in processing of timber.

Roundwood products, which are used primarily in the production of lumber, pulp, and plywood, claim the largest portion of annual removals of timber in the United states. Forest Service estimates show that during the 1970's, nearly 95 percent of annual harvest of softwood timber was in the form of roundwood. Miscellaneous products such as poles, pilings, posts, mine timber, etc., accounted for an additional 2.5 percent; and the remaining 2.5 percent was divided in near equal proportions between fuelwood and residual products. (USDA/Forest Service, 1982). 
The present study focuses on two of the primary forest products: softwood lumber and plywood. These products are two of the most important outputs of the forest products industry in the U.S. and together account for about 70 percent of annual consumption of softwood timber in the country.

\section{THE MARKET PROCESS}

In a free market, "industrial competition" is defined in part as a condition wherein every productive resource in an industry "earns as much, but no more than, it would in other industries" (Stigler, 1968, p. 10). This condition holds because the profit maximizing behavior of owners guarantees that resources are employed where they obtain the highest returns. Timber is a versatile raw material which is used in the production of a wide range of products. At any given time, the producers' economic considerations, i.e. profits, determine the type of product into which timber is likely to be transformed.

The level of output for each product is in turn determined by market conditions. Producers supply what consumers demand of them. Prices are the equilibrating mechanism. For each product, market clearing prices and quantities are dictated jointly by consumer demand and supply conditions.

Demand: Softwood lumber and plywood are producer goods. Demand for these products is, therefore, a derived 
demand and depends largely on the level of activity in their respective end use markets. The principal end uses for softwood lumber and plywood and levels of demand in each market in selected years are shown in TABLE I.

TABLE I

DOMESTIC LUMBER CONSUMPTION BY END USE CATEGORY (PERCENT OF TOTAL CONSUMPTION)

\begin{tabular}{|c|c|c|c|c|c|}
\hline Lumber & $1952^{1}$ & $1962^{2}$ & $1970^{2}$ & $1976^{3}$ & $1984^{4}$ \\
\hline $\begin{array}{l}\text { Residential } \\
\text { construction....: } \\
\text { Non-residential }\end{array}$ & 36.7 & 45.4 & 34.1 & 38.1 & 38.8 \\
\hline $\begin{array}{l}\text { construction....: } \\
\text { Repair and }\end{array}$ & 18.7 & 9.90 & 10.2 & 10.5 & 15.4 \\
\hline $\begin{array}{l}\text { alterations...: } \\
\text { Material handling }\end{array}$ & 16.5 & 15.2 & 13.0 & 13.3 & 26.3 \\
\hline $\begin{array}{l}\text { and shipping.... } \\
\text { Manufacturing }\end{array}$ & 16.0 & 14.1 & 15.8 & 16.1 & 10.0 \\
\hline $\begin{array}{l}\text { and other...... } \\
\text { Plywood }\end{array}$ & 12.0 & 12.8 & 12.9 & 10.1 & 9.50 \\
\hline $\begin{array}{l}\text { Construction..... } \\
\text { Manufacturing }\end{array}$ & 51.0 & 55.4 & 59.1 & 65.7 & $69.0^{5}$ \\
\hline and other...... & 49.0 & 44.6 & 40.9 & 34.3 & 31.0 \\
\hline
\end{tabular}

2 It is important to note that the data on consumption patterns are based on estimates derived from different sources. In several instances comparison of data across various sources show considerable discrepencies. For example in a 1982 survey of lumber use in non-residential construction (Spelter and Anderson, 1985) lumber consumption in this market is estimated at around seven percent of total domestic consumption. 
Historically, the construction industry has been the single most important source of demand for softwood lumber and plywood. As figures in Table I indicate, since 1950, the construction sector has accounted for an average of 70 percent of all softwood lumber and 60 percent of all softwood plywood consumed in the United States. Witiin the construction industry, new residential construction is responsible for the largest portion of lumber and plywood consumed in this sector.

other major uses of lumber and plywood are in shipping and manufacturing (mostly wood furniture). During the past three decades, the use of lumber and plywood in these activities has followed a continuously declining trend. The declining role of timber products in activities other than construction is particularly evident in the historical pattern of plywood consumption.

Supply: Levels of output in a competitive industry are determined by the producers' ability to respond to changing demand and factor supply conditions. In order to succeed in a competitive environment, the industry has to continuously improve its productivity so as to decrease its production costs subject to technological constraints inherent in its production process.

The production of lumber and plywood is each comprised of a series of operations in which roundwood is converted into the final product. These operations are summarized in Table II. During the time period covered in the present 
analysis, most of these operations have undergone considerable technological change.

TABLE II

LUTBER AND PLYWOOD PRODUCTION PROCESSES

\begin{tabular}{|c|c|c|}
\hline & Lumber & Plywood \\
\hline $\begin{array}{l}\text { 1) } \\
\text { 2) } \\
\text { 3) } \\
\text { 4) } \\
\text { 5) } \\
\text { 6) }\end{array}$ & $\begin{array}{l}\text { Log handling } \\
\text { Breakdown } \\
\text { Pipping \& Trimming } \\
\text { Crosscutting } \\
\text { Drying } \\
\text { Surfacing }\end{array}$ & $\begin{array}{l}\text { Log handling } \\
\text { Peeling or slicing } \\
\text { Drying } \\
\text { Assembly lay-up } \\
\text { Glueing } \\
\text { Finishing }\end{array}$ \\
\hline
\end{tabular}

Technological improvements in the wood products industry have been characterized by Heady (1952) as being either "biological", or "mechanical". According to this classification biological innovations are essentially of the "neutral" type and tend to increase the marginal output of all inputs without altering their substitution properties. Improvements in plant lay-out, enhanced waste utilization techniques, and the use of thinner saw kerfs are all but few examples of this type of technical progress. Mechanical innovations, on the other hand, are resource saving changes that raise the marginal product of specific inputs relative to others. Some examples of the latter type of technical change are mechanized $\log$ handling techniques, computerized log scanning methods, and improvements in small-log peeling technology in veneer production. 
The structure of production in the lumber and wood products industry has been analyzed in several recent studies including those by Robinson (1975), Humphrey and Moroney (1975), Alperovich (1980), Stier (1980), Merrifield and Haynes (1983, 1984), and Nautiyal and Singh (1985). With the exception of Alperovich (1980), and Merrifield and Haynes studies of the Pacific Northwest forest products industry, these studies generally involve analysis of broad product categories at the aggregate national level. There is therefore little information on patterns of technical change associated with specific products in various regions.

Since these studies have employed different production functions and involve different product categories, their results are not always directly comparable. They do, however, reach some general, though important, conclusions that bear directly on our analysis. The first conclusion is that the rate of technical progress and productivity gains in the lumber and wood products industry has at least paralelled those of other manufacturing industries in the country. Second, due to rapid increases in labor and stumpage costs, the trend in technological change has tended towards labor --and to a lesser extent stumpage-- augmenting improvements. Third, most factor inputs in the industry are substitutable; and, that substitution possibilities between capital and labor, and capital and stumpage, are greater than those of other inputs. 
With respect to scale effects, however, the results of these studies remain by and large inconclusive. Merrifield and Haynes (1984), for instance, find no evidence of scale effects in the industry; while Robinson (1975) concludes that gains in productivity have been largely attributable to economies of scale.

\section{THE SPATIAL DIMENSTON}

The market processes disscussed in the preceeding section determine the quantity and type of product that is likely to be produced at any given point in time. In an industry characterized by a geographically fragmented market, the very same forces also decide "where" each product will be produced.

In the softwood products economy, this locational dimension arises because of the spatial imbalance of supply and demand resulting from an uneven distribution of producers and consumers of forest products throughout the United states. Historically, the consumers of forest products have been concentrated in the Northern states, while major sources of timber supply and production facilities are located in the south and the west.

The two sets of supply and demand areas, together with the transportation costs that connect them, constitute a dynamic system. The supply regions compete with one another to market their products in supply areas. Prices are again the equilibrating mechanisms. If demand for a region's 
product is excessive relative to production possibilities, the price in that region will rise leading demand to shift to other producing regions. This will in turn lead prices in the initial region to fall until a new equilibrium is reached.

In the present study, this spatial dimension is represented by partitioning the continental United states into a set of contiguous regions. Five domestic lumber supply regions (Pacific Northwest, South, Southwest, Inland, and North), two plywood supply regions (NW and sO), and six product demand regions are considered. See Figures 4 and 5. Lumber output from the North region is treated as exogenous. Product supplies from Alaska and Hawaii are not included because their contributions to the domestic market are small; and regional exports of plywood are ignored.

The main factor underlying the development of this spatial framework was the practical considerations of data availability. A basic consideration in specification of supply regions was that activities and product types should possess some degree of homogeneity. The supply region boundaries specified here correspond closely with the Forest Service Administrative Regions and are essentially identical to supply areas considered in the Timber Assessment Market Model (Adams and Haynes 1980). The choice of demand regions was determined entirely by the availability of transport costs data. 


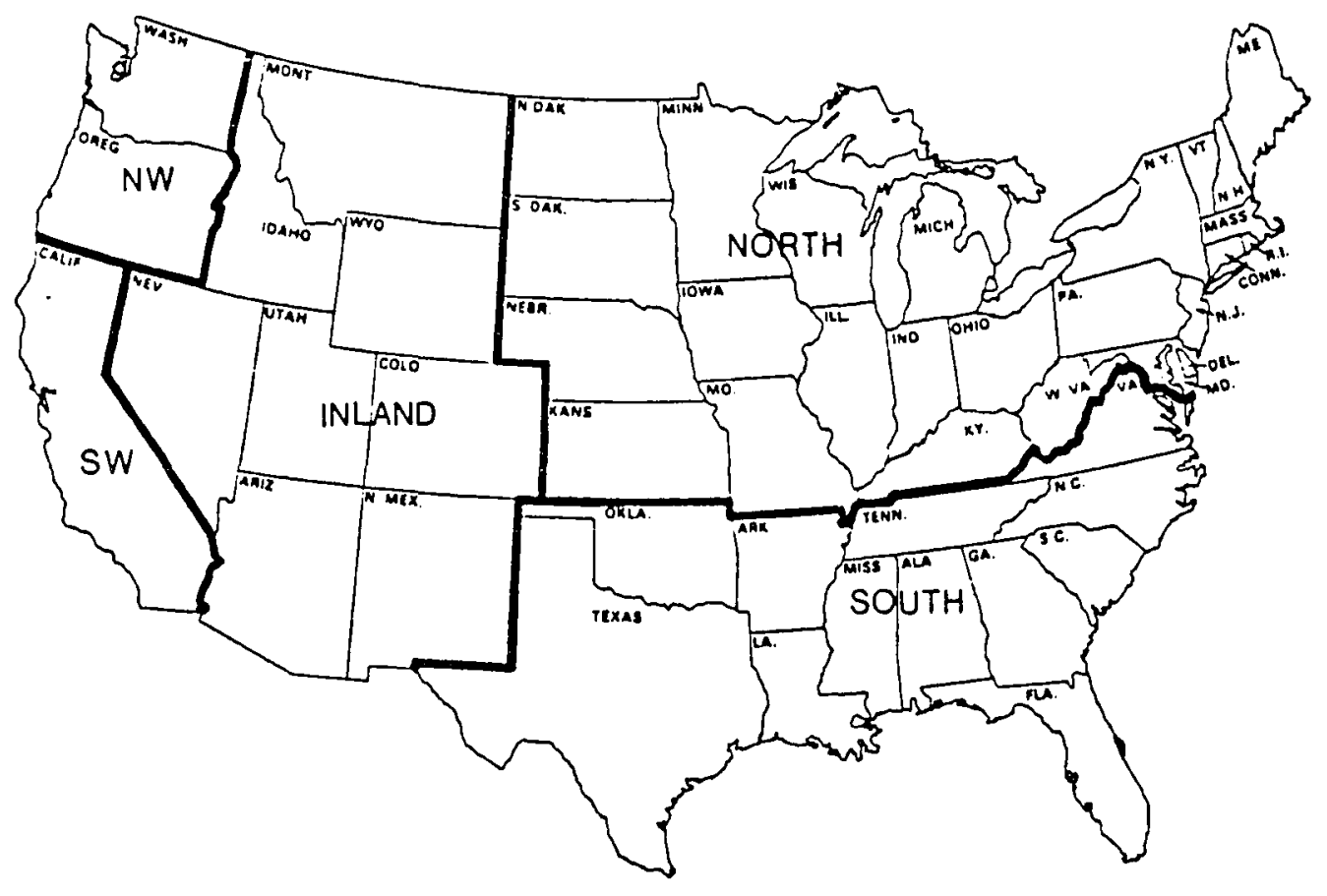

Figure 4. Product supply regions.

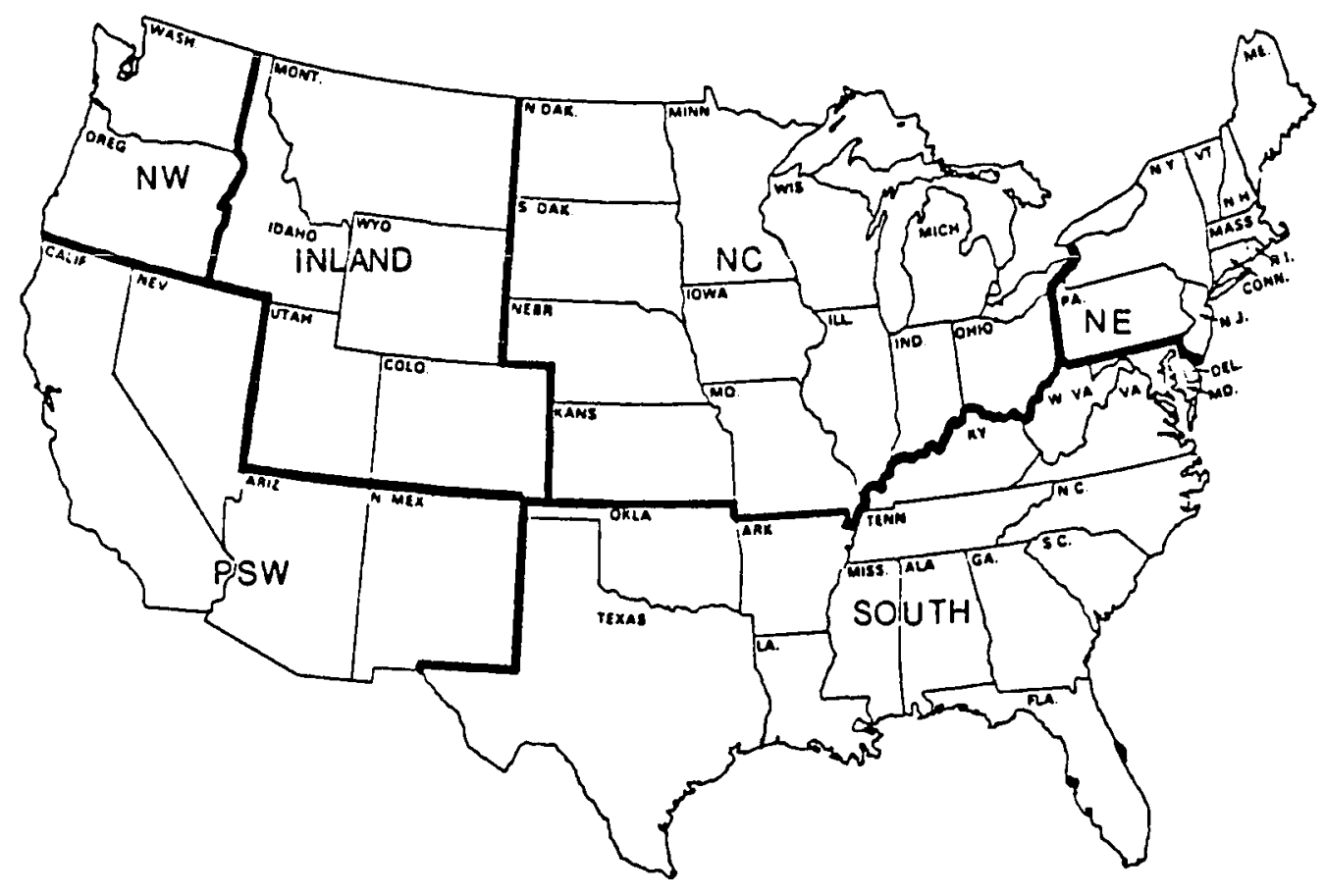

Figure 5. Product demand regions. 


\section{REGIONAL MARKET SHARES}

Market shares are here defined as the percentage of total domestic demand supplied by a producing region. Total demand on producers in a supply region (regional production) is determined by combining market shares with exports to other countries.

Tables II and III present market share data covering the 1950-1984 period for softwood lumber and plywood produced in various supply regions. Examination of the these historical trends in market shares reveals that significant changes in distribution of production across various regions has taken place.

Pacific Northwest: The main lumber products of this region come from Douglas Fir which is especially prized for its structural properties. Until 1965, the Pacific Northwest enjoyed a relatively stable position in the domestic softwood lumioer market, producing annualiy about one third of total softwood lumber consumed in the country. Since then, save minor increases in 1974 and 1975, the region's market share has declined steadily (see Figure 6).

Data on shipments of lumber from the Northwest show that the region's loss in market share in recent years can be primarily attributed to losses in the Northeast and Northcentral markets. Rapid rises in transport costs combined with increases in stumpage prices in the Northwest have placed the region in great disadvantage vis-a-vis other 
TABLE III

REGIONAL LUMBER MARKET SHARES

( $\%$ OF TOTAL CONSUMPTION)

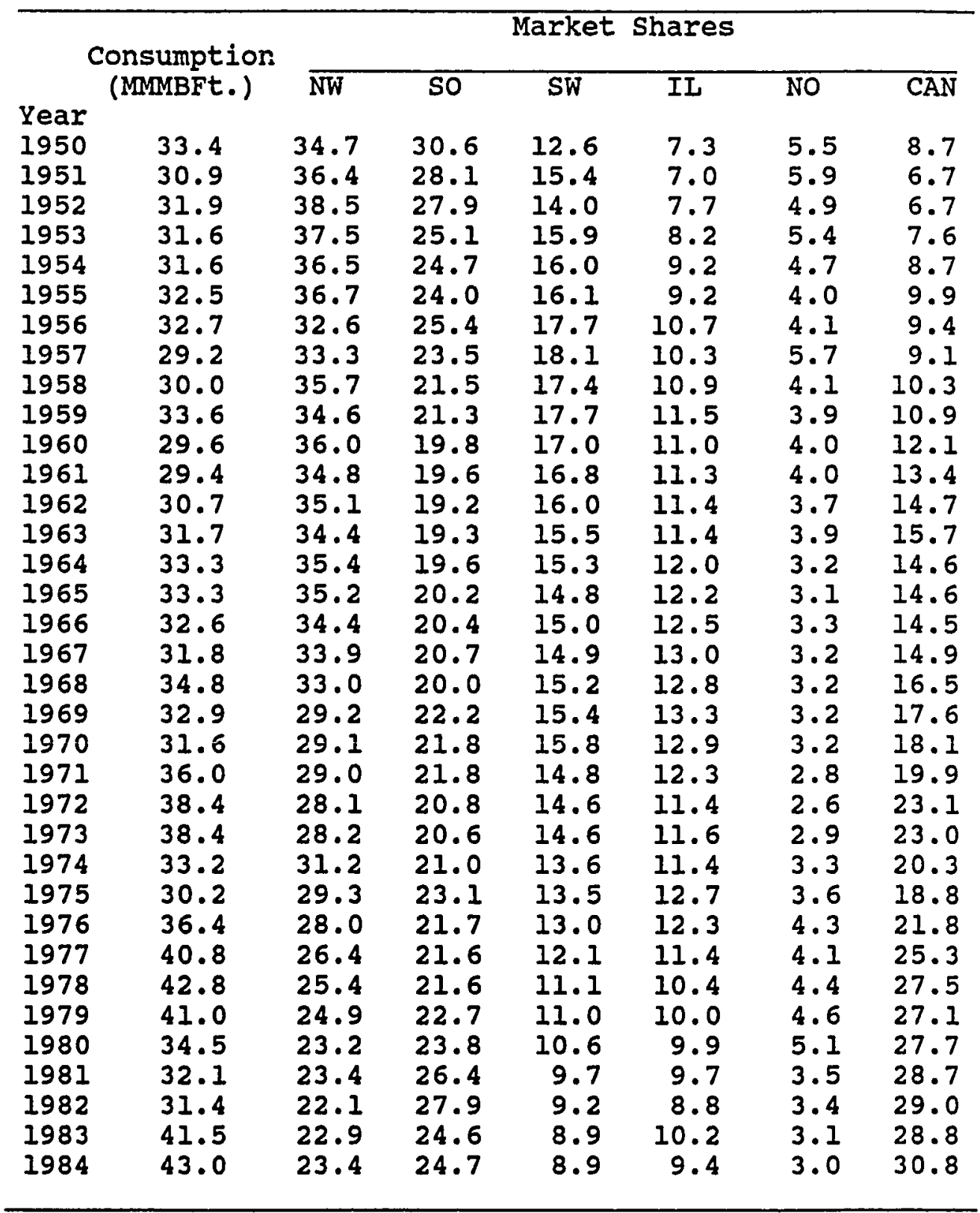

Source: Adams, Jackson, and Haynes (1986); Western Wood Products Association Statistical Yearbook. 
producing regions, leading to significant encroachments on this region's share of the Northern market.

Recent trends in lumber production in the Northwest do, however, suggest that the region's market shares during the 1980's have been somewhat stable, fluctuating around a historical low level of about 23 percent.

The South: The historical trend in lumber production and market shares for the South are markedly different from what we have observed in the Northwest. During the decade of 50 's, lumber production in the south declined steadily resulting, on the average, in an annual loss of about one percent in market shares. After a relatively long period of stability in the sixties and the greater part of the seventies, however, the region's market shares began to rise considerably. In 1983 lumber production in the south reached an historically high level of 10.5 billion BFt. and rose to near 11 billion BFt. in 1984 .

The Southern region covers a significantly large territory and, unlike the Northwest, the largest segment of its market consists of intra-regional shipments. The most significant change in market shares of the southern lumber in recent years was associated with the region's performance in 1981 and 1982. During these years, the market share of Southern producers increased by nearly 2.5 points per year. The performance of the south in the plywood market has been much more astounding. During the past three decades, plywood consumption in the United states has grown 
consistently at an average rate of near 500 million square feet per year. Prior to 1964 virtually no plywood was produced in the south. In this period, the Northwest producers, located mostly in the coastal region, comfortably commanded near 90 percent of the domestic plywood market.

Refinements in small-log peeling technology during the 1960's, induced by the rapid growth in plywood demand, provided the grounds for the development, and subsequent expansion, of the industry in the South. Production figures for the southern plywood show that since 1965 the South has not only absorbed nearly all increases in domestic demand for softwood plywood, but indeed has encroached significantIy on the Northwest's market shares.

Market share figures for the two regions show that the Northwest entered the $1970^{\prime} \mathrm{s}$ with a market share of almost three times that of the south (see Figure 7). Currently, South's market share stands 11 points above the Northwest.

Southwest: softwood lumber production in the sw has remained at a more or less steady level of approximately 4.5 billion BFt. a year. During the 1950's and 1960's, the species composition of lumber produced in the region --consisting of large quantities of redwood-- allowed it to maintain a relatively stable share in the domestic market. In recent years, however, declines in redwood production have made it more and more difficult for the region to keep pace with increases in domestic demand, leading to substantial losses in market shares. 
TABLE IV

REGIONAI PLYWOOD MARKET SHARES

( $\%$ OF TOTAL CONSUMPTION)

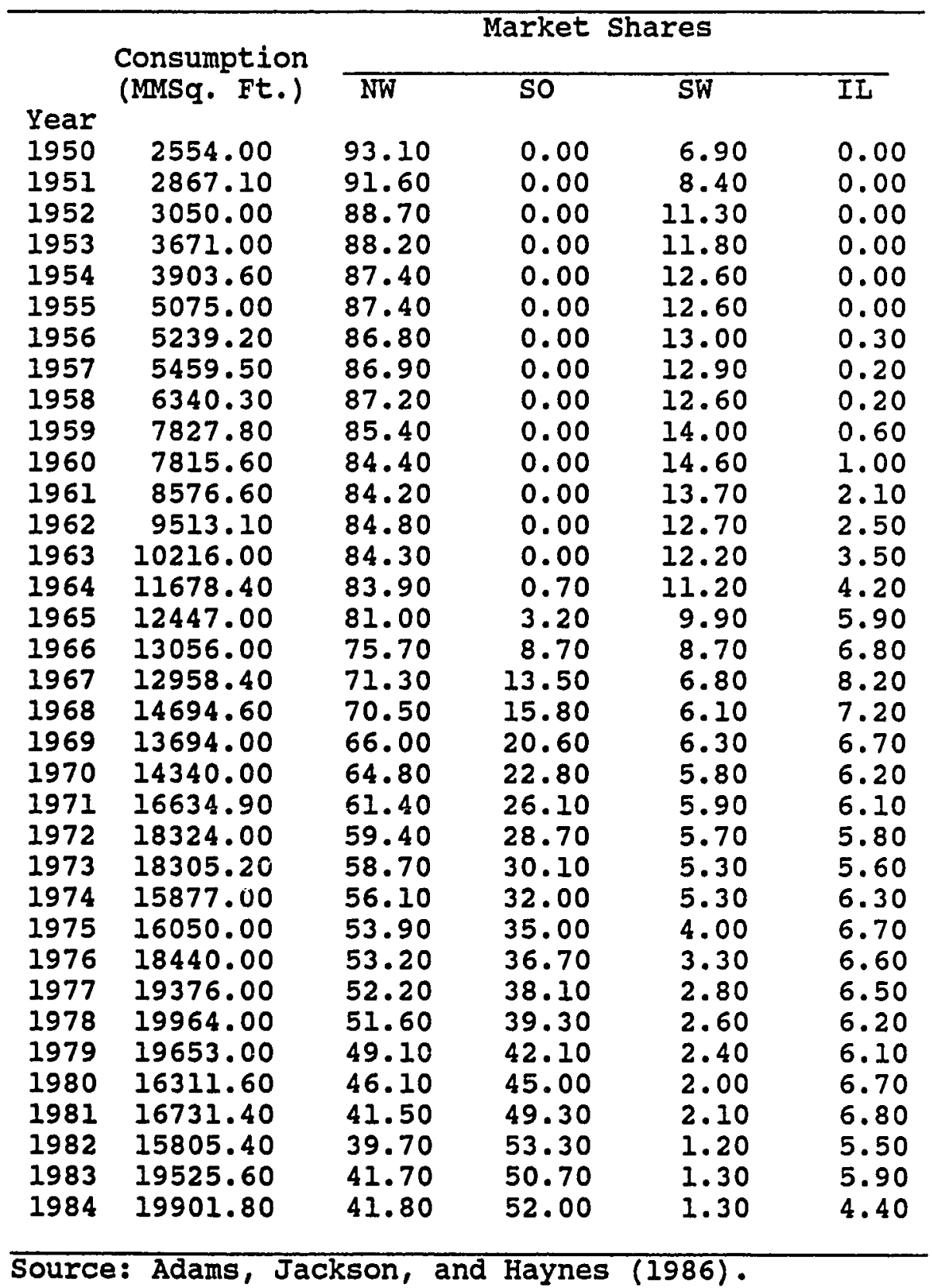




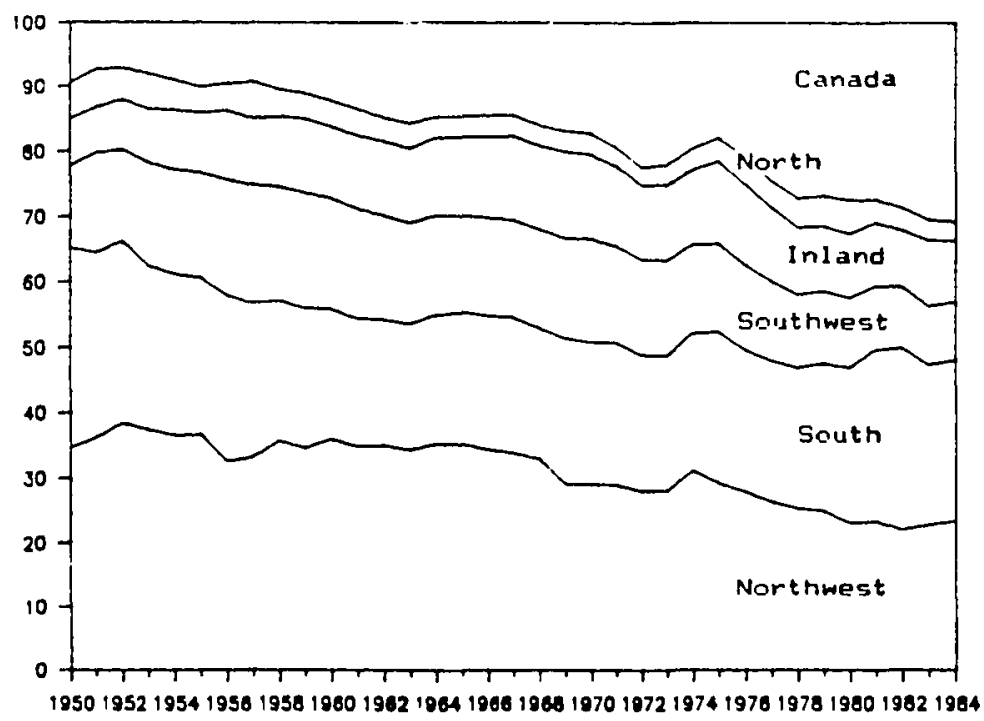

Figure 6. Regional market shares in lumber as percent of apparent consumption (1950-84). Source: Table III.

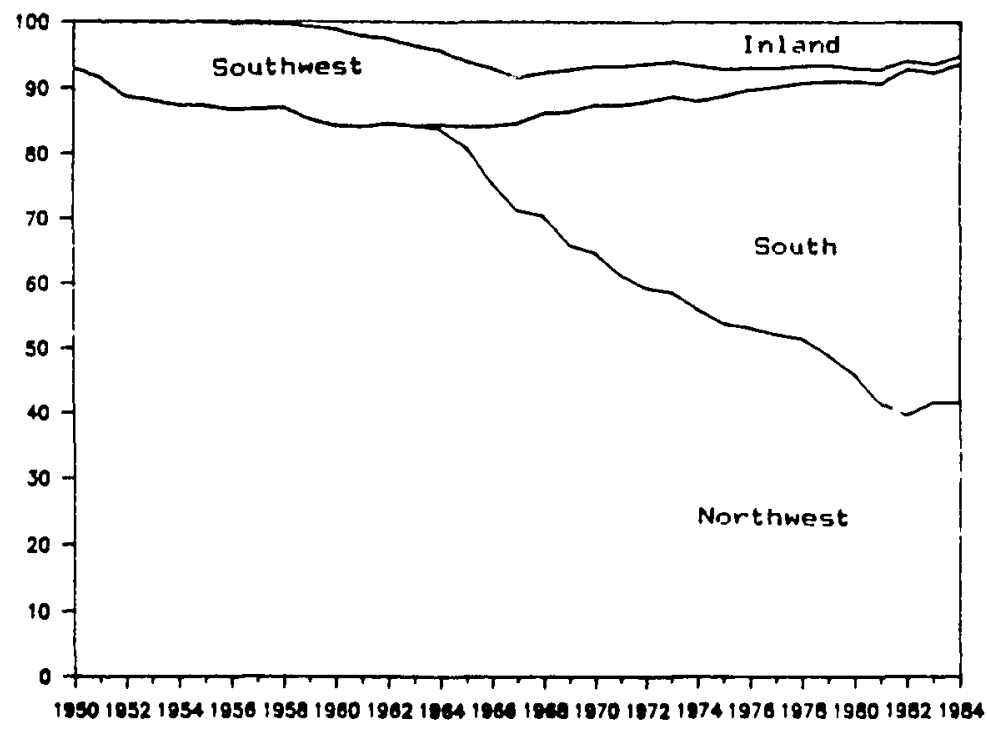

Flqure 7. Regional Plywood market shares as percent of apparent consumption (1950-84). Source: Table IV. 
Inland: Most lumber produced in this region comes from the Northern Rocky Mountains part of the region. Minor fluctuations notwithstanding, Inland's share of the domestic lumber market has remained relatively flat since the early 1950's. Lumber production figures for the Inland region suggest that changes in regional output correspond somewhat closely with fluctuations in demand for lumber at the national level leaving region's market shares unaffected.

Canadian Imports: The United states is the largest single market for the Canadian softwood lumber (Figure 8). Indeed Canadian exports to the U.S. constitute the largest flow in international lumber trade (Lindell, 1979).

Imports of lumber from canada have expanded continuously since 1950. This expansion has brought about

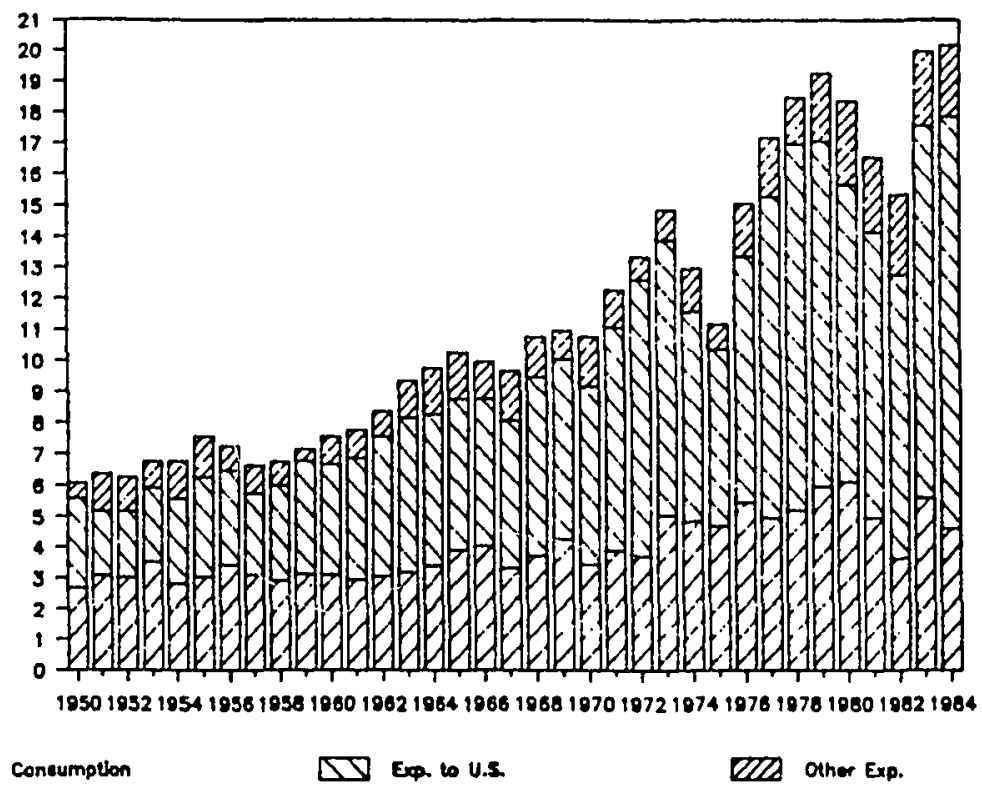

Figure 8. Canadian lumber production, consumption, and exports. Source: Adams, Jackson, and Haynes (1986). 
equal, but opposite, changes in market shares of domestic producers particularly in the West. Traditionally, imports from Canada have served a market clearing function fluctuating with changes in demand in the domestic market. In recent years, however, these imports have exhibited a behavior suggestive of an increasingly competitive displacement of domestic production.

The increase in Canadian imports in recent years and the strengthening of its competitive position are often attributed to declines in the value of the Canadian dollar in relation to U.S. currency. However, as Adams and Haynes (1980a) have demonstrated, an equally important factor has been the production conditions in Canada characterized by low production costs and elastic supply.

\section{REGIONAI TIMBER RESOURCES}

A fundamental consideration in the analysis of the spatial patterns of production in the wood products industry is the geographical distribution of timber resources and variations in supply behavior that arise from differences in economic objectives and management practices across ownership categories.

The continental United states contains about 470 million acres of timberland with an additional 12 million acres in Alaska and Hawaii, which together constitute around 22 per cent of the total land area in the country. 
Timberlands, as listed in Table $V$, are categorized by region and type of ownership. The rows in Table $\mathrm{V}$ show the distribution of timberlands within each region by ownership type. Four types of ownership are recognized: "National Forests", "other public", "forest industry", and "other private". "National Forests" designates commercial forestlands that are owned by the Federal Government and come under the jurisdiction of the Forest Service (Department of Agriculture). National forests are chiefly concentrated in the western regions where they constitute nearly 53 percent of all timberlands in the region.

The "other public" category includes Federal lands other than National Forests (primarily lands administered by the Bureau of Land Management, Department of the Interior), Bureau of Indian Affairs; and state, county, and municipal forests. Much of the latter holdings (over 50 percent) are in the Lake states and consist of lands reverted to local governments as a result of tax delinquencies during the 30 's. The BLM lands are primarily located in the Pacific Northwest (4.1 MM acres) and the Rocky Mountain (1.7 MM acres) regions.

The "forest industry group", i.e., integrated firms that engage in both growing and processing of timber, holds approximately 15 percent of total timberlands. The remaining 59 percent (277 MM acres) of timberlands in the continental United States are owned by farmer and other private 
entrepreneurs who grow and sell timber but in general! are not involved in wood processing. These holdings, which constitute the largest single ownership class, are by and large concentrated in the North and the South regions where 70.8 and 71.3 , respectively, of timberlands fall in this category.

TABLE V

DISTRIBUTION OF TIMBERLANDS BY REGION AND OWNERSHIP IN 1977

(MM ACRES)

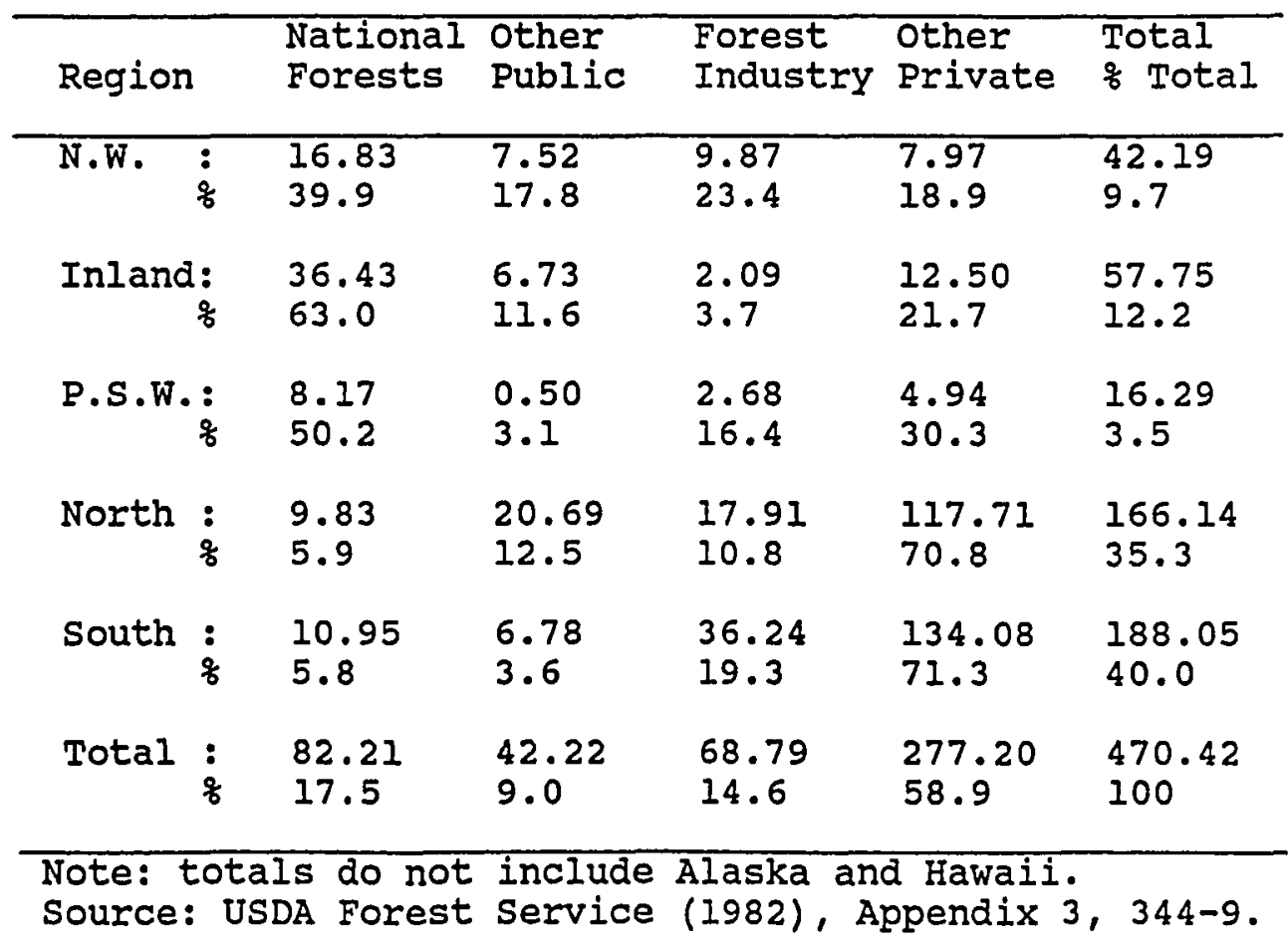

Distribution of timberlands is an important indicator of where timber will be produced in the future. From the standpoint of the near term supply of wood products, however, supply sources will be determined by the location 
of existing inventories of mature timber (Dowdle and Henke, 1985 p. 80).

The quantities of timber supply from these sources are in turn influenced by biological determinants such as land quality, growth rates, and type of species; and specific economic objectives pursued by owners in each region. Attention here will be focused on two general ownership categories of "public" and "private". These categories represent the two timber supply sectors for which management objectves are distinctly defined.

Timber Supply: Private. The economic theory of timber supply concerns two central issues of when to harvest and how much to harvest. The problem of when to harvest (optimal rotation) may be viewed as a special instance in the classical theory of capital (Hyde, 1980, pp. 60). The profit maximizing solution to this problem can be derived directly from the owner's profit function. Under the condition of perfect competition, and assuming economic rationality, timber owners choose harvesting schedules that maximize the present discounted value of their holdings.

In terms of a fixed land-base with an even-aged stock of timber, the optimality condition implies that trees should be cut when the discounted marginal product of the timber stand (annual growth rates) equals the marginal cost of withholding the timber for an additional year. These costs consist of the interest on the revenues from the cut, 
value of silvicultural efforts and, as Samuelson (1976) has pointed out, the rent on the forest land. ${ }^{3}$

Economic theories of optimum harvest provide a useful framework for the analysis of timber supply in the long-run. Their utility in explaining actual output levels in the short-run, however, is limited. A major impediment in the application of these theories to short-term analysis is the predominance of noneconomic objectives for private owners such as tax considerations and the immediate nature of cash-flow needs. These issues will be considered in greater detail in the next chapter as we develop empirically testable relationships for our model.

Timber Supply: Public. Conventional economic tools of price theory (supply and demand analysis) provide an ample framework for the analysis of timber supply. These economic considerations will, however, be of limited use in explaining supply behavior where significant areas of commercial forestlands are owned, managed, or in one form or another regulated by public policy. The reason is that in such cases an entirely different set of administrative considerations, which are themselves based on biological or

3 For a thourough theoretical treatment of economic issues concerning timber production see Hyde (1980) particularly Chapter 4. A complete mathematical derivation of the optimality condition can be found in Johansson and Lofgren (1985) Chapters 4 and 6. 
otherwise "non-economic" functions, dominate the amount of timber made available to the market.

During the course of this century public policy has become an increasingly important force in the timber market in the United States. Indeed, as Deacon and Johnson (1985) have observed, no other natural resource industry has ever been as heavily influenced by government ownership and policy as the timber industry. In 1977, the latest year for which data is available, public ownership accounted for 28.1 percent (135.7 miliion acres) of the total timberland in the country ( 482.5 million acres). Timber production patterns, at the same time, indicate that in all parts of the country, particularly in the west, producers of wood products have become increasingly dependent on timber supplies from public lands (see Table VI).

Broadly defined, public timber policy encompasses a wide range of issues concerning management practices, marketing procedures and harvesting patterns of timber from publicly owned forests, taxation of private holdings, and other regulatory policies at the federal and local government levels. These issues, in particular practices concerning the management of the National Forests by the Federal Government, have been the subject of a perennial debate between economists on the one hand, and environmentalists and professional forestry experts on the other. A substantial body of research has now been accumulated by either camp 
TABIE VI

ANNUAL HARVEST OF SOFTWOOD TIMBER BY REGION AND OWNERSHIP $(1950-1984)$

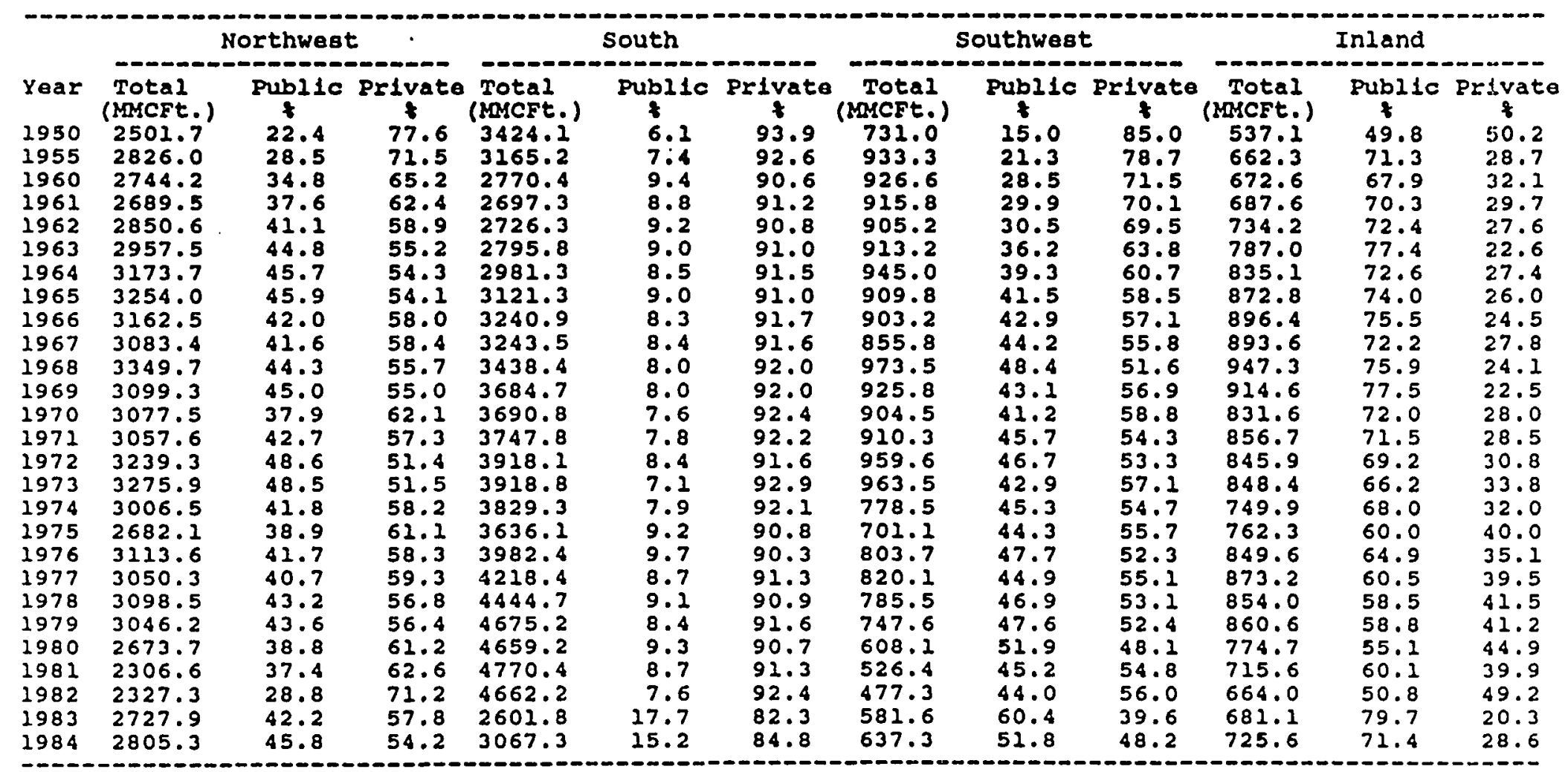

Source: Appendix A, [1], [19]. 
in support of its position. ${ }^{4}$ Much of this controversy centers on two principles that have dominated the management of National Forests in the country over the past two and half decades: "sustainable yield" and "multiple use", both embodied in the Multiple-Use Sustained-Yield Act of 1960.

A central issue in this controversy concerns the "sustained yield" requirement of the act and the concepts of "even flow" and "allowable cut", the practical implications of the mandate. At the core of criticisms concerning public timber policy in the U.S. lies the issue of economic efficiency of these principles and their inconsistency with the economic concept of "supply".

Regional inventories of softwood sawtimber on National Forests and other ownerships are presented in Table (VII). A comparison of figures in Tables (V) and (VII) reveals that distribution of timber resources does not follow the same pattern as timberlands. Major differences exist in the intensity of timber stands across regions and among ownership categories. The most readily discernible pattern in the distribution of sawtimber is that the volumes of standing timber on National Forest lands are generally in

4 Deacon and Johnson (1985) provide a collection of most recent studies on the subject of government timber policy. More technical treatments can be found in Hyde (1980) especially Chapters 2 and 7; and Samuelson (1976). 
excess of the proportion of forest area in all regions, indicating much higher densities on the average. This latter observation has, among other things, been cited as an important indication that National Forests produce less than their share of domestic timber output (Howe, $1979 \mathrm{pp} .223$ ).

TABLE VII

VOLUME OF SOFTWOOD SAWTIMBER

BY REGION AND OWNERSHIP

1977 (MM BFt.)

\begin{tabular}{|c|c|c|c|c|c|}
\hline Region & $\begin{array}{l}\text { National } \\
\text { Forests }\end{array}$ & $\begin{array}{l}\text { Other } \\
\text { Public }\end{array}$ & $\begin{array}{l}\text { Forest } \\
\text { Industry }\end{array}$ & $\begin{array}{l}\text { Other } \\
\text { Private }\end{array}$ & $\begin{array}{l}\text { Total } \\
\text { Total }\end{array}$ \\
\hline N.W. & $\begin{array}{l}386623.0 \\
53.1\end{array}$ & $\begin{array}{l}140322.0 \\
19.3\end{array}$ & $\begin{array}{l}141004.0 \\
19.4\end{array}$ & $\begin{array}{l}59537.0 \\
8.2\end{array}$ & $\begin{array}{l}727486.0 \\
40.4\end{array}$ \\
\hline Inland: & $\begin{array}{l}260758.2 \\
68.5\end{array}$ & $\begin{array}{l}42774.1 \\
11.2\end{array}$ & $\begin{array}{l}23260.4 \\
6.2\end{array}$ & $\begin{array}{l}53586.8 \\
14.1\end{array}$ & $\begin{array}{l}380379.5 \\
21.1\end{array}$ \\
\hline P.S.W.: & $\begin{array}{l}157958.0 \\
61.8\end{array}$ & $\begin{array}{l}6356.0 \\
2.5\end{array}$ & $\begin{array}{l}40833.0 \\
16.0\end{array}$ & $\begin{array}{l}50397.0 \\
19.7\end{array}$ & $\begin{array}{l}255594.0 \\
14.1\end{array}$ \\
\hline North : & $\begin{array}{l}8049.9 \\
8.3\end{array}$ & $\begin{array}{l}11942.1 \\
12.4\end{array}$ & $\begin{array}{l}22734.4 \\
23.6\end{array}$ & $\begin{array}{l}53777.1 \\
55.7\end{array}$ & $\begin{array}{l}96503.5 \\
5.5\end{array}$ \\
\hline South & $\begin{array}{l}33979.7 \\
10.0\end{array}$ & $\begin{array}{l}I 3883.6 \\
4.0\end{array}$ & $\begin{array}{l}86389.7 \\
25.4\end{array}$ & $\begin{array}{l}206769.5 \\
60.6\end{array}$ & $\begin{array}{l}341022.5 \\
18.9\end{array}$ \\
\hline Total & $\begin{array}{l}847368.8 \\
47.0\end{array}$ & $\begin{array}{l}215277.8 \\
12.0\end{array}$ & $\begin{array}{l}314271.5 \\
17.4\end{array}$ & $\begin{array}{l}424067.4 \\
23.6\end{array}$ & $\begin{array}{l}1800985.5 \\
100\end{array}$ \\
\hline
\end{tabular}

These and other normative issues concerning public timber policy are important and merit close scrutiny and detailed analysis. Such undertaking, however, is well beyond the scope of the present study. Our interest in the area is 
a purely empirical one: the manner in which such policies manifest themselves in timber supply behavior of various regions; and the insight they can provide in modeling this behavior.

The extent to which timber offerings from public lands affect regional markets is determined by the relative share of the public component of total production. In analyzing the short-run effects of public timber supply on local stumpage markets, it is essential to distinguish between "timber offerings" and actual "harvest levels". Timber from National Forests and other public lands is usually sold under four-year removal contracts. Quantities of timber harvested in any one period thus do not necessarily correspond with timber offerings in that period. While market conditions in the long-run are decided by levels of timber "sold" from public lands, actual short-run harvest levels are determined by local demand and price levels. In short-run analysis, therefore, no distinction need be made between supply sources. Total harvest, consisting of harvest on both public and private ownerships, can be explained in terms of conventional supply theory. 
CHAPTER III

THE EMPIRICAL MODEL

In Chapter I we outlined a general conceptual framework for a multiregional, multi-industry model and described its major ingredients and their conceptual contents. Based on these theoretical considerations and the insight we have gathered from our discussions of the lumber and plywood industries and the timber economy in Chapter II, we are now in a position to proceed with the development of our industry-specific model. To aid us in the task, is also the wealth of information provided by previous econometric analyses of the forest economy, most notable among them, the pioneering studies by the stanford Research Institute (1954), Holland (1960), Gregory (1960), McKillop (1967, 1969), and other more recent works of Adams and Blackwell (1973), Robinson (1974), Mills and Manthy (1974), Holley, Haynes, and Kaiser (1975), Adams (1977), and Adams and Haynes $(1980)$.

Although these studies have, by and large, adopted fundamentally similar specifications in presentation of individual behavioral relationships, there are marked differences among them in terms of objectives, scope (the degree of spatial aggregation and sectoral presentation), 
and model structure. ${ }^{1}$ From a genealogical point of view, our model is a direct descendant and extension of Adams'multiregional, multiproduct model of the U.S. softwood timber market (Adams 1977) and the Timber Assessment Market Model developed by Adams and Haynes (1980).

Both studies were designed as forecasting tools for the long-range projection of activity in the product and stumpage markets and assessment of potential impacts of alternative resource use policies in the private and public timber sectors. In the taxonomy of regional models, Adams' approach is a combined top-down/bottom-up framework. The model considers two products (softwood lumber and plywood), four product supply regions (including Canadian imports) and three stumpage supply regions (see Figures 4 and 5 in Chapter II). Treating regional supplies as perfect substitutes, equilibrium quantities and aggregate product prices (at the national level) are then established jointly by the levels of aggregate demand and regional supplies. The model ignores transportation costs so that product prices in the supply regions are identically the same as the demand price at the national level.

Timber Assessment Market Model (TAMM), on the other hand, is a purely bottom-up model. It is by far the most

1 For a comprehensive survey of econometric studies of the forest economy see Adams and Haynes (1980). A bibliography of earlier projection studies can be found in Gregory, et al. (1971). 
comprehensive modeling effort in the analysis of the timber economy in the United States. The spatial structure of TAMM is based on partitioning of the national market into nine product and stumpage supply regions and six demand regions. For each supply region equilibrium solutions for product prices and quantities are found by simultaneous estimation of the regional product and stumpage relationships. Given interregional transportation costs in a given period, equilibrium spatial price and regional outputs are computed via a programming procedure which utilizes the reduced form of the regional supply equations and regional demand relationships in an iterative process to find the profit optimizing levels of supply in each region.

The most outstanding feature of TAMM that distinguishes it from most other projection models of the forest economy, is its explicitly simultaneous treatment of interdependent market relationships, specifically, the linkage between regional stumpage and product sectors which allows simultaneous determination of market clearing prices in both markets. For a complete description of the model structure and interactions of TAMM the reader is referred to Adams and Haynes (1986).

The model developed in the present study incorporates and combines features of the two models we have described. It is, however, designed for the purpose of short term (one to two year) forecasting. Certain long-run consideratiens 
such as regional production capacity adjustment mechanisms are ignored and resource availability takes on either a simplified form, or in some cases, is ignored completely.

\section{THE MODEL, ITS STRUCTURE, AND COMPONENTS}

The model, as described in Part one, contains three interrelated components: 1) the national product market, 2) regional product market, and 3) the regional factor market.

Due to exigencies of estimation, certain modifications of the initial conceptual model were deemed necessary without compromising the theoretical consistency of the model. First, regional lumber supply equations were estimated in inverse form so that regional lumber prices can be obtained directly. Second, the regional factor market relationships were reduced to single equations with price as the dependent variable. The linkages between the product and stumpage sectors in each region was thus established by directly relating prices in the two markets. Third, in the demand equations for regional lumber outputs, quantities were replaced by identities that represented actual market shares. Finally, in the market share equations, a regional "accessibility index" was included to represent regional locational advantage. These modifications helped simplify the model structure considerably. The resulting system, its components and interactions are illustrated in Figure 9. The complete system to be estimated may be represented as: 


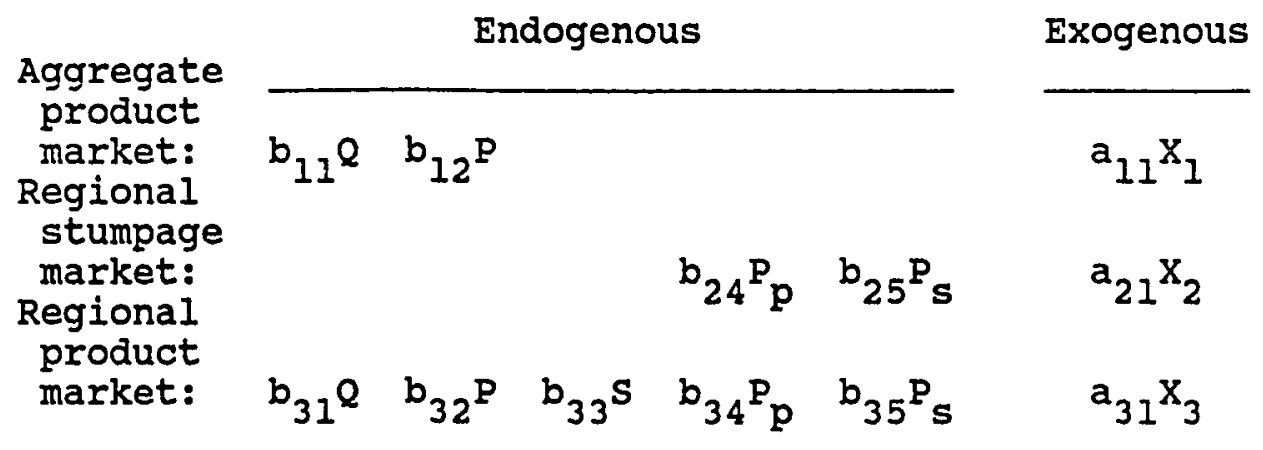

where,

$Q$ and $P$ are, each $2 \times 35$ vectors of, respectively, aggregate quantities consumed and average prices for both lumber and plywood;

$P_{p}$ is a $6 \times 35$ vector of regional mill level prices of lumber and plywood;

$P_{S}$ is a $4 \times 35$ vector of regional stumpage prices;

$\mathrm{S}$ is a $7 \times 35$ vector of supply region lumber and plywood quantities ;

$x_{1}, x_{2}$ and $x_{3}$ are vectors of predetermined variables; and $b_{11}, b_{12}, b_{21}, b_{22}, b_{31}, b_{32}, b_{33}, b_{34}, b_{35}, a_{11}, a_{21}$, and $a_{31}$ are arrays of coefficient estimates for endogenous and predetermined variables with their appropriate dimensions.

There are four equations in (1), one aggregate demand and one aggregate supply relationship for each of the two products. (2) contains four equations, they are regional stumpage price relationships. There are thirteen equations in (3); four regional lumber price relationships; four relationships representing supply of, and demand for, plywood in the N.W. and the south; and five regional lumber market share equations, including Canadian imports. 


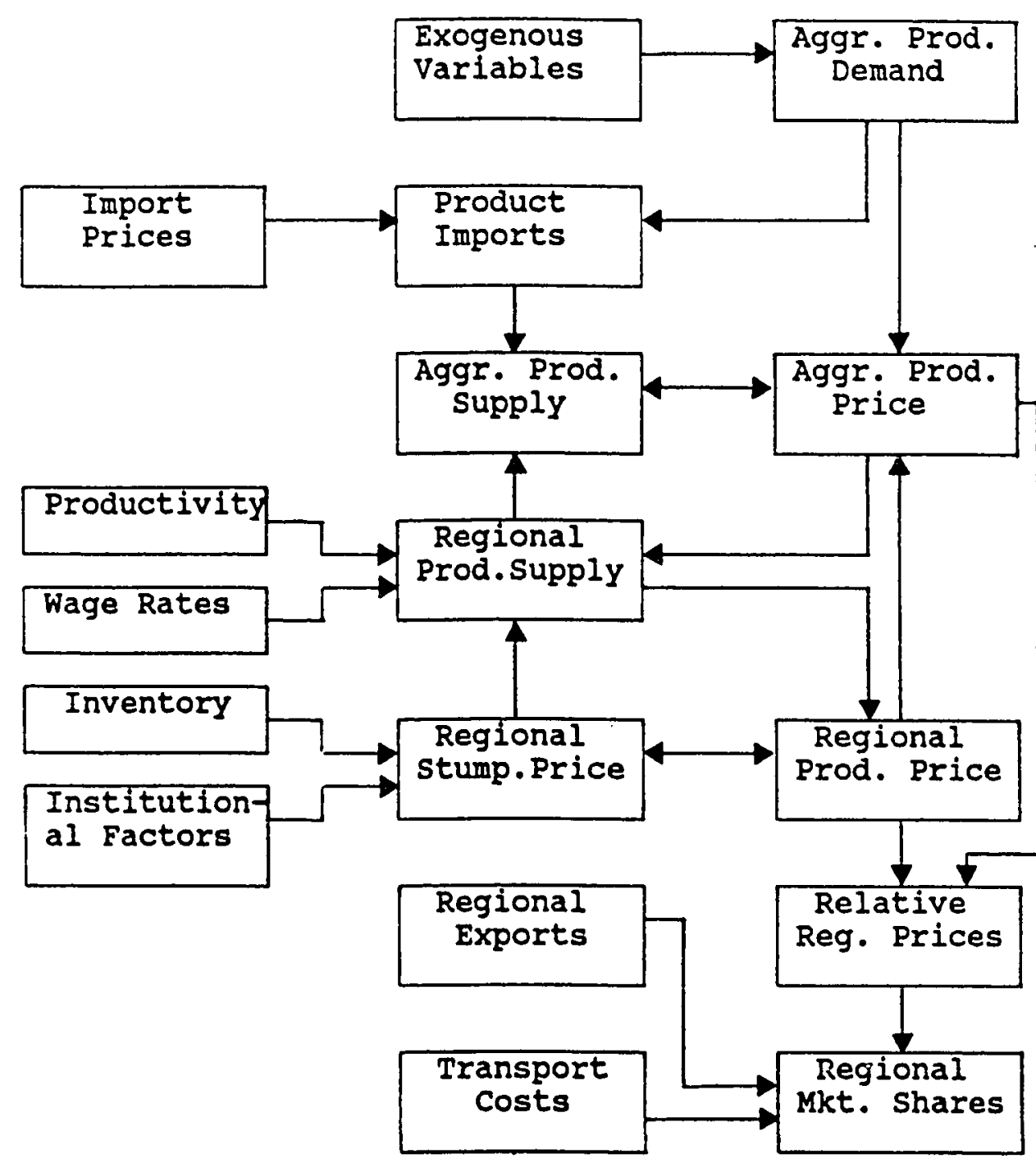

Figure 9. Model structure and its main interactions.

Following a general explanation of the estimation procedures and presentation of results, we will describe each of these model components separately and in detail; and will provide theoretical justifications for the forms used in the final estimating structures. 
MODEL ESTIMATION

As a first approximation, all parameters of the behavioral equations in the model were estimated via Ordinary Least Square (OLS). This was done to ascertain the appropriateness of specifications; and to test the goodness of fit in individual relationships. In several cases this procedure led to some modification in the equations under study.

The model contains several interdependent relationships. Two stage Least Square procedure was therefore used as the estimation method for all relationships where one or more of the explanatory variables were endogenously determined. Since the model contains a large number of exogenous variables, in order to avoid problems with degrees of freedom, it was necessary to select only a subset of predetermined variables as instruments in the first stage.

Traditionally, the problem of choice among predetermined variables has been dealt with either through arbitrary selection of a small set of regressors, or by using a principal components method to derive linear combinations of predetermined variables that maximizes their covariance (for the original presentation of the latter approach see Kloek and Mennes, 1960). The first procedure is obviously faulty and can lead to serious errors in specification. The second procedure, though it has been shown to produce efficient 
estimates in large samples, can cause confusion in the theoretical interpretation of the mixture of variables.

In order to maintain procedural consistency in selection of first stage regressors, a method was adopted based on guidelines suggested by Fisher (1965) and McCarthy (1971). The procedure was as follows: for each explanatory endogenous variable, a set of regressors was selected that include: 1) all predetermined variables in the equation containing the endogenous variable, 2) all exogenous variables in the equation that explains that variable, and 3) any lagged values of the endogenous variable present in the model. Additional first stage regressors were then drawn from other parts of the model by causal ordering of variables in the entire system and choosing only variables of the first causal order, i.e., variables that were judged to be directly related to the equation under study.

An additional complication in the estimation of the model arises from the contemporaneous correlation between the disturbance terms in the lumber market share equations. This problem emerges from the implied restriction that the market shares must sum to unity, or 100 percent, so that in any given period an over (under) estimation of one region's market share is bound to lead to under (over) estimation of other regions' market shares. To deal with this problem, the lumber market share equations were estimated as a separate block by the more appropriate method of Three stage Least 
Square (Zellner, 1962; Zellner and Theil, 1962).2 The decomposition of the model in this fashion is justified because no current endogenous variables appear on the right-hand side of these equations. Verification by the order condition shows that the identification requirement of the Zeliner procedure is also satisfied. In the NW market share equation this procedure resulted in an unreasonably small coefficient on the accessibility index. These equations were subsequently reestimated with imposed restriction that the coefficient on the accessibility index (see Table XIV) for NW should equal the value obtained from the ols estimate. The estimation results of the complete model are presented in Table VIII. For the definitions of variables, their derivation and sources see Table IX.

\section{TABLE VIII}

PARAMETER ESTIMATES OF THE MODEL

(1) Lumber Demand (Aggregate Consumption) TLUMCON $=34867.25-64.07$ *LUMPRUS $-31050 *$ MAL/PLY + (2.5)

$(4.1)$

(2) Lumber Consumption Identity

TLUMCON = TLUMPRD + TLUMIMP - TLUMEXP

2 The method is based on simultaneous solution of all parameters of the system using the variance-covariance of the disturbance terms of equations. For a complete description of the method see Johnston (1984, pp. 486-90) and Pindyck and Rubinfeld (1981, pp. 334-6). 
(3) Average Price of Lumber in U.S.

LUMPRUS $=-37.16+0.238 *$ LUMPRUS $_{-1}+0.000994 *$ TLUMCON + (1.93) (1.72)

$1.665 *$ STMPRUS $+19.77 *$ RW/IIPL

$R^{2}=.844^{(3.3)} \quad{ }_{D W}=1.30 \quad$ Estimation Method: $2 S L S$

(4) Plywood Demand (Aggregate Consumption)

TPLYCON $=-7356.4-8.30 *$ PISWPLY $-183.1 *$ MAPLY $/ \mathrm{S}+$ (1.1)

$(0.2)$

$154.68 *$ VNCONST $+72.57 *$ INDINDP

$\mathrm{R}^{2}=.967 \quad(3.5) \quad(1.8)$

$R^{2}=.967$ DW $=1.56$ Estimation Method: I2SLS

(5) Plywood Supply

TPLYPRD $=7105.7+4.14 *$ PISWPLY $-2656.0 *$ RW/ILPP + (1.05)

$R^{2}=.955 \stackrel{0.699 * \text { TPLYCON }}{D W}=1.51$ Estimation Method: 2SLS

(6) Stumpage price NW

STMPRNF $=47.20+0.005 *$ TTCUTNW $-1+0.413 *$ LUMPRNW (1.23) $-1 \quad(6.0)$

$0.0015 *$ INVPRNW $-0.0047 *$ TVSNFNW

$R^{2}=.861 \stackrel{(4.7)}{D W=1.38 \quad \text { Estimation Method: } 2 \text { SLS }}$

(7) Stumpage Price so

STMPRSO $=0.954+0.988 *$ STMPRSO $_{-1}+0.654 *$ LPCHGSO

$\mathrm{R}^{2}=.803 \quad \mathrm{DW}=1.88^{(11.1)}$ Estimation Method: $2 \mathrm{SLS}$

(8) Stumpage Price SW

STILPRSW $=-11.72+0.0092 *$ TTCUTSW $_{-1}+0.485 *$ LUMPRSW (2.0) 0.00087 *INVPRSW $-0.021 *$ TVSNFSW

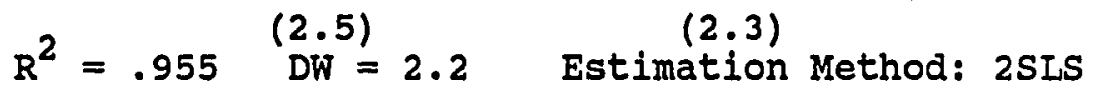

(9) Stumpage Price II

STMPRIL $=1.86+0.853 *$ STMPRIL $_{-1}+0.235 *$ LPCHGIL

$R^{2}=.873 \quad D W=2.3 i^{(13)}$ Estimation Method: $2 S L S$

(10) Price of Lumber NW Region

LUMPRNW $=-33.9+0.26 *$ LUMPRNW $_{-1}+0.0056 *$ LUMPDNW + (2.0) $(4.9)$

$0.917 *$ STMPRNW $+4.09 *$ LCSTLNW

$R^{2}=.829^{(5.6)} \quad{ }_{D W}=1.63 \quad$ Estimation Method: 2 SLS 
(11) Price of Lumber so Region

LUMPRSO $=-19.9+\frac{0.339 * \text { LUMPRSO }}{(2.9)}+\frac{.0046 * \text { LUMPDSO }}{(3.5)}+$ $0.73 *$ STMPRSO $+0.72 *$ IRLWRSO $-0.26 *$ ILPDLSO

$\mathrm{R}^{2}=.760^{(0.6)} \mathrm{DW}=1.65 \quad \begin{gathered}(4.4) \\ \text { Estimation Method: } 2 \text { SLS }\end{gathered}$

(12) Price of Lumber SW Region

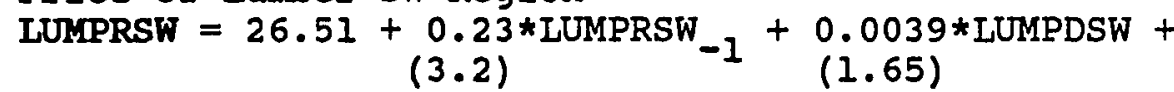
$1.34 *$ STMPRSW $+0.03 *$ IRLWRSW

$\mathrm{R}^{2}=.960^{(7.6)} \mathrm{DW}=1.98 \quad \begin{aligned} & (1.23) \\ & \text { Estimation Method: } 2 \text { SLS }\end{aligned}$

(13) Price of Lumber IL Region

LUMPRIL $=1.55+0.286 *$ LUMPRIL $_{-1}+0.0029 *$ LUMPDIL + (2.4)

$1.29 *$ STMPRIL $+12.8 *$ LCSTLIL

$\mathrm{R}^{2}=.805^{(2.4)} \mathrm{DW}=1.83 \quad \begin{aligned} & (2.7) \\ & \text { Estimation Method: } 2 \text { SIS }\end{aligned}$

(14) Plywood Supply NW

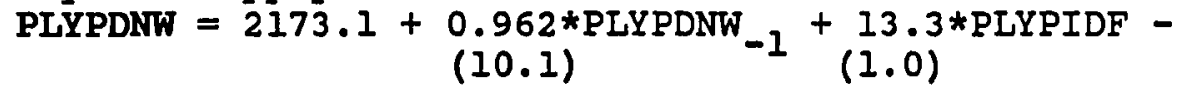
33.13*STMPRNW $-834.7 *$ LCSTPNW

$\mathrm{R}^{2}=.904^{(1.5)} \stackrel{\mathrm{DW}}{ }=1.74 \quad \begin{gathered}(1.3) \\ \text { Estimation Method: } 2 \mathrm{SLS}\end{gathered}$

(15) Plywood supply so

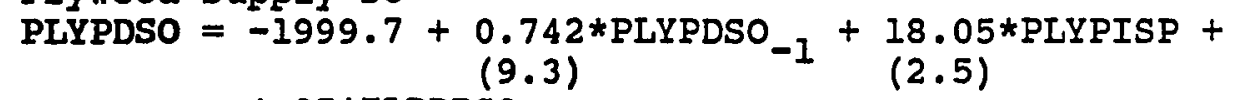
$4.87 *$ ILPDPSO

$\mathrm{R}^{2}=.981^{(1.42)} \mathrm{DW}=2.16 \quad$ Sample $1965-84$, OIS

(16) Market Share Lumber Canada

MIKTSLCA $=9.237+0.938 *$ MKTSICA $_{-1}-8.886 * \mathrm{MACA} / \mathrm{US}$

$\mathrm{R}^{2}=.967 \quad \mathrm{DW}=1.30^{(14.4)}$ Estimation Method: OLS

(17) MKTSLCA $=100 *$ (LUMIMPC / TLUMCON)

(18) Market Share Lumber $\mathrm{NW}$

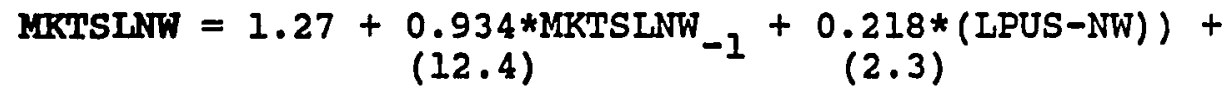
$0.095 *$ ACCSLNW

$\mathrm{R}^{2}=.914^{(--)} \mathrm{DW}=2.1 \quad$ Estimation Method: 3SLS

(19) MKTSLNW $=100 *$ [(LUMPDNW - EXPLUNW $) /$ TIUMCON $]$ 
(20) Market Share Lumber so

MIKTSISO $=9.29+\underset{(7.0)}{0.0017 * \text { LUMPDSO }_{-1}}+\underset{(1.9)}{0.152 *(\text { LPUS }-S O)}+$ $0.0082 *$ ACCSLSO

$\mathrm{R}^{2}=.610^{(1.4)} \mathrm{DW}=1.36^{\text {Estimation Method: } 3 \text { SLS }}$

(21) MKTSISO $=100 *[($ LUMPDSO - EXPLUSO $) /$ TLUMCON $]$

(22) Market Share Lumber sw

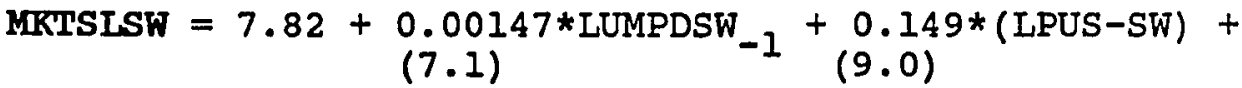
$0.00876 *$ ACCSLSW

$\mathrm{R}^{2}=.923^{(2.0)} \mathrm{DW}=1.58 \quad$ Estimation Method: 3 SIS

(23) MKTSLSW $=100 *$ [ (LUMPDSW - EXPLUSW $) /$ TLUMCON $]$

(24) Market Share Lumber IL

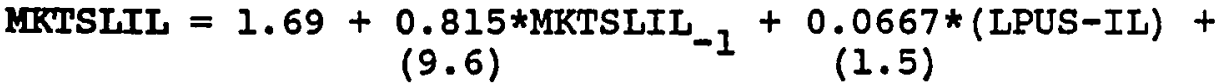

$0.00065 *$ ACCSIIL

$\mathrm{R}^{2}=.738^{(0.9)} \mathrm{DW}=2.42^{\text {Estimation Method: } 3 \text { SLS }}$

(25) MKTSIIL $=100 *[($ IUMPDIL - EXPLUIL $) /$ TLUMCON $]$

(26) Demand for NW Plywood

PLYPDNW $=15369.1+0.239 *$ TPLYCON $-9658.1 *$ MANW $/ \mathrm{SO}+$ (5.5) (11.9)

$149.62 *$ ACCSPNW

$R^{2}=.926^{(3.4)} \quad D W=1.97 \quad$ Sample $1965-84, \quad$ 2SLS

(27) Demand for so Plywood

PLYPDSO $=5784.9+0.719 *$ TPLYCON $-16289.8 * \mathrm{MASO} / \mathrm{NW}+$ $184.4 *$ ACCSPSO

$(8.0) \quad(7.4)$

$R^{2}=.936 \quad\left(\begin{array}{ll}(1.4) \\ D W\end{array}=1.51 \quad\right.$ Sample $1965-84, \quad$ 2SIS

Figures in parantheses are $t$ statistics. 
TABLE IX

DESCRIPTION OF VARIABLES USED IN THE MODEL

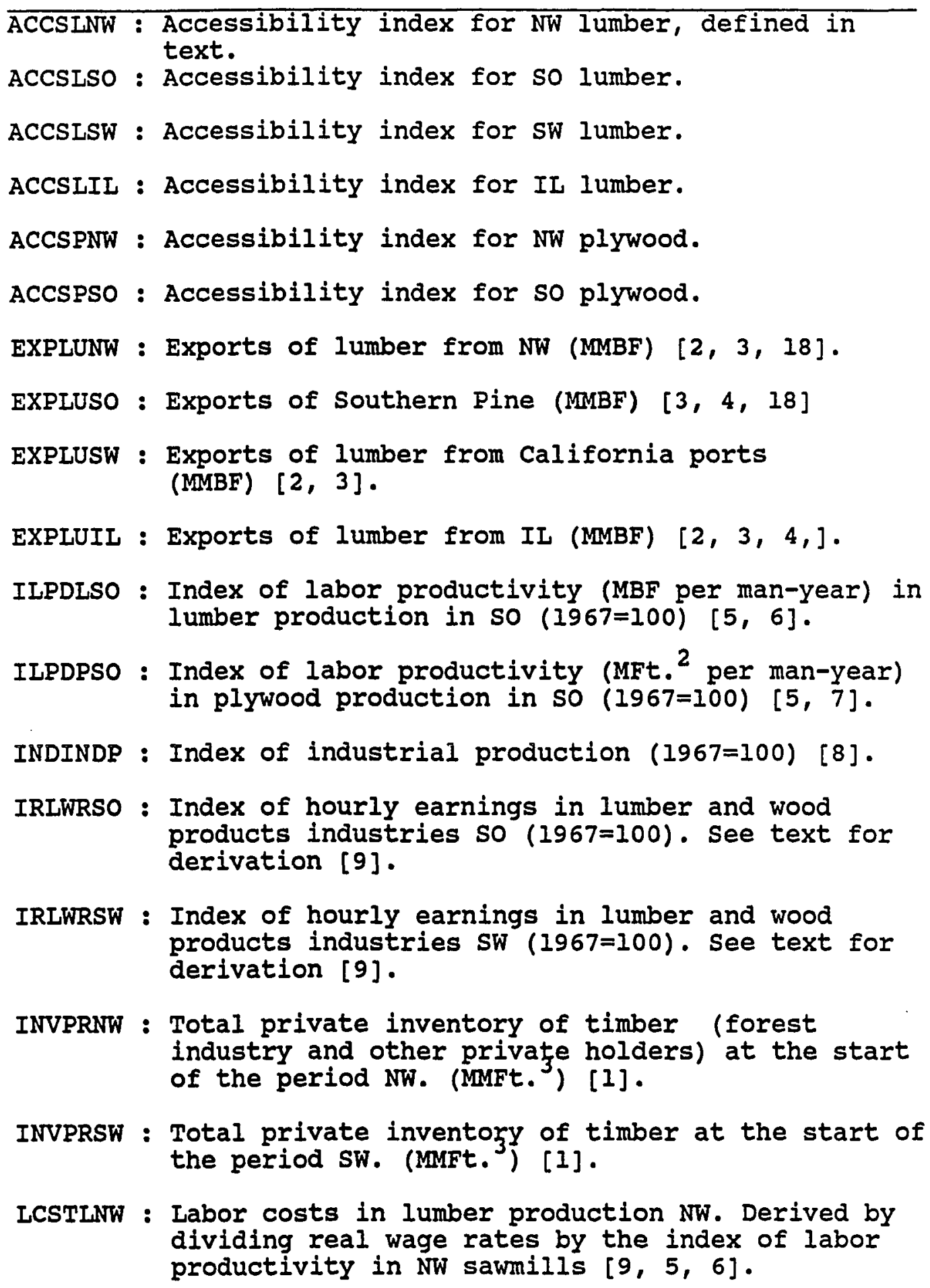

IRLWRSW : Index of hourly earnings in lumber and wood products industries $S W(1967=100)$. See text for derivation [9].

INVPRNW : Total private inventory of timber (forest industry and other privaţe holders) at the start of the period NW. (MMFt. ${ }^{3}$ ) [1].

INVPRSW : Total private inventory of timber at the start of the period SW. (MMFt. ${ }^{3}$ ) [1].

LCSTINW : Labor costs in lumber production NW. Derived by dividing real wage rates by the index of labor productivity in NW sawmills $[9,5,6]$. 
LCSTLIL : Labor costs in lumber production NW. Derived by dividing real wage rates by the index of labor productivity in IL sawmills $[9,5,6]$.

LCSTPNW : Labor costs in lumber production NW. Derived by dividing real wage rates by the index of labor productivity in $\mathrm{NW}$ plywood mills $[9,5,6]$.

LPUS-NW : (LUMPRUS-LUMPRNW) .

LPUS-SO : (LUMPRUS-LUMPRSO) .

LPUS-SW : (LUMPRUS-LUMPRSW) •

LPUS-II : (LUMPRUS-LUMPRIL) •

LPCHGSO : (LUMPRSO ${ }_{t}-$ IUMPRSO $\left._{t-1}\right) \cdot$

LPCHGIL : (LUMPRII $I_{t}-$ LUMPRII $\left._{t-I}\right)$.

LUMIMPC : Lumber imports from Canada (MMBF) [1] .

LUMPDNW : Lumber production in the NW (MMBF) [1].

LUMPDSO : Lumber production in the so (MMBF) [1] .

LUMPDSW : Lumber production in the SW (MMBF) [1].

LUMPDII : Lumber production in the IL (MMBF) [1] .

LUMPRNW : Price of softwood lumber NW, f.o.b. mill, \$/MBF (Deflated by All Commodity PPI) [1].

LUMPRSO : Price of softwood lumber so, f.o.b. mill, \$/MBF (Deflated by All Commodity PPI) [1] .

IUMPRSW : Price of softwood lumber SW, f.o.b. mill, \$/MBF (Deflated by All Commodity PPI) [1].

LUMPRIL : Price of softwood lumber IL, f.o.b. $\mathrm{mill}, \$ / M B F$ (Deflated by All commodity PPI) [1].

LUMPRUS : Weighted average f.o.b. mill price of all producing regions including canadian imports, deflated by All comm. PPI.

MACA/US : Two-year moving average ratio of price of Canadian lumber to average price of lumber in U.S., both prices in U.S. currency $[1,10]$.

MAHSTRT : Two-year moving average of housing starts in U.S. $[11,12]$. 
MAL/PLY : Two-year moving average ratio of Producer Price Index for softwood lumber to the Producer Price Index for softwood plywood.

MAPLY/S : Two-year moving average ratio of PPI for softwood plywood to composite index of substitutes: PISWPLY $/(.5 *$ PPI particle boards $+.25 *$ PPI gypsum products $+.25 *$ PPI building paper and board) [13, 14].

MANW/SO : Two-year moving average of (PLYPIDF / PLYPISP).

MASO/NW : TWO-year moving average of (PLYPISP / PLYPIDF).

MKTSLCA : Canadian lumber imports as percent of total U.S. consumption. [1]

PERSINC : Aggregate national personal income (MMM\$), deflated by GNP Implicit Price Deflator $(1972=100)$ [15].

PISWPLY : Producer price index for all softwood plywood $(1967=100) \quad[13,14]$.

PISSPRD : Producer price index for structural steel products $(1967=100) \quad[14]$.

PLYPDNW : Plywood production in the NW (MMBFt. ${ }^{2}$ ) [1].

PLYPDSO : Plywood production in the so (MMBFt. ${ }^{2}$ ) [1].

PLYPIDF : Price of Douglas fir plywood, deflated by All Comm. PPI. (Index 1967=100) [1].

PLYPISP : Price of Southern pine plywood, deflated by All Comm. PPI. (Index 1967=100) [1].

RW/ILPL : Real hourly earnings in lumber and wood products industry in U.S. divided by the index of output per employee in sawmills $[9,16]$.

RW/ILPP : Real hourly earnings in lumber and wood products industry in U.S. divided by the index of output per employee in plywood mills $[9,16]$.

STMPRNW : Average price of timber harvested from National Forests in the NW, \$/MBF, (deflated) [1].

STMPRSO : Average price of timber harvested from National Forests in the so, \$/MBF, (deflated) [1].

STMPRSW : Average price of timber harvested from National Forests in the SW, \$/MBF, (deflated) [I]. 
STMPRIL : Average price of timber harvested from National Forests in the II, S/MBF, (deflated) [1].

STMPRUS : Weighted average price of timber harvested from National Forests in all regions, 1967 \$/MMBF.

TLUMCON : Total apparent domestic consumption of softwood lumber, MMBF [1].

TLUMEXP : Total annual exports of softwood lumber, MMBF [1]

TLUMIMP : Domestic imports of softwood lumber from all origins, MMBF [I].

TLUMPRD : Total domestic lumber production, MMBF [1].

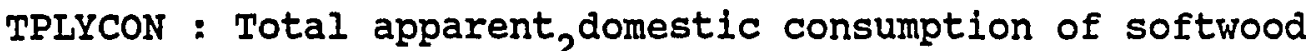
plywood, MMFt. 2 .

TTCUTNW : Total annual, harvest of timber by all ownerships in NW, MMFt. 3 .

TTCUTSW : Total annual ${ }_{3}$ harvest of timber by all ownerships in SW, MMFt. ${ }^{3}[1]$.

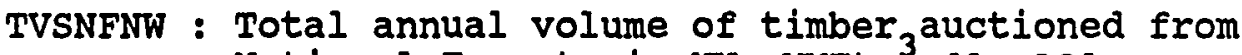
National Forests in NW, MMFt. ${ }^{3}[1,19]$.

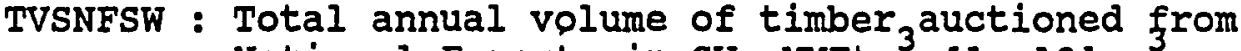
National Forests in SW, MMFt. ${ }^{3}[1,19]$.

VNCONST : Total value of new construction put in place, deflated by the GNP Implicit Price Deflator $(1972=100)$ [17].

* Numbers in brackets indicate sources of data as listed in Appendix A.

3 All volumes of timber auctioned and sold from National Forests were converted from BF, local log rules to cubic feet. The appropriate conversion factors were provided by Dr. R.W. Haynes at the PNW Forest and Range Experiment station in Portland, Oregon. These conversion factors are: Western Oregon and Washington: 5.5; Eastern Oregon aुnd Washington: 4.96 ; SO: 4.67 ; SW: 5.27 ; IL: 4.67 BF per Ft. ${ }^{3}$. 
MODEL COMPONENTS

The Aggregate Product Market

The four equations in this part of the model represent a simple supply-demand relationship for each of the two products. The postulated relationships in these equations are essentially the same as the conceived structures set forth in chapter I. Their specifications are common to several other econometric studies of the wood products industry, as well as other commodity models.

In the demand equations, quantities of aggregate product demand (apparent consumption) are related to own price, price of substitutes and one or more measures of the level of activity in relevant end-use markets. The choice of the latter variables, sometimes referred to as "shifters" (since they serve to locate the function), is based on our discussion of end use markets in Chapter II.

Another component of the demand relations is the substitution effect. The problem of correctly identifying patterns of substitution among commodities is a serious one and merits careful consideration. Forces of technological change are, more often than not, quite unpredictable. New products appear on the market on short notices; and old ones disappear from the face of the market unnoticed. Indeed, as Pringle (1971) has pointed out, many cases of substitution in the forest products market have been the result of development of new and often superior products, especially within the industry itself. In such cases, reliance on the 
conventional price considerations to explain substitution, may be inappropriate. Due to the time related nature of these developments, the time dimension in demand analysis, therefore, becomes crucial. The longer the period of analysis, the higher the likelihood of error.

In our analysis, plywood and structural steel prices are included in the lumber demand relation to account for the substitution effect. In case of plywood, the moving average ratio of plywood price index to a composite index of three substitutes is used (see Table IX). In both cases the commodities considered are established products with a long history of competition with the product under study.

The aggregate product supply functions are also conventional in form, except that the lumber supply equation is expressed in terms of price. The average price of lumber in the national market is determined by its own value in the previous period, total quantity consumed, average price of stumpage from all regions, and real wage rates (hourly earnings) in the industry. In order to account for the offsetting influence of historical gains in productivity on the rising cost of labor, wage rates in both relations are adjusted by the BLS indexes of labor productivity for sawmills and planing mills (SIC 2421) and plywood (SIC 2430).

\section{Regional stumpage Markets}

Direct estimation of structural relationships in the regional stumpage markets posed many serious problems. 
Differential patterns of ownership among regions, diversity of economic objectives pursued by the private holders within each region, and combination of various species in each geographical area are but a few of the factors contributing to the complexity of this market. It is therefore not surprising that the majority of previous empirical studies of the timber economy have resorted to somewhat ad hoc specifications in explaining the behavior of this market.

The approach adopted here begins with the stipulation that the derived demand behavior for stumpage is more appropriately described in a dynamic setting. Firms producing the final products, i.e. lumber and plywood, usually do not plan their levels of output in the spur of the moment. Adjustments in capacity and input flows, and employment decisions, produce rigidities in their supply adjustments that require some advance planning (Adams 1977, p.20). In addition, due to the relatively low short-run price elasticities of demand for lumber and plywood, much of the increase in factor price (i.e. stumpage) can be transmitted to the final product market. It is therefore unlikely that producers' demand for stumpage would adjust immediately to changed conditions of price.

We can therefore postulate that the "expected" level of demand for stumpage is given by:

$$
{ }^{*} D_{t}=a_{0}+a_{1} P_{t}+a_{2} P_{1 t}
$$


where $P_{t}$ and $P_{1 t}$ are, respectively, current stumpage and lumber prices. However, due to the constraints discussed above, we would expect the actual demand to adjust only partially to the expected level, that is:

$$
D_{t}-D_{t-1}=b\left({ }^{*} D_{t}-D_{t-1}\right)
$$

which, by substitution and rearrangement of coefficients to estimable forms, gives the following estimating relationship that is indeed the partial adjustment model widely applied to agricultural commodities (Nerlove, 1958a, 1958b):

$$
D_{t}=c_{0}+c_{1} P_{t}+c_{2} D_{t-1}+c_{3} P_{1 t}
$$

On the supply side, we assume that harvest levels are determined by stumpage prices and other supply determinants. In our analysis we relate stumpage supply directly to price, and inventory levels at the start of the period (INV). Also, we include timber offerings from the National Forests (QNF) as an additional shift variable so that the stumpage supply relationship is expressed as:

$$
s_{t}=d_{0}+d_{1} P_{t}+d_{2} I N V+d_{3} Q N F
$$

Equations (3.3) and (3.4), together with the implied equilibrium condition, provide all the information we need on the regional stumpage markets. Given these simultaneous 
relationships for each region, it is possible to obtain an estimating relationships for stumpage price directly from the reduced form of equations (3.3) and (3.4) by regressing $P_{t}$ on all the exogenous variables in the system.

In estimation, the above formulation proauced satisfactory results only for the NW and SW markets. In the case of the southern stumpage, the coefficient for the National Forest offerings, contrary to our expectation, carried a positive sign. In the Inland region, on the other hand, although the coefficients all had the right signs, two were found to be statistically insignificant. An even more serious problem in the case of the Inland region proved to be the presence of very high serial correlation and the fact that corrective procedures led to incorrect signs on two coefficients. These results are reported below. Note that the inventory volume for the Inland region has been replaced by the ratio of total private harvest to private inventory.

$$
\begin{aligned}
& \text { (3.5) } \text { STMPRSO }=-37.09+0.482 * \text { LUMPRSO }+0.0685 * \text { TVSNFSO }+ \\
& \text { (5.9) (7.5) (1.8) } \\
& 0.0064 * \text { TTCUTSO }-1-0.0957 * \text { INVPRSO } \\
& \text { (3.6) (0.7) } \\
& R^{2}=0.871 \quad D W=1.69 \\
& \text { (3.6) } \text { STMPRIL }=-6.39+0.296 * \text { LUMPRIL }-0.0008 * \text { TVSNFIL }+ \\
& \text { (29) (6.6) } \\
& (0.19) \\
& 0.021 * \text { TTCUTIL }_{-1}+0.224 * \text { CUT/IIL } \\
& R^{2}=0.777 \quad \text { DW }=0.944
\end{aligned}
$$


Due to these difficulties an alternative approach is adopted. It is based on a simplified derived demand approach and is a variant of the price mark-up procedure applied to the analysis of many agricultural commodity prices (Tomek and Robinson 1952) and the stumpage price projections in the USDA 1982 analysis of the timber situation in the United States (USDA/FS 1982, pp. 150 and 212).

In its most simplified and general form, the method involves the establishment of a relationship between the product market and the factor market in terms of a marketing margin: $P P=F P+M M$

or inversely,

$$
\mathrm{FP}=\mathrm{PP}-\mathrm{MM}
$$

where PP is the product price, FP is the factor price, and MM denotes the marketing margin.

Haynes (1977) has suggested several possible forms for the linkage between the two markets based on alternative treatments of the marketing margin as either constant, a constant percentage, or a linear function of prices. In the case of the latter, stumpage prices are regressed on product prices and the coefficient on the product price is 
interpreted as the coefficient or elasticity of price transmission between the two markets according to whether the prices are expressed in logarithms or not. In our study the relationship between stumpage price and lumber price follows a specification that has come to be known as the "pass-through" technique in the forestry literature (Haynes ibid., p.284). It involves an expression relating the price change in the two markets. The implication here is that changes in the product market are only partially transmitted to the stumpage market; i.e.

$$
F P=a_{0}+a_{1} F P_{t-1}+a_{2}\left(P P_{t}+P P_{t-1}\right)
$$

This relationship was used to estimate stumpage prices in all four regions. As indicated by the statistical properties of the estimates shown in Table $\mathrm{x}$, the relationship appears to adequately depict the linkages between regional stumpage and product prices in all regions. Note that the coefficients on lumber price change measure the extent to which changes in product prices are transmitted to the stumpage market, and thus reflect the elasticity of supply in regional stumpage markets. The results in Table $x$ indicate that for a shift in demand for regional lumber, greater stumpage price changes in the so than in the NW would be expected. The elasticity of regional stumpage supplies has been examined in several other studies such as Adams (1976), Haynes (1977), and Adams and Haynes (1980). A 
comparison of findings from these studies indicate that the stumpage market in the so has lost much of its fluidity over the past two decades. In the light of relatively significant declines in NW stumpage prices during the past ten years, it is not surprising to find a higher elasticity in the NW stumpage market than in the so.

The results of this latter formulation were used to represent the product-stumpage linkage in the south and Inland regions. No attempts were made to incorporate the inventory and National Forest offerings in this formulation.

TABLE $\mathrm{X}$

ESTIMATION RESULTS FOR REGIONAL STUMPAGE PRICE RELATIONSHIPS

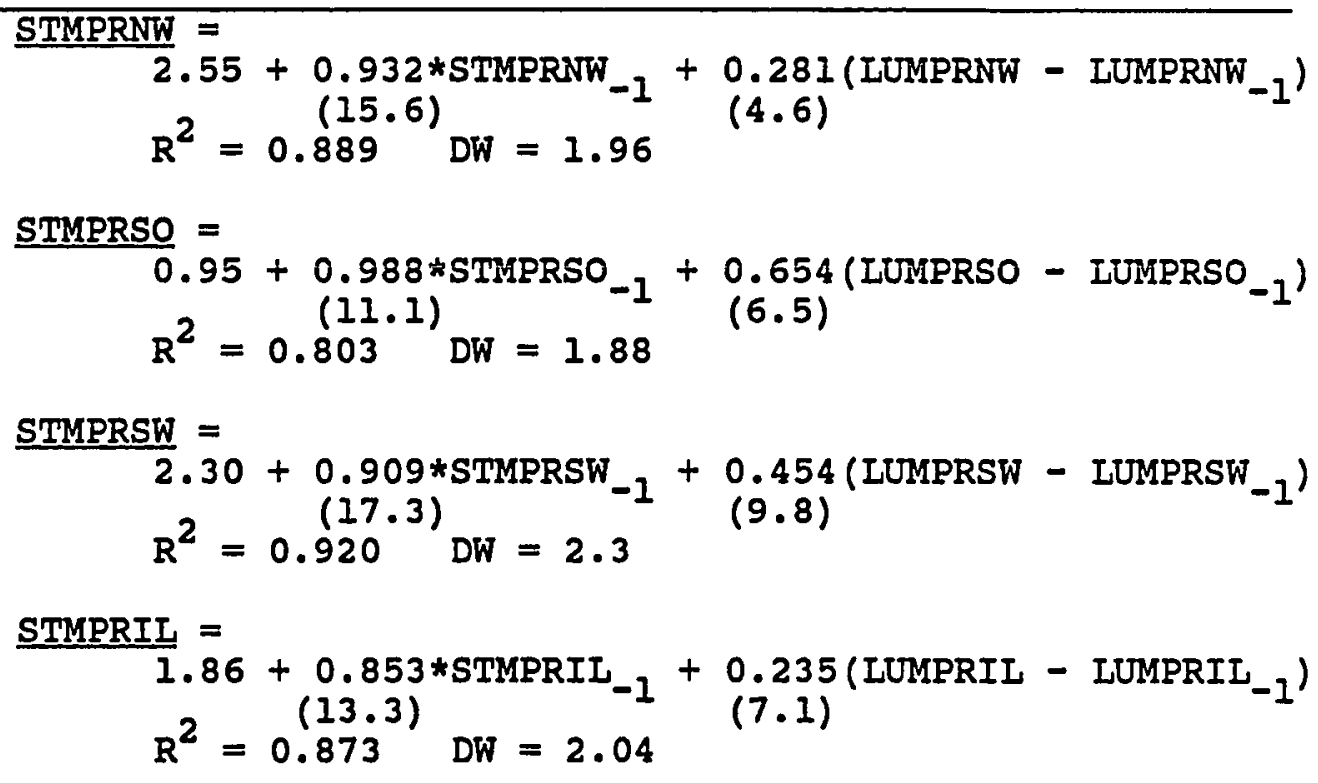

The reason is that although both variables are important indicators of supply behavior in the long-run, they are unlikely to result in the loss of much information in a 
short-run analysis. Their omission, however, does somewhat limit the utility of the model in the area of policy analysis. This is, nevertheless, a small loss within the context of the model as a whole.

A complete analysis of the regional stumpage markets requires a different and more appropriate setting than the present one. The impact of the Forest service policies regarding harvest levels, for instance, can more amply be analyzed within the framework of regional private stumpage markets. For, as Haynes and others (1981), and connaughton and Haynes (1983) have shown, the relative impact of changes in the National Forest offerings on local stumpage prices depend largely on the behavior of private owners; and their reaction --or ability to react-- to the changing price conditions. In other words, if the stumpage supply from private ownerships is elastic, then we can expect the effect of changes in National Forest offerings to be mitigated by adjustments in the private supply.

In order to examine this proposition, price elasticities of private stumpage supply were estimated for the four regions. The analysis is based on a simple regression equation that relates supply of stumpage from all private ownerships ("forest industry" and "other private" owners) in a given region to the price of stumpage and inventory levels in that region. The results are tabulated in Table XI. The aim of the analysis is purely illustrative. It is intended to measure possible losses of information 
incurred as a result of omissions in our approach to modeling the stumpage price in the so and IL regions. Though the statistical properties of these estimates were in general satisfactory, the resulting low coefficients of determination (between .57 to .79) and serial correlation in some cases, precluded the use of these relationships in our model.

The observed variations in cross regional supply behavior in the private stumpage markets, as indicated by these elasticity measures, is considerable. Stumpage price elasticities in the NW and so are shown to be higher than those found in other regions. Inventory, on the other hand, appears to be a much more important factor in determining supply patterns in the SW and IL regions. These results are generally consistent with those found by previous studies for example Adams (1977), Adams and Haynes (1980), and Adams, et.al. (1982). One important implication of these

TABLE XI

ESTIMATES OF REGIONAL ELASTICITIES OF PRIVATE STUMPAGE SUPPLY

\begin{tabular}{lcc} 
& \multicolumn{2}{c}{ Elasticities } \\
Supply Region & Stump.Price & Inventory \\
\cline { 2 - 3 } NW : & 0.493 & 0.732 \\
SO : & 0.458 & 0.162 \\
SW : & 0.135 & 1.564 \\
IL : & 0.111 & 1.073 \\
\hline & & \\
\hline Point estimates measured at means for each \\
variable.
\end{tabular}


results is that the impact of public timber offerings will probably be much smaller in the so and NW than in the SW and II regions. With regards to the inventory levels, on the other hand, it seems that resource availability is a much more constraining factor for the suppliers in SW and IL than in NW, and especially the so region. Empirical evidence of rapid expansion of private inventories in the south during the sample period also support this conclusion.

\section{Regional Product Markets}

This part of the model contains a total of thirteen equations: four relationships for regional lumber prices, four relationships for plywood supply and demand in NW and so, and five regional market share relationships. The regional lumber price and plywood supply relations are specified in forms identical to the aggregate market relations. All equations include labor productivity, expressed in terms of physical output per man-year in each period. It is calculated by dividing annual regional output by the average number of production workers. Inadequate regional or state level data precluded the construction of more suitable measures such as value added per employee. The productivity measure is employed here as a surrogate for technological change in the industry over time. See Appendix C for data.

Technological change is defined here in the positive sense of the development or adoption of more efficient 
production techniques such that greater output can be obtained from a given combination of inputs. But this conclusion (technological change) cannot be inferred directly from the data. An alternative --and equally valid-explanation of the movements in this measure is economies of scale. In other words, the over time variations in the output/employment ratio may be interpreted as actual shifts in the production function, or movements along the same function. If the latter is indeed the case, then we can expect the productivity measure to be highiy correlated with output and lead to collinearity problems in estimation of supply functions.

We have therefore used this measure with caution. In all cases where the index of productivity exhibited a high correlation with output, it was either excluded from the relationship, or used as a deflating factor to adjust real wage rates.

Regional wage rates in the lumber and wood products industry (SIC 24) were calculated as the average of hourly earnings in the industry in the major producing states in that region. 4 This data, however was not available for the entire sample period. Industry-specific data on hourly

4 The regional averages are based on data from a select number of leading states. They are; NW: oregon and Washington; so: Texas, S.Carolina, Florida, Georgia, Luisiana; SW: California; IL: Idaho, Colorado, Montana, Utah, and N.Mexico. 
earnings at the state level are generally available only from 1972 as reported by the Bureau of Labor Statistics. The remainder of the series from 1950 were estimated by first constructing an index of average regional hourly earnings in manufacturing (with 1967 as the base) from the state level data; and then applying this index to the first available observation in the series to calculate the rest of the observations. These data are reported in Appendixe B.

In order to check the accuracy of these estimates, a second procedure was adopted for deriving the same estimates. This latter procedure consisted of adjusting weighted regional average hourly earnings in manufacturing by the weighted ratios of hourly earnings in manufacturing to average hourly earnings in the lumber and wood products industry at the national level in each period; i.e., for each region,

$$
\frac{\text { EMPLWP }_{t} * \text { AVWRLWP }_{t}}{\text { EMPMFG }_{t} \text { AVWRMFG }_{t}}=\frac{\text { EMPLWPUS }_{t} * \text { AVWRLWPUS }_{t}}{\text { EMPMFGUS }_{t} \text { AVWRMFGUS }_{t}}
$$

where the first two terms are respectively regional wage rates in lumber and wood products, and manufacturing; and the terms on the right-hand side are the same variables at the national level. The results from both procedures were quite close and produced identical results in estimation. The two regional plywood supply equations were specified according to the classical partial adjustment 
model and include a one-period lagged quantity term, own price, and factor prices as explanatory variables.

Estimation of the plywood equation for the southern plywood produced a positive sign on the stumpage price variable. The stumpage price term was consequently dropped in final estimation. This result, though contradictory to the postulated relationship, may have an explanation. Softwood plywood is a relatively new product in the southern market and has expanded very rapidly during the past decade. Expansion of plywood output has in turn intensified local competition for stumpage, leading to higher prices in the stumpage market. Hence, the positive correlation is justified; yet the stumpage price term cannot be retained because the causal inference with respect to the direction of causation, as implied by the supply equation, is no longer valid.

\section{Regional Market Shares}

The seven equations in this part of the model constitute the pivotal relationships in our model and comprise the very core of the analysis. Structurally, all other components of the model can be viewed as peripheral to this set in the sense that the information they provided is ultimately channeled into this set of relationships.

These equations are all essentially similar in form and structure; except that the two plywood share equations are expressed in terms of total regional output. Regional 
market shares in plywood are therefore obtained indirectly from the ratio of output estimates to total consumption at the national level. In estimation, regional exports of plywood were ignored because they constitute a small percentage of regional production and the volumes are very close in both regions. The plywood market share equations were estimated for both regions over the sample period 1965-1984. The reason is that the advent of plywood production in the South represents a major transformation in the competitive structure of the plywood market. Since practically no plywood was produced in the south before 1964, the behavior and position of the NW prior to this date would be of little relevance to the analysis of competition in this market.

Each equation contains a measure of price competitiveness which is expressed either in terms of price ratios (in plywood equations), or price difference (in lumber equations). In the market share equation for Canadian imports, the price of Canadian lumber is measured in U.S. dollars. Thus the impact of fluctuations in currency exchange rates are incorporated in the price term. All market share relationships for lumber contain a lagged output term. The underlying justification for this formulation is that changes in interregional trade patterns do not respond instantaneously to small changes in market conditions. In view of the relatively low elasticities in regional supply and demand conditions that prevail in the 
lumber and plywood markets, this is indeed a very reasonable assumption. In the lumber market share equations for the NW and IL regions the lagged output terms were replaced by the regional market shares in the previus period. Since in both regions, the $\mathrm{NW}$ in particular, exports constitute a substantial share of the total output, the use of the lagged output term appeared inappropriate in that they lead to over estimation of actual shares of the domestic market.

The other major component of the market share equations is the regional accessibility index which represents relative locational advantage of each region. These measures are intended to approximate the overall economic accessibility, or, the potential of each region in marketing its outputs. Construction of this index is based on the principle of "potential interaction" as employed in the context of general gravity models.

Gravity models constitute a large family of flexible methods widely applied to a range of analytic situations involving interaction between spatially separated nodes. The general approach in gravity models is predicated on the physical law of mass gravitation. It explains gravitation (or interaction) between two points in space in terms of some surrogate measure of their respective masses, and as a decreasing function of the distance between them. Among the many different forms of the gravity model used in transportation and migration analysis, the types that are of 
relevance to the present study are the commodity flow variants. 5 As distinct from the more general forms of the gravity models that measure interaction "between" two points, commodity flow models are based on the "potential" concept of gravity that pertains to the measurement of potential interaction at a given area or point. Within the context of commodity flow analysis, the most general formulation of the potential gravity model may be given as:

$$
F_{i j}=b D_{j} f\left(d_{i j}\right)
$$

where $F_{i j}$ is the commodity flow from $i$ to $j, D_{j}$ is a measure of demand at $j$ for the commodity under question, $d_{i j}$ is distance or a measure of transport cost between the two points, and $b$ is a constant. 6

Our presentation of regional accessibility is based on a formulation of the gravity model given by Isard (1960 p. 499). It is defined as:

5 Attempts at formalization and theoretical derivation of the gravity model have followed two distinct paths: the probabilistic approach of Isard (1960, pp. 493-502) and Wilson (1967); and the economic approach based on the utility theory set forth by Niedercorn and Bechdolt (1969). For a comprehensive treatment of the gravity model see Isard, ibid. pp. 493-566.

6 This formulation and parts of the discussion are borrowed from Richardson (1979 pp. 194-5). 


$$
A_{i}=\Sigma D_{j} /\left(T C_{i j}\right)^{a}
$$

where $A_{i}$ is accessibility of the suppiy region $i, D_{j}$ denotes level of demand in region $j$, and $\mathrm{TC}_{i j}$ is the average transport cost between $i$ and $j$ for all demand regions. Two different indexes of accessibility were constructed using either personal income or annual change in population to approximate levels of regional demand for lumber and plywood. Both variables are highly correlated with the level of construction activity and are potentially appropriate surrogates for wood consumption. The second index, measured in terms of population change, however, produced consistently better statistical results in all equations and was adopted. In regional market share equations for lumber, the exponent to be applied to transportation costs was set to equal one. An alternative formulation of (3.11) above, with an exponent of two on transport costs $(a=2)$ produced much better results in the plywood demand equations and was consequently used. The obtained index numbers are shown in Table XIV.

Interregional transport costs were derived for every period in the sample by applying the Producer Price Index for Wood Products Freight to the average 1977 estimates of transport costs for lumber and plywood provided by the Pacific Northwest Forest and Range Experiment station. See Tables XII and XIII. 
Since the Bureau of Labor statistics began reporting the Producer Price Index for Wood Products Freight in 1969 (see Fehd 1975), it was necessary to construct the remaining series from 1950 indirectly. This was accomplished by regressing the available observations on the Producer Price Index for Transportation services during the same sample period. The missing observations were thus estimated from the regression equation: PPIWPF $=-32.571+1.265$ [PPI Trans. Services] $\left(R^{2}=.99\right)$. See Appendix D. 


\section{TABLE XII}

INTERREGIONAL TRANSPORT COSTS FOR LUMBER

1977 (\$ PER MBFt., DEFIATED)

\begin{tabular}{lcccccc}
\hline & & & & & & \\
From/TO & NW & PSW & II & NC & NE & \multicolumn{1}{c}{ SO } \\
NW & 5.39 & 16.02 & 17.07 & 26.54 & 31.21 & 28.54 \\
SO & 25.92 & 25.85 & 24.25 & 15.45 & 15.67 & 9.35 \\
SW & 11.61 & 11.72 & 17.68 & 26.78 & 31.24 & 27.41 \\
IL & 21.25 & 19.38 & 8.61 & 24.18 & 28.95 & 25.48
\end{tabular}

TABLE XIII

INTERREGIONAL TRANSPORT COSTS FOR PLYWOOD

1977 (\$ PER MBFt. ${ }^{2}$, DEFLATED)

\begin{tabular}{|c|c|c|c|c|c|c|}
\hline From/To & NW & PSW & IL & NC & $\mathrm{NE}$ & so \\
\hline$N W$ & 5.74 & 16.34 & 17.20 & 26.98 & 31.72 & 27.82 \\
\hline so & 29.22 & 29.22 & 26.60 & 15.65 & 16.69 & 9.50 \\
\hline SW & 11.81 & 11.91 & 17.97 & 27.23 & 31.69 & 27.79 \\
\hline II & 22.15 & 20.25 & 8.75 & 24.58 & 29.43 & 25.90 \\
\hline
\end{tabular}


TABLE XIV

REGIONAL INDEXES OF ACCESSIBILITY IUMBER AND PLYWOOD

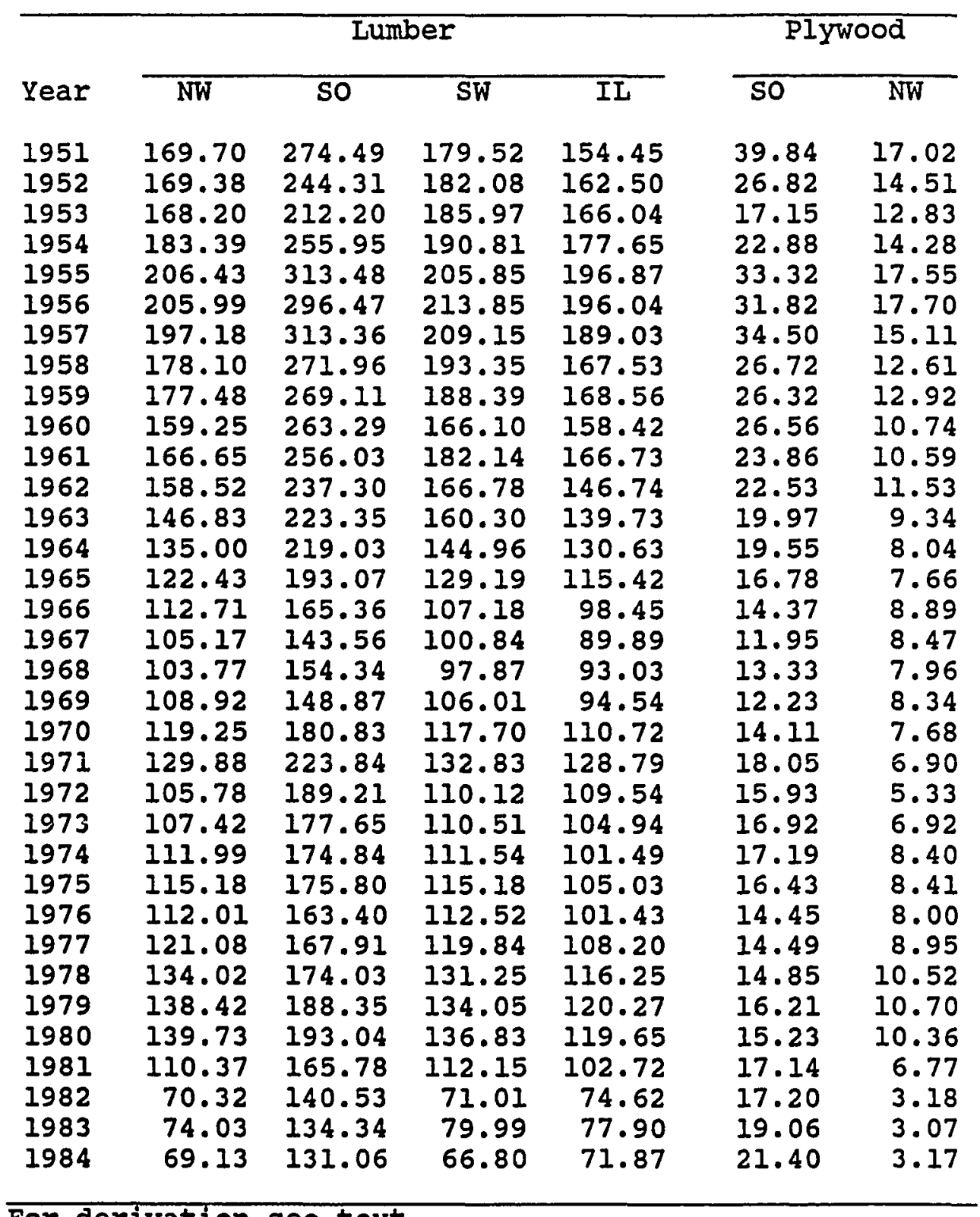

For derivation see text. 


\section{CHAPTER IV}

\section{MODEL VALIDATION}

A model is, by definition, a representation of real world phenomena. A "good" model, it hence follows, is one that is true to the original. Likewise, the "goodness" of an econometric model is evaluated by the extent of its accuracy in depicting the economic system it intends to describe.

Evaluation of an econometric model, as Dhrymes and others (1972) have pointed out, is a continuous process that accompanies every step in model specification, estimation, and implementation. There is a wide array of criteria, parametric and otherwise, that can be used to evaluate performance of econometric models. Choice of specific criteria, and the degree of the stringency with which we apply each, depend on the stage in model development and the purpose for which the model is built. In this chapter we will consider various properties of individual components of the model developed in Chapter III and evaluate the performance of the model as a whole.

\section{VALIDATION IN PARAMETER ESTIMATES}

Construction of an econometric model involves much more than the working out of a plausible configuration for sets of seemingly related economic variables. The primary 
orcutt iterative procedure in the second stage of estimation. In case of the latter equation, however, the estimaition method involved precluded the use of such solution scheme and the original estimates were retained. With the exception of two market share equations (the south and the Inland regions), the statistical fit of alI equations, measured in terms of their respective coefficients of determination, appear acceptable. Of the total of seventy-two estimated coefficients in the model, fifty-one are statistically significant at the .01 and eleven more at the .1 level.

Statistical significance of estimated coefficients is a highly desirable property in an econometric model for it shows the significance of the information conveyed by particular data. Yet, statistical significance by itself does not constitute sufficient ground for validity. The estimated coefficients must also make sense. A second--and perhaps a more relevent-- perspective on model validity can be gained by examining the accuracy of model parameters. There are, however, no formal procedures for insuring that the coefficients are of the right magnitudes. The decision as to what constitutes the right size for a given coefficient is a judgemental one that depends on the analyst's knowledge of the market under irvestigation.

Fortunately, the literature on the wood products economy is rich with predictions about the magnitude of certain effects. The more recent econometric studies, in 
orcutt iterative procedure in the second stage of estimation. In case of the latter equation, however, the estimation method involved precluded the use of such solution scheme and the original estimates were retained. With the exception of two market share equations (the South and the Inland regions), the statistical fit of all equations, measured in terms of their respective coefficients of determination, appear acceptable. of the total of seventy-two estimated coefficients in the model, fifty-one are statistically significant at the .01 and eleven more at the .1 level.

statistical significance of estimated coefficient is a highly desirable property in an econometric model for it shows the significance of the information conveyed by particular data. Yet, statistical significance by itself does not constitute sufficient ground for validity. The estimated coefficients must also make sense. A second --and perhaps a more relevent-- perspective on model validity can be gained by examining the accuracy of model parameters. There are, however, no formal procedures for insuring that the coefficient are of the right magnitudes. The decision as to what constitutes the right size for a given coefficient is a judgemental one that depends on the analyst's knowledge of the market under investigation.

Fortunately, the literature on the wood products economy is rich with predictions about the magnitude of certain effects. The more recent econometric studies, in 
particular, provide much insight in this area. An examination of certain key parameters in the model such as relative impacts of various exogenous variables and price elasticities reveals that these estimates are quite comparable with those obtained in other studies.

The multiregional structure of the present model imposes a further condition for evaluating the accuracy of estimated coefficients: that for any particular behavioral relationship, variations in functional properties across various regions must be justifiable and reasonably consistent with actual market experience in each region. This condition was employed most intensively in construction of regional market share relationships, where essentially identical specifications are used across all regions. This condition formed the basis for choosing among alternative formulations of the accessibility index and price terms in these equations.

Cross-regional differences in response to movements in various exogenous variables can be analyzed by examining the relevant impact multipliers. Impact multipliers for regional lumber outputs associated with selected explanatory variables are reported in Table $\mathrm{XV}$.

These multipliers are computed numerically by successive substitution of relevant equations in the model. Multipliers associated with other exogenous variables not reported in Table $X V$, can also be obtained in the same fashion. Due to the rather complex structure of the access- 
ibility index, however, a simple analytical solution for the impact multipliers associated with the Producer Price Index for Lumber and Wood Products Freight is difficult to obtain. The reported multipliers in this case were computed numerically at the means for each variable. Figures in each column of Table $\mathrm{XV}$ show the effects on regional lumber outputs that is likely to result from a unit increase in variables listed in the first column.

TABLE XV

IMPACT MULTIPLIERS FOR SELECTED EXPLANATORY VARIABLES: REGIONAL LUMBER OUTPUT

(Measured as $\&$ of Total Consumption)

\begin{tabular}{|c|c|c|c|c|c|}
\hline $\begin{array}{l}\text { Housing starts..... } \\
(\times 1000)\end{array}$ & $\begin{array}{c}N W \\
0.0035\end{array}$ & $\begin{array}{c}\text { So } \\
0.0024\end{array}$ & $\begin{array}{c}\text { SW } \\
0.0018\end{array}$ & $\begin{array}{c}\text { II } \\
0.0011\end{array}$ & $\begin{array}{c}\overline{C A N} \\
0.0059\end{array}$ \\
\hline $\begin{array}{l}\text { Personal income...: } \\
\text { (MMM } 1972 \$)\end{array}$ & 0.0174 & 0.0132 & 0.0085 & 0.0044 & 0.0237 \\
\hline $\begin{array}{l}\text { Average lumber } \\
\text { price in U.S......: } \\
\text { (1967 \$ / MBFt.) } \\
\text { Regional lumber }\end{array}$ & 0.218 & 0.152 & 0.149 & 0.067 & 0.1090 \\
\hline $\begin{array}{l}\text { prices... . . . .... : } \\
\text { (1967 } \$ \text { / MBFt.) } \\
\text { Regional stumpage }\end{array}$ & -0.218 & -0.152 & -0.149 & -0.067 & 0.0160 \\
\hline $\begin{array}{l}\text { prices............ : } \\
\text { (1967 \$ / MBFt.) } \\
\text { PPI wood products }\end{array}$ & -0.120 & -0.110 & -0.119 & -0.085 & -- \\
\hline $\begin{array}{l}\text { freight. } \ldots \ldots \ldots \text { : } \\
\qquad(1967=100)\end{array}$ & -0.0035 & -0.0014 & -0.0013 & -0.0011 & - \\
\hline
\end{tabular}

These multipliers are also the mechanisms by which changes in aggregate consumption can be allocated across producing regions. This can be illustrated by an example. Suppose there is an increase of one thousand units in national housing starts. From equation (1), Table VIII, we 
would expect a corresponding increase, on the average, of approximately 5.1 MMBFt. in total lumber consumption. The multipliers in the first row of Table XV, can now be used to determine how such increase in aggregate demand will be allocated across producing regions. The results show that on the average, holding all other variables constant, such an increase in national housing starts would lead to increases of $1.2,0.9,0.61,0.47$, and 1.98 MMBFt. respectively in the NW, so, SW, II, and Canadian imports. Due to errors in coefficient estimates, the total does not add to 5.1 MMBFt. The discrepency, however, is negligible and can be corrected by proportional adjustment of multipliers. This procedure can be appl:Ed to determine the relative impacts on regional market shares of unit change in these variables. Regional market share impacts for selected variables are reported in Table XVI.

The dynamic context of the present model and interdependencies that are built into it, limit the usefulness of analysing multipliers in a static setting. These multipliers do, however convey important descriptive information on parameter estimates and behavioral consistency of individual relationships. Examination of impact multipliers in Tables $X V$ and XVI, for example, reveals some interesting patterns of differential response to various exogenous factors across the four domestic supply regions.

It is apparent from these results that short-run impacts on market shares of the variables considered here 
TABLE XVI

IMPACT MUITIPLIERS FOR SELECTED EXPLANATORY VARIABLES: REGIONAL ILUMBER MARKET SHARES

\begin{tabular}{|c|c|c|c|c|c|}
\hline $\begin{array}{l}\text { Housing starts.: } \\
\qquad(x 1000)\end{array}$ & $\begin{array}{c}\mathrm{NW} \\
.00059\end{array}$ & $\begin{array}{c}\text { SO } \\
-.00051\end{array}$ & $\begin{array}{c}\text { SW } \\
-.00116\end{array}$ & $\begin{array}{c}\text { II } \\
-.00176\end{array}$ & $\begin{array}{c}\text { CAN } \\
.00294\end{array}$ \\
\hline $\begin{array}{l}\text { Personal income: } \\
\text { (MMM } 1972 \$ \text { ) }\end{array}$ & .0039 & -.00018 & -.0050 & -.0091 & .0100 \\
\hline $\begin{array}{l}\text { Average lumber } \\
\text { price in U.S...: } \\
\text { ('67 \$/MBFt.) } \\
\text { Regional lumber }\end{array}$ & .0790 & .0130 & .0100 & -.0720 & -.0300 \\
\hline $\begin{array}{l}\text { prices... ...... : } \\
\text { ('67 \$ /MBFt.) } \\
\text { Regional stump. }\end{array}$ & -.2180 & -.1520 & -.1490 & -.0670 & -.0160 \\
\hline $\begin{array}{l}\text { príces........: } \\
\text { ('67 \$ /MBFt.) } \\
\text { PPI Wood Prod. }\end{array}$ & -.1200 & -.1100 & -.1190 & -.0850 & -- \\
\hline $\begin{array}{l}\text { freight. } \ldots \ldots \ldots \text { : } \\
(1967=100)\end{array}$ & -.00167 & .00043 & .00052 & .00072 & -- \\
\hline
\end{tabular}

are generally quite small. The NW, however, appears to be relatively more sensitive to these exogenous impacts than other regions. Market shares for the NW appear to be particularly sensitive to transport costs. In the case of the sw region, the magnitude of some impacts --particulariy those associated with transport costs and price variables-are somewhat higher than expected. For a net importing region such as the $\mathrm{sw}$, it is indeed reasonable to expect the market share to be inversely related to accessibility. Such expectation is justified because a decline in transport costs (i.e. increased accessibility) can in effect make the region itself more accessible to other producing regions and invite competition. 
A possible explanation for the observed sensitivity of the SW market shares to accessibility lies in the species composition of the region's lumber products. Redwood, which constitutes a large portion of the lumber produced in the SW region, is a specialty product in demand in all other regions in the country. Thus, though a net importer of lumber products; the region has historically exported considerable volumes of redwood to other regions.

As indicated in Chapter I, the coefficients on price terms in market share relationships measure the degree of competitiveness and reflect the extent of regional substitution in the product market. If products from competing regions are perfect substitutes, then small changes in relative prices in one region can be expected to result in large changes in the demand facing that region. As evidenced by the low elasticities on price terms (ranging between 0.02 for the $N W$ and 0.1 for the $S W$ ), this clearly is not the case in the lumber market. The low price responsiveness of regional market shares found here suggest that the extent of regional substitution in the lumber market is indeed quite limited.

In view of the low price elasticities of regional lumber supplies (ranging from 0.08 for the $N W$ and 0.15 for the so), this finding is not all too surprising. A more serious implication here is that this finding also casts doubt on the validity of the product homogeneity assumption. There is no doubt that consumers' species preferences has 
some influence on determination of demand for lumber produced in specific regions. The extent of this influence, however, cannot be deduced directly within the context of the present model.

Price elasticities of demand for regional plywood, on the other hand, are significantly greater than those found for lumber, indicating a much higher level of competitiveness in this market. Estimated elasticities indicate that a one percent change in plywood price ratios can be expected to lead to 1.3 and 2.0 percent change, respectively, in demand for plywood produced in the $\mathrm{NW}$ and the so.

\section{VALIDATION IN SIMULATION AND FORECASTING}

Validity in simulation performance was used as the primary guideline in evaluation of the model. As indicated earlier, the objective in constructing the present model was, in part, simulation analysis and forecasting. An important test of the model's validity is, therefore, its efficacy in serving these ends. To test the adequacy in simulation performance of the model, we will first consider the accuracy with which the model can replicate the actual time paths of endogenous variables through a graphical analysis of historical and simulated series; and then use the model to develop projections of key variables for two years beyond the estimation period.

A comparisons of actual and predicted series for all enodogenous variables are shown in Figures 10 through 30 . 


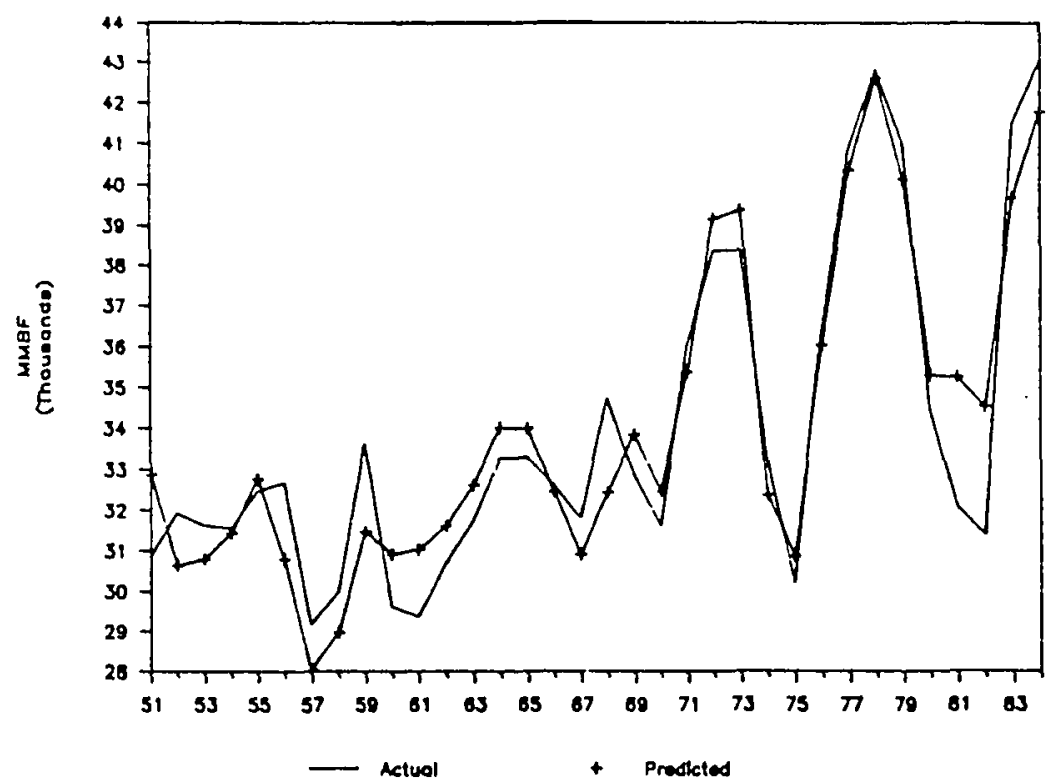

Figure 10. Historical simulation total lumber consumption.

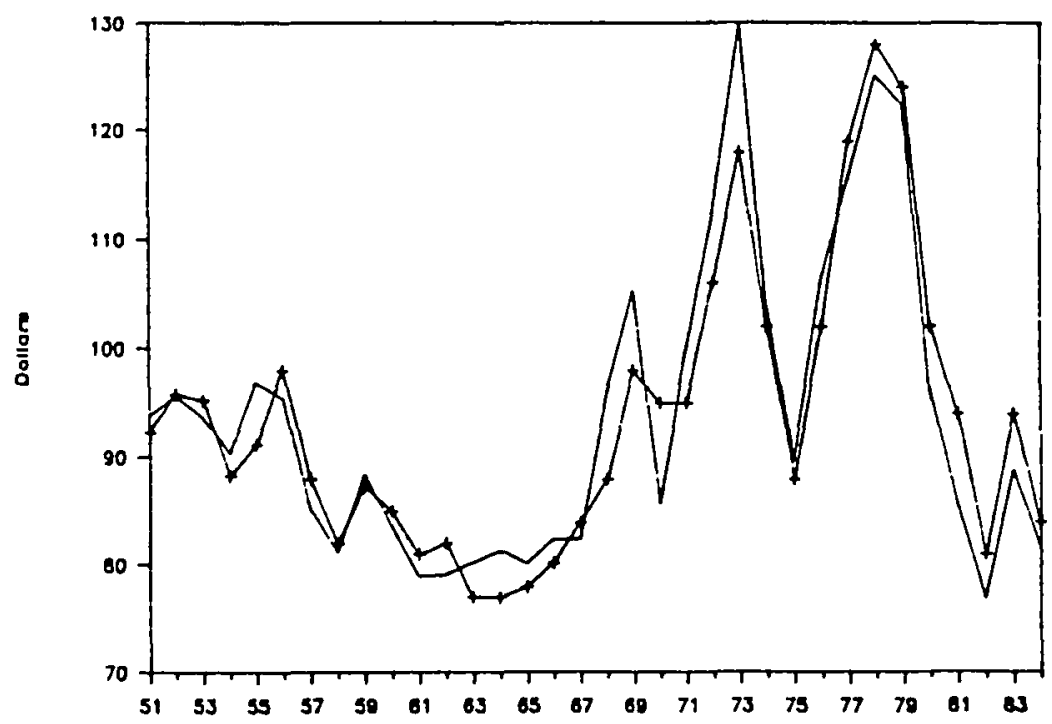

Figure 11. Historical simulation average lumber price. 


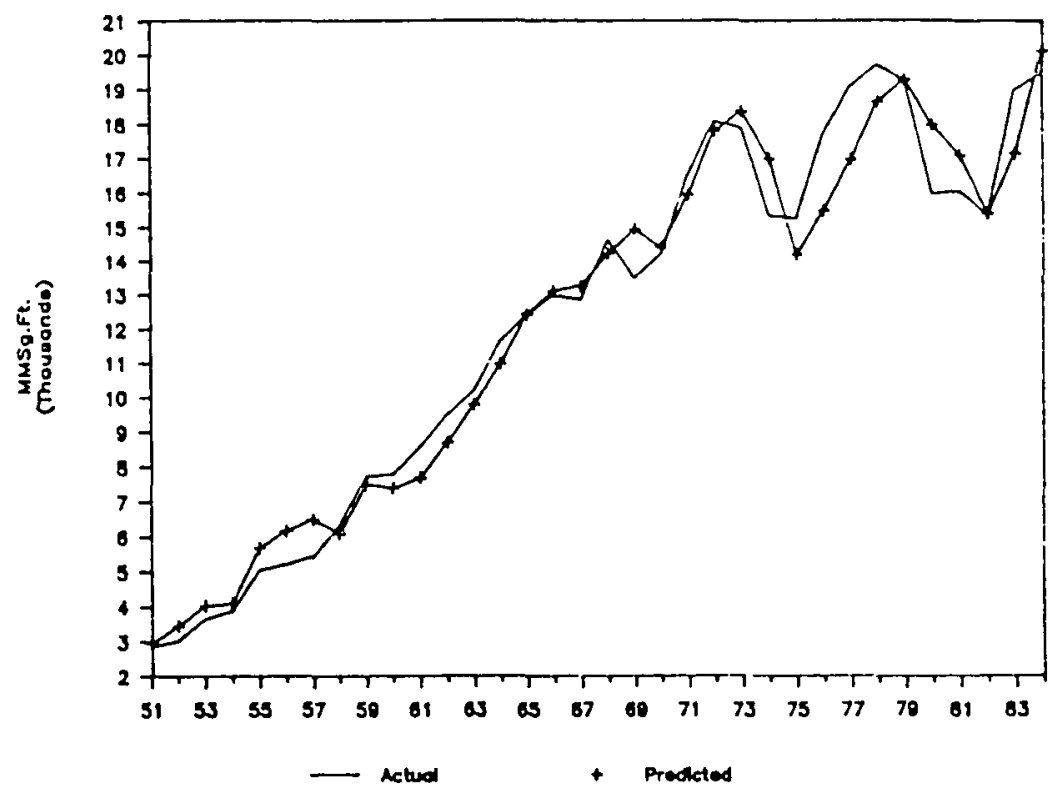

Figure 12. Historical simulation total plywood consumption.

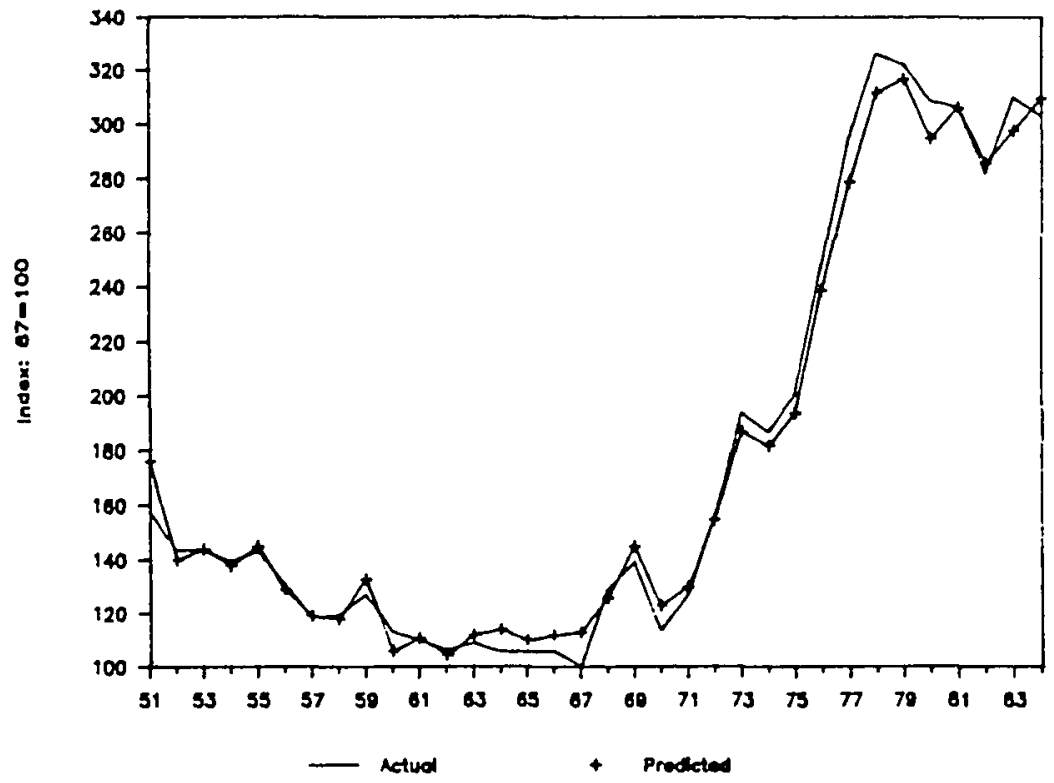

Figure 13. Historical simulation PPI softwood plywood. 


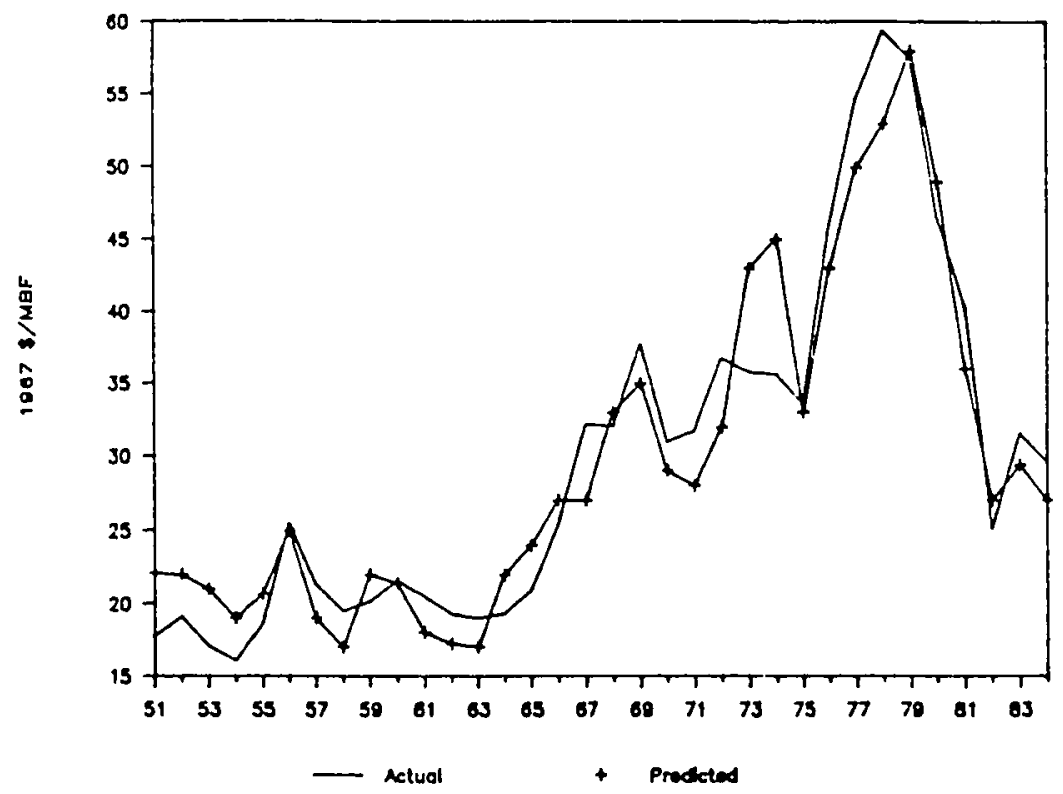

Fiqure 14. Historical simulation stumpage price NW.

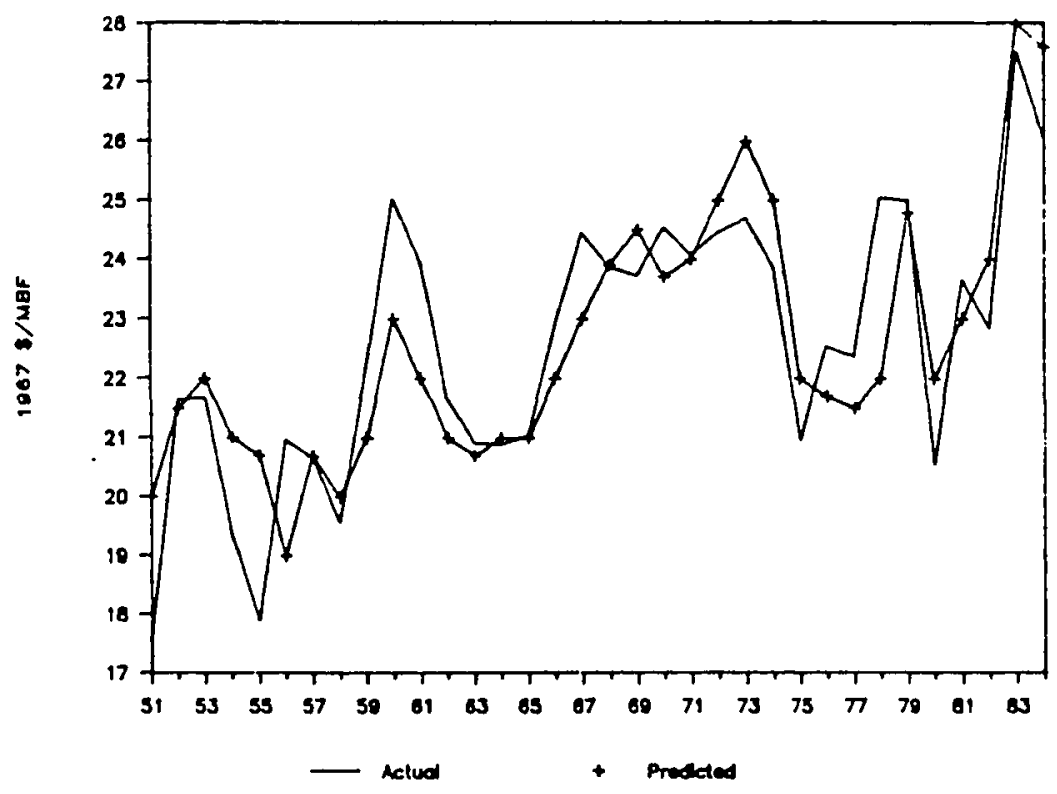

Fiqure 15. Historical simulation stumpage price so. 


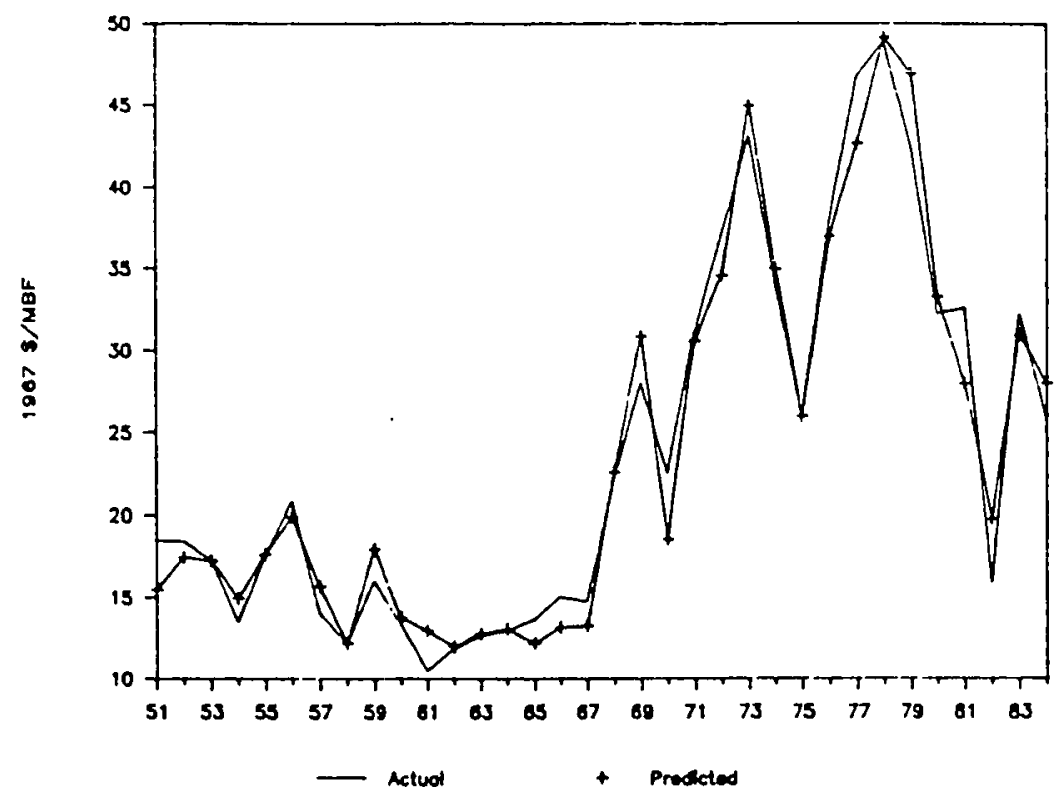

Figure 16. Historical simulation stumpage price SW.

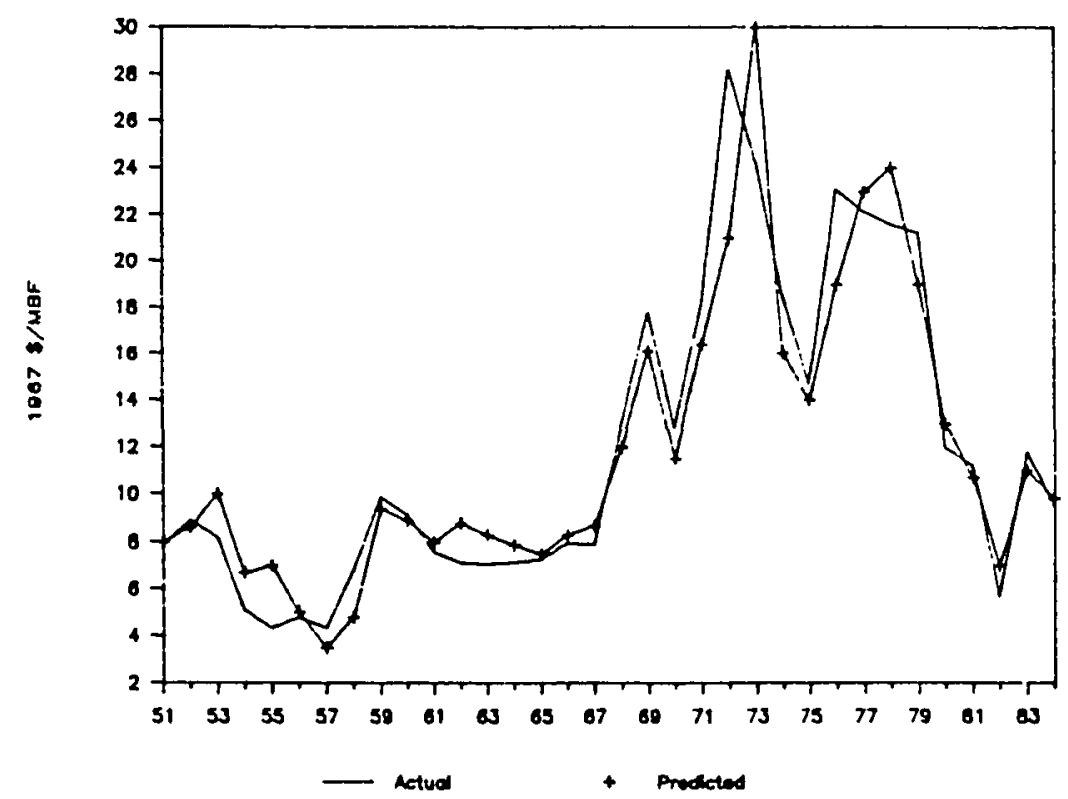

Figure 17. Historical simulation stumpage price IL. 


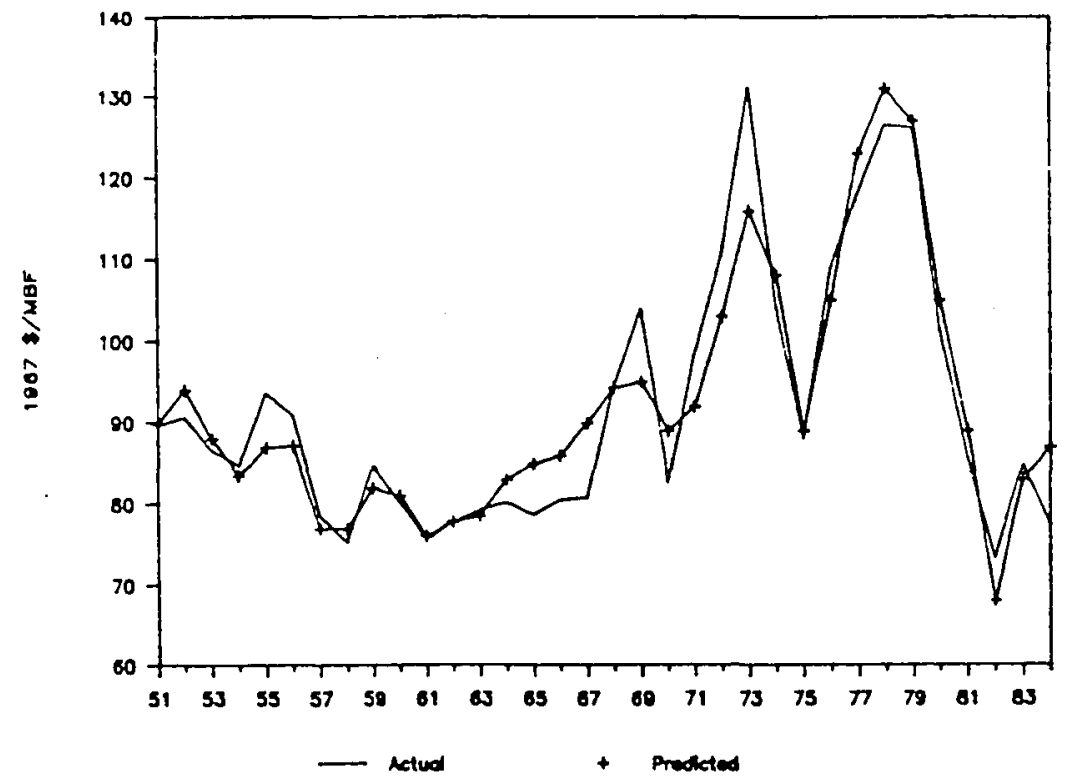

Figure 18. Historical simulation lumber price NW.

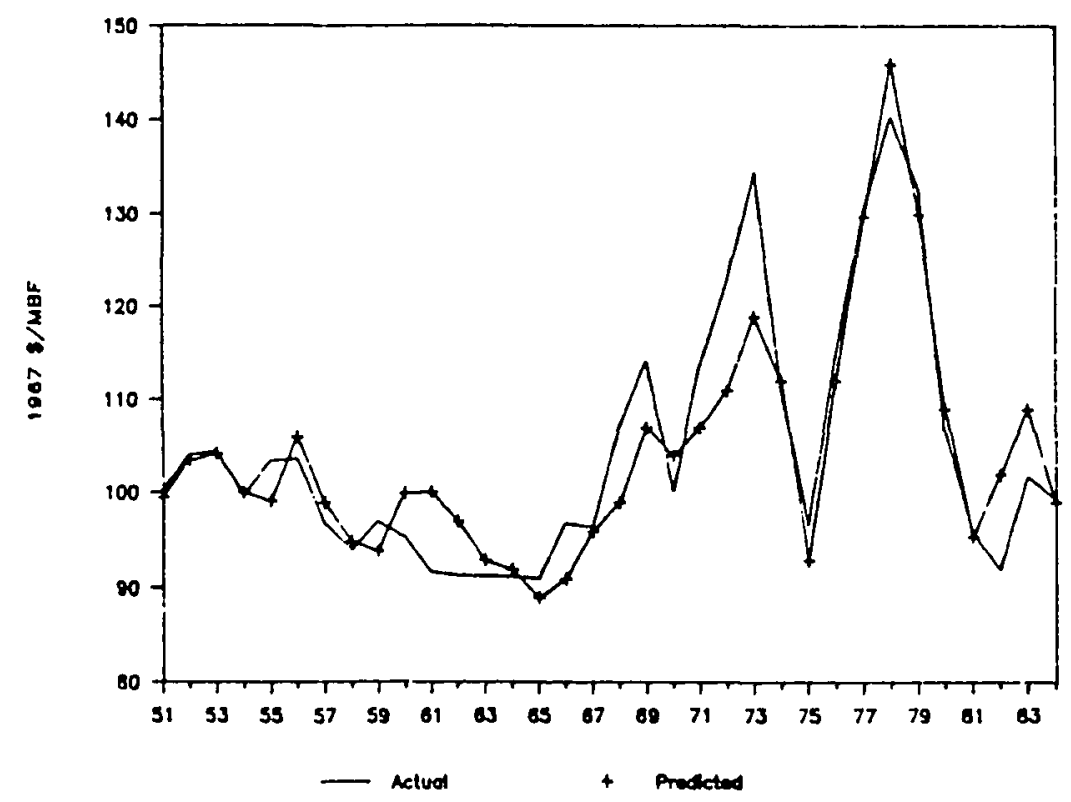

Figure 19. Historical simulation lumber price so. 


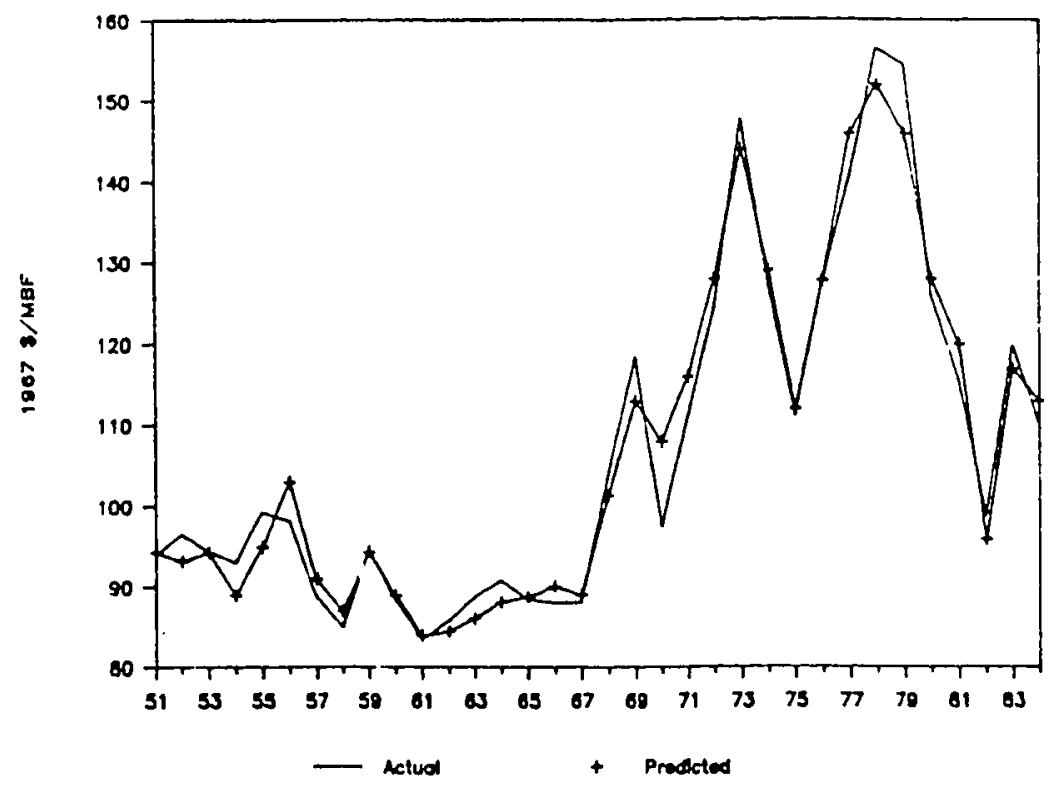

Figure 20. Historical simulation lumber price SW.

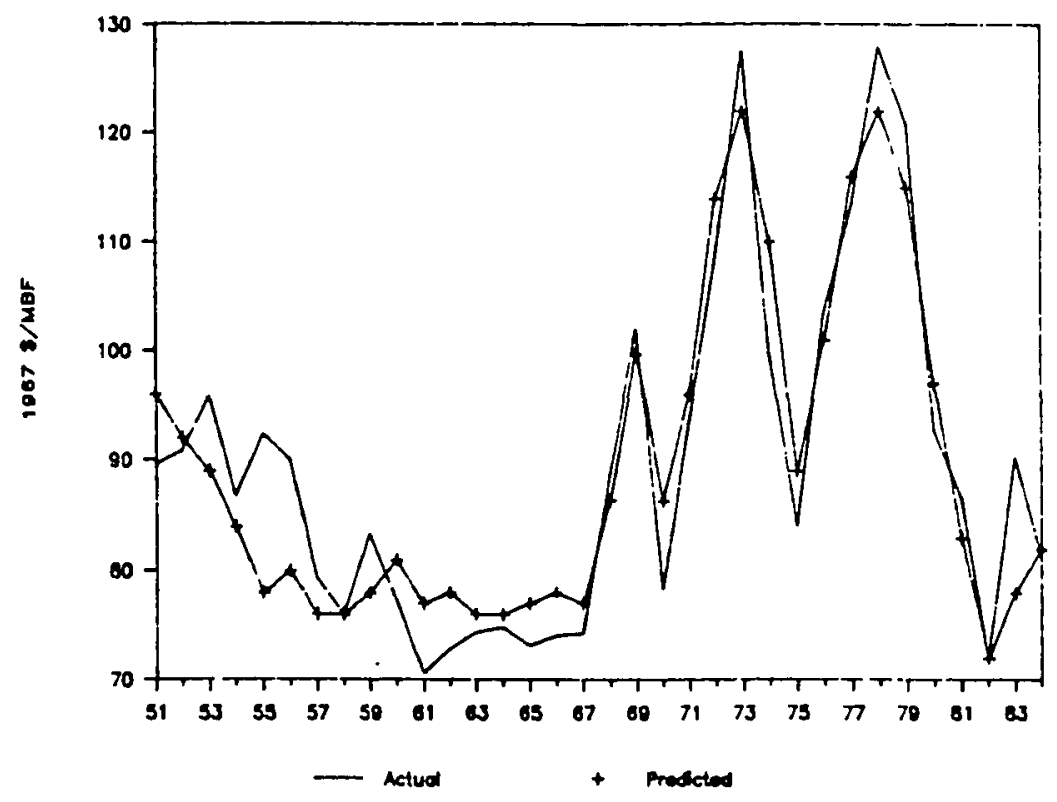

Figure 21. Historical simulation lumber price IL. 


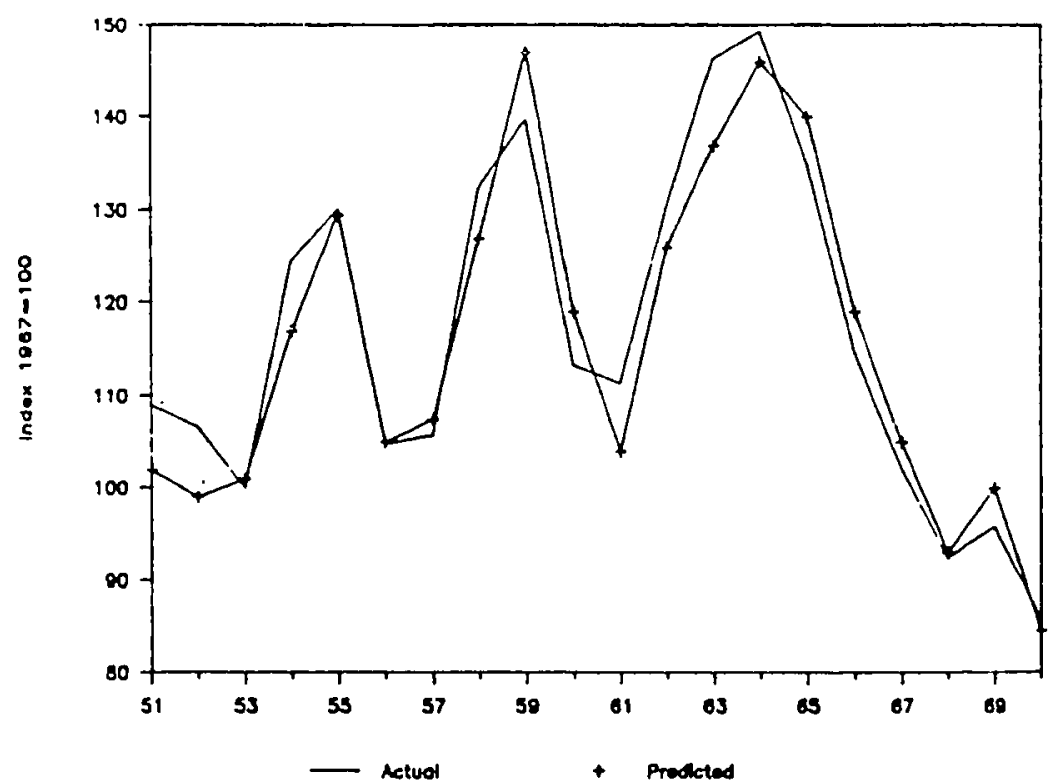

Figure 22. Plywood price Douglas fir.

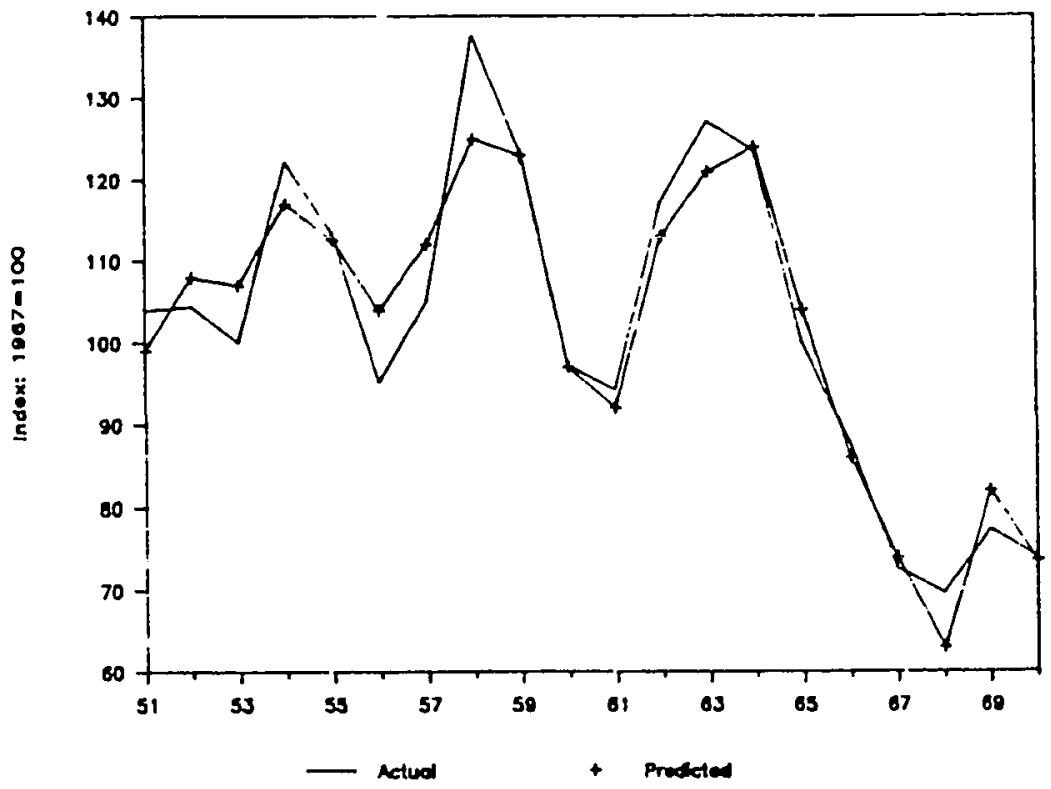

Fiqure 23. Plywood price Southern pine. 


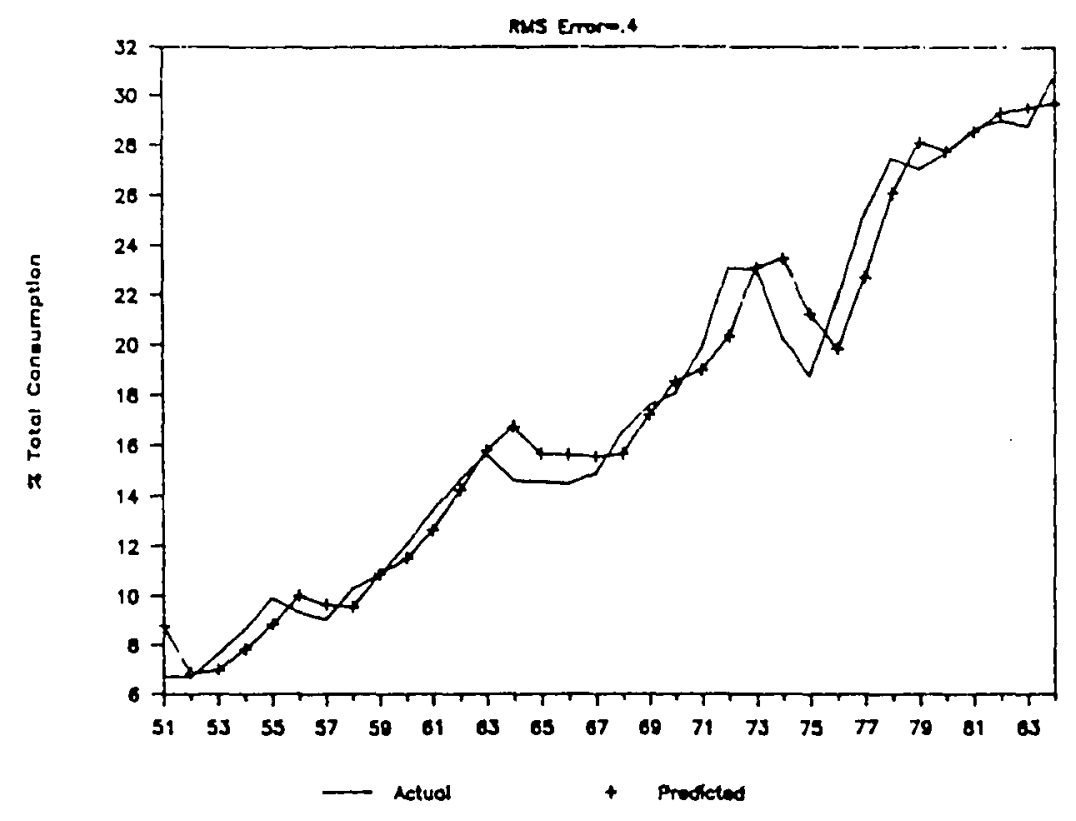

Figure 24. Lumber market share Canada.

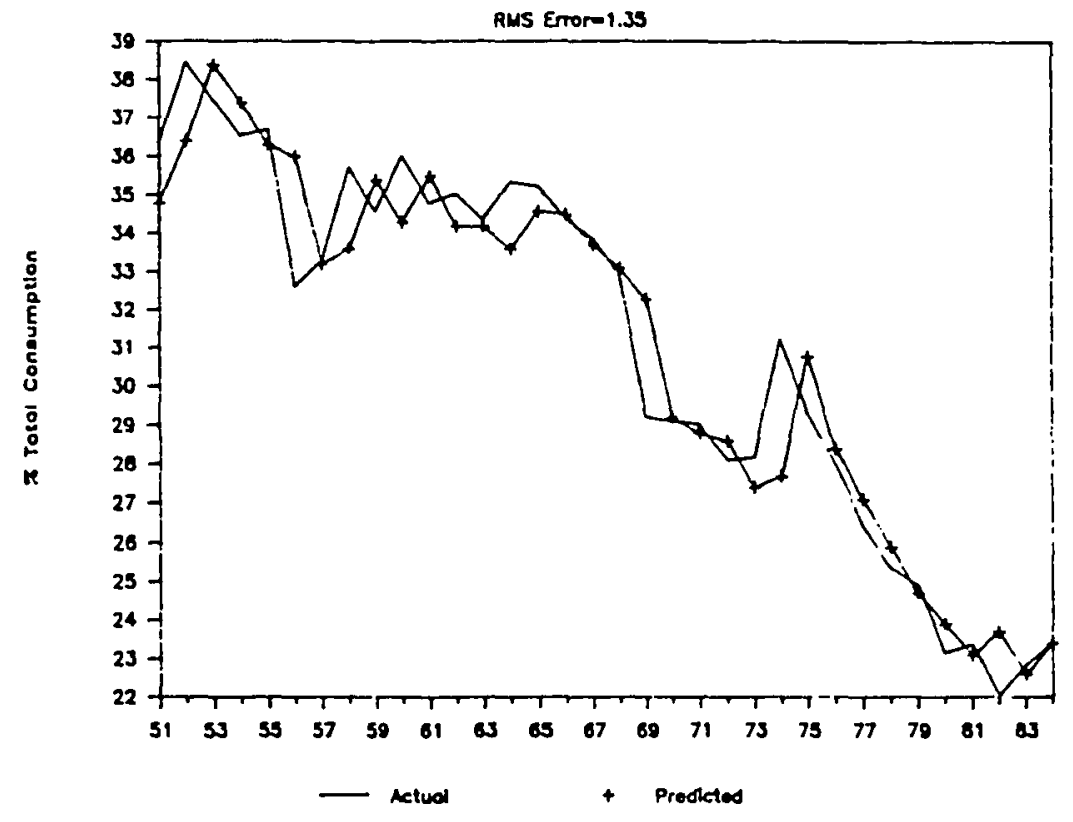

Figure 25. Lumber market share NW. 


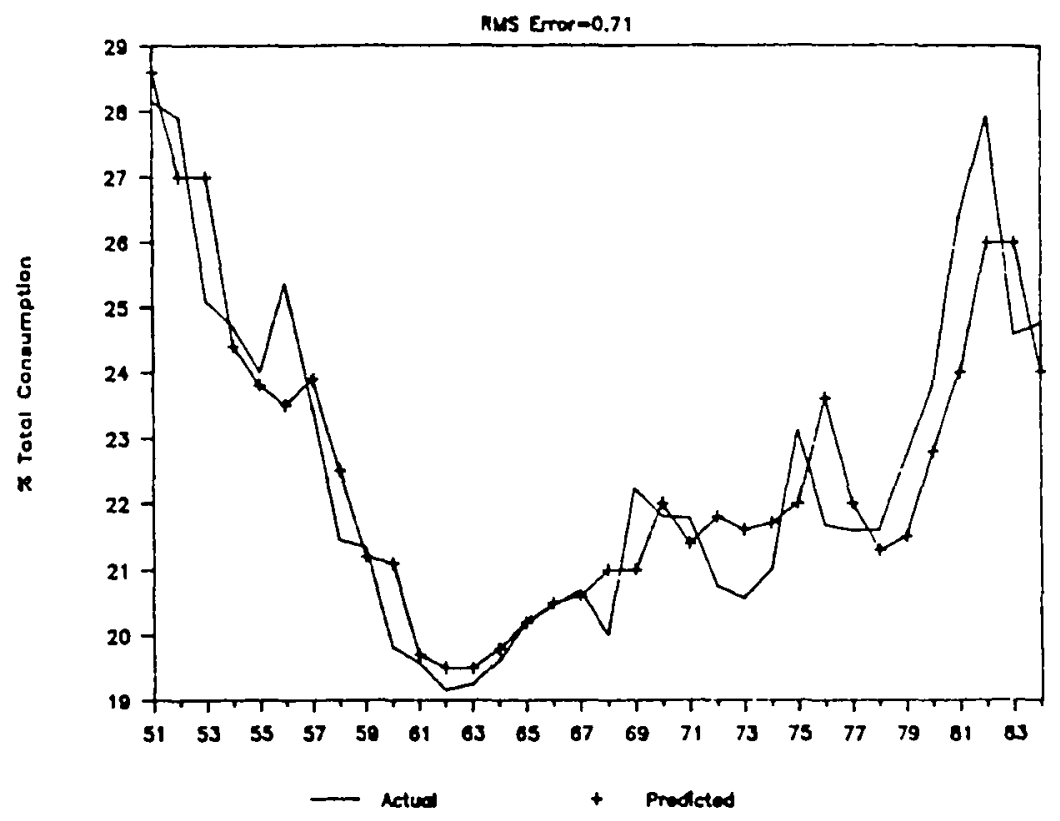

Figure 26. Lumber market share so.

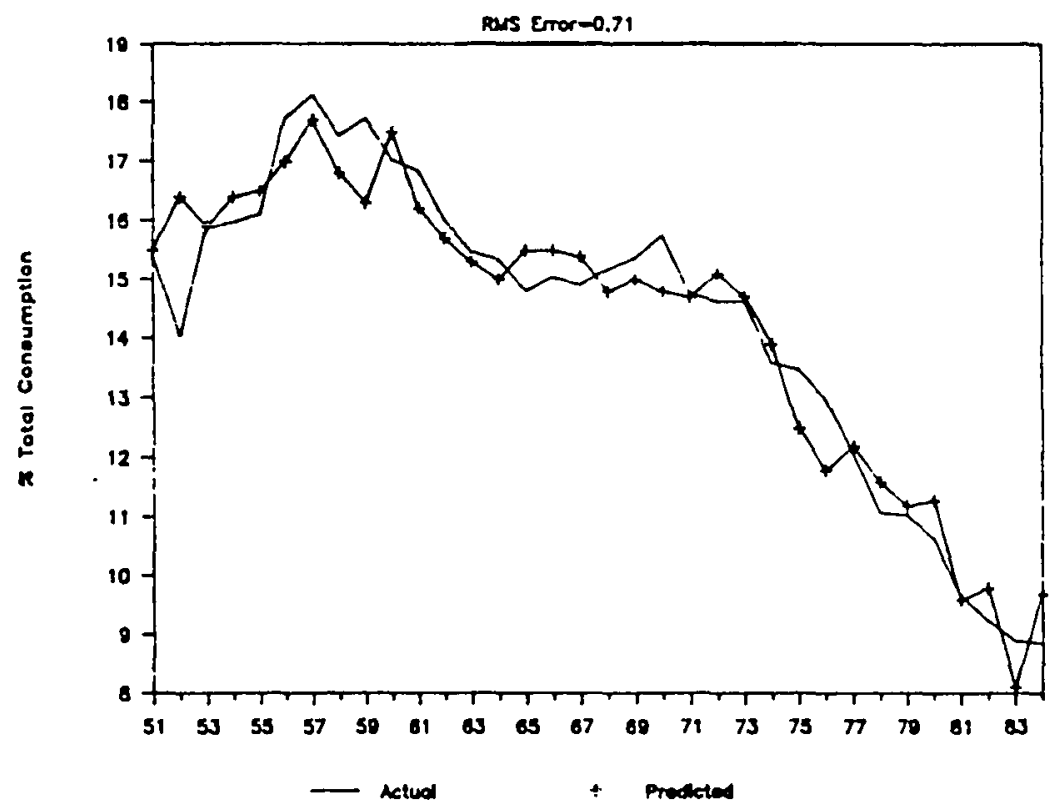

Figure 27. Lumber market share $\mathrm{SW}$. 


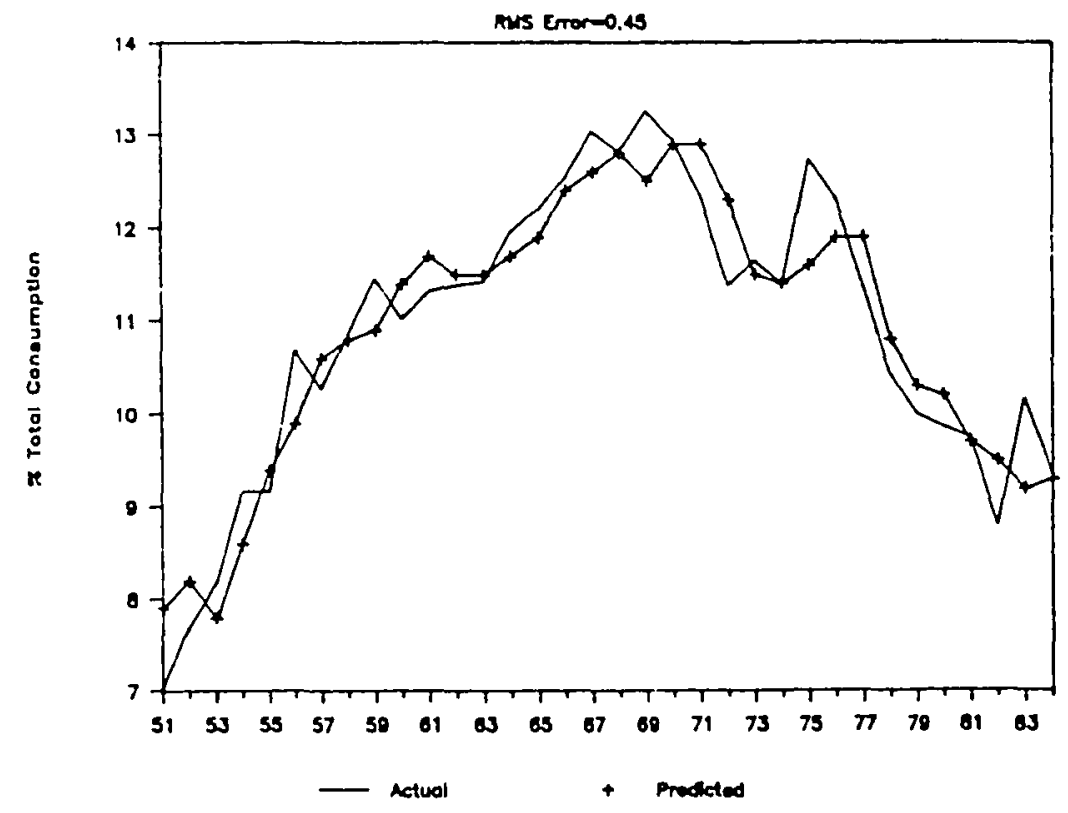

Figure 28. Lumber market share II.

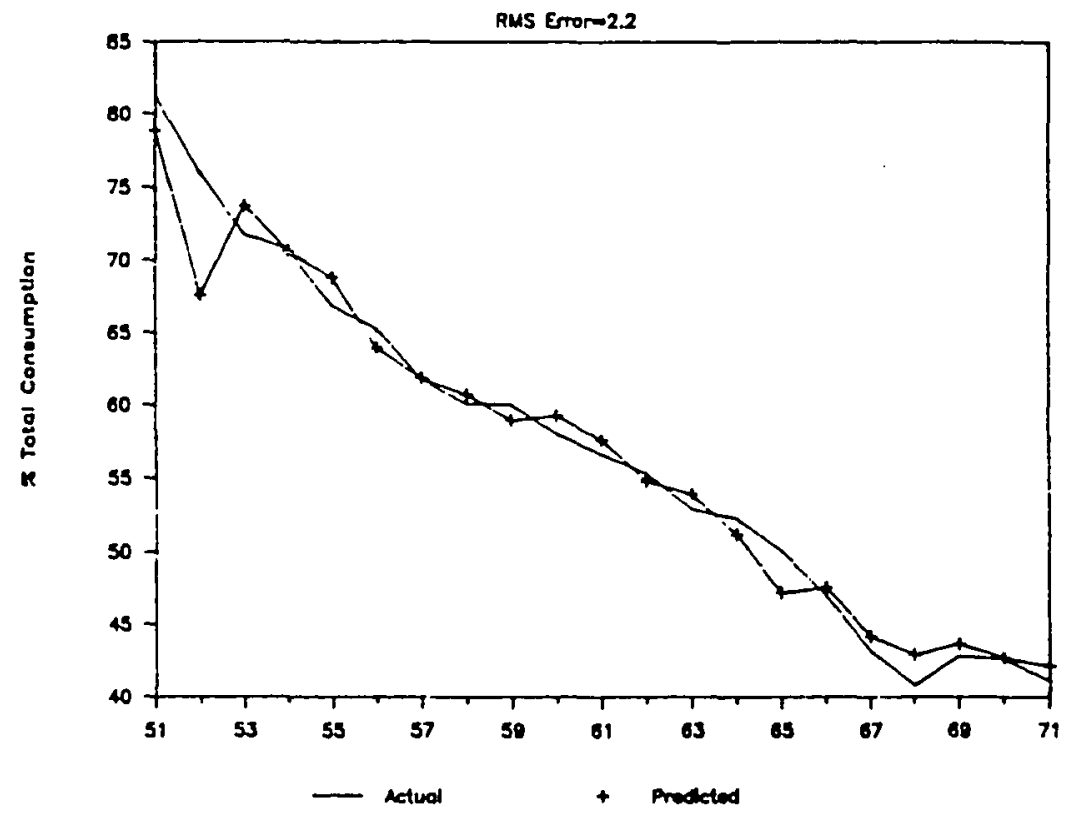

Figure 29. Plywood market share NW. 


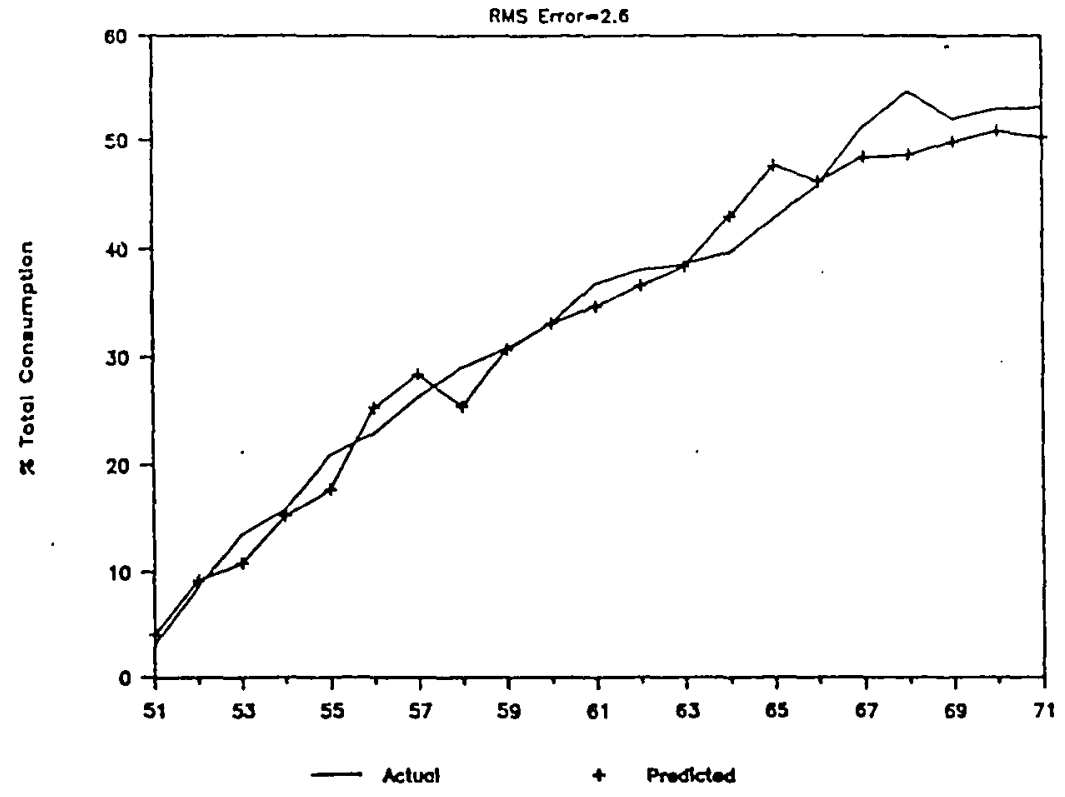

Fiqure 30. Plywood market share so.

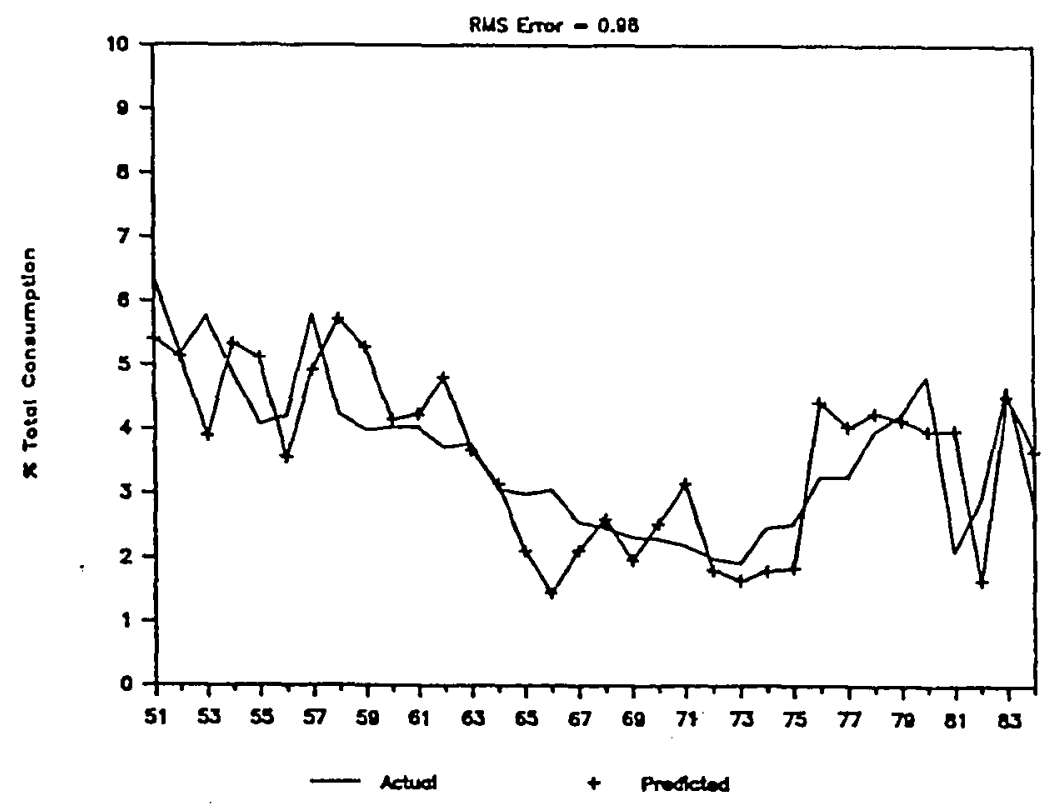

Figure 31. Lumber market share North 
For the seven key variables, i.e. regional lumber and plywood market shares, "root-mean-square" (rms) simulation errors are also reported.

In general, the results of ex post simulations appear to support the overall structure of the model. Nearly all simulated series seem to track the principal trends closely and, in most cases, replicate the timing of turning points accurately. In the aggregate market, the results for total product consumption are superior to product price outcomes for both lumber and plywood. Simulations of regional stumpage and product prices are of mixed quality. Although in all cases long-run trends are closely approximated, in several instances such as stumpage prices in the NW and so short-run fluctuations and the timing of several peaks and troughs are poorly depicted.

In evaluating the simulation performance of the model, the heaviest weight was given to regional market share variables. Because of their pivotal role, and the fact that market shares constitute the primary output of the model, the ultimate validity of the entire model is decided by the performance of these relationships. In judging the accuracy of market share predictions, it is important to recognize the serious implications of bias in terms of actual quantities. A seemingly negligible error in these variables, once translated into product quantities, can lead to unacceptable results in estimates of regional outputs. 
Historical simulations for regional market shares are shown in Figures 25 through 30. A graphical comparison of these results, shows that in all cases historical trends are reproduced remarkably well. The relatively low rms errors in these simulations also verify this conclusion. However, in a model designed for short-run projections, it is also essential that short term fluctuations be approximated accurately. As evidenced by the simulation results, it is apparent that in some cases this condition is not satisfied as fully as we would have liked.

In general, the results obtained for Canada, NW, and SW appear to be much more representative of the historical behavior than those found for other regions. For the last several years of the sample period, South's shares of lumber and plywood markets are both under estimated. In the case of the II lumber market shares, many short term fluctuations are either missed or represented with delay.

The untimely simulation of short term peaks and troughs of historical series appears as a common problem in several market share relationships. This problem is, in part, attributable to the autoregressive structures of market share relationships. In all cases, however, deviations from actual values are very small in absolute magnitude and can be corrected by making minor adjustments in few parameters of the model.

The historical trend in the share of the North region in the lumber market is shown in Figure 31. Since the region 
was not included in the model, the predicted values were derived by subtracting cumulative market shares of other regions in each period from 100 percent. It is important to note that since market shares for this region are determined exogenously, discrepencies between the predicted and actual values represent the magnitude of total error in market share equations. Comparison of actual and simulated series, as shown in Figure 31, show that the cumulate error in market share estimates is indeed negligible.

As a final check on the performance of the model as a whole, the complete model will be simulated forward for two years beyond the estimation period. This ex post forecasting exercise has the two-fold purpose of showing the predictive accuracy of the model, and providing a means for judging the overall utility of the model as a forecasting tool.

Values for nearly all exogenous variables for both years are available from same sources as listed in Appendix A. Also available, are the 1985 values for certain key endogenous variables such as aggregate consumption and regional outputs. Thus it is posssible to compare model projections with known values of certain variables. Since 1986 values for some exogenous variables were not available, it was necessary to use estimated values derived under certain assumptions. For instance the national forest offerings were held constant at the 1985 level. Change in output per employee for all regions were assumed to continue 
TABLE XVII

PROJECTED VALUES FOR MAJOR SOFTWOOD LUMBER AND PLYWOOD MARKET VARIABLES

\begin{tabular}{|c|c|c|c|}
\hline Variable & 1984 & 1985 & 1986 \\
\hline $\begin{array}{l}\text { Total Lumber } \\
\text { Cocsumption. . : }\end{array}$ & 43021 & $\begin{array}{l}44207.4 \\
(44204)^{*}\end{array}$ & 45867.3 \\
\hline $\begin{array}{l}\text { Average Price } \\
\text { for lumber...: }\end{array}$ & 81.79 & 79.82 & 88.17 \\
\hline $\begin{array}{l}\text { Total plywood } \\
\text { consumption...: }\end{array}$ & 19508 & $\begin{array}{c}22735 \\
(22838)\end{array}$ & 23618.3 \\
\hline $\begin{array}{l}\text { PPI softwood } \\
\text { plywood....... }\end{array}$ & 303.5 & $\begin{array}{c}307.2 \\
(302.9)\end{array}$ & 314.9 \\
\hline $\begin{array}{l}\text { Average lumber } \\
\text { price NW..... }\end{array}$ & 77.70 & 73.35 & 84.90 \\
\hline $\begin{array}{l}\text { Average lumber } \\
\text { price so...... }\end{array}$ & 99.40 & 104.7 & 109.0 \\
\hline $\begin{array}{l}\text { Average lumber } \\
\text { price Sw..... }\end{array}$ & 110.29 & 106.2 & 114.9 \\
\hline $\begin{array}{l}\text { Average lumber } \\
\text { price IL..... }\end{array}$ & 81.40 & 75.13 & 74.70 \\
\hline $\begin{array}{l}\text { Plywood } \\
\text { production NW: }\end{array}$ & 8319.2 & $\begin{array}{c}8281.9 \\
(8395.5)\end{array}$ & 8319.2 \\
\hline $\begin{array}{l}\text { Plywood } \\
\text { production so: } \\
\text { Mkt. share }\end{array}$ & 10351.7 & $\begin{array}{c}11406.4 \\
(11033.8)\end{array}$ & 11912.6 \\
\hline lumber Canada: & 30.80 & $\begin{array}{c}32.50 \\
(33.04)\end{array}$ & 33.48 \\
\hline $\begin{array}{l}\text { Mkt. share } \\
\text { lumber NW. . . . : }\end{array}$ & 23.41 & $\begin{array}{c}24.45 \\
(23.21)\end{array}$ & 24.20 \\
\hline $\begin{array}{l}\text { Mkt share } \\
\text { lumber so..... }\end{array}$ & 24.75 & $\begin{array}{c}25.14 \\
(24.54)\end{array}$ & 25.02 \\
\hline $\begin{array}{l}\text { Mkt. share } \\
\text { lumber SW.... : }\end{array}$ & 8.86 & $\begin{array}{c}9.30 \\
(8.79)\end{array}$ & 8.71 \\
\hline $\begin{array}{l}\text { Mkt. share } \\
\text { lumber IL. . . . : }\end{array}$ & 9.37 & $\begin{array}{c}10.39 \\
(10.32)\end{array}$ & 10.50 \\
\hline
\end{tabular}

* Figures in parantheses show actual values. 
at their average historical rates in all regions; and the price of Canadian lumber was estimated at a level commensurate with the Producer Price Index for all softwood lumber.

The two-year projections for aggregate levels of consumption and prices for both lumber and plywood, and regional product prices and market shares are shown in Table XVII. Plywood price index and regional product and stumpage prices were all estimated from reduced form equations so that current endogenous variables were eliminated from the right-hand side of these equations.

A comparison of projected and actual values of the main market variables in 1985 indicates that nearly in all cases the actual values are closely approximated. The major exception is the regional plywood market. Plywood production in the NW is slightly underestimated, while production in the so is overestimated by nearly 400 million square feet (1.6 percent of total consumption). PPI for softwood plywood also appears to miss the 1985 mark by six points.

During this two year period, the projected trend is one of increasing demand in both lumber and plywood markets stimulated by the surge in the national housing market. With the exception of the southern pine lumber, 1985 product prices are projected to fall below their 1984 levels and then increase slightly in 1986.

Projected pattern for regional market shares in lumber show that increases in quantities of lumber consumed will 
not be distributed evenly across producing regions. As indicated by results in Table XVII, domestic producers' shares of the lumber market are expected to remain largely stable. Canadian producers appear as the single most important beneficiary of the increased demand for lumber. The market share outcomes suggest that nearly all of the anticipated increments in demand for lumber will be satisfied by Canadian imports; thus adding to the prominence of Canada as the major supplier of lumber in the U.S. market.

Canada's role in the domestic lumber market is, however, sensitive to price conditions both in Canada and in the U.S. Shifts in the delivered prices of the Canadian lumber are likely to take place as a result of changes in exchange rates and/or imposition of tariffs. In view of recent trends in the international currency market, and the current debate over the imposition of tariff on the Canadian lumber imports, the position of Canada in the U.S. Iumber market is Iikely to undergo some change in the future.

The results of the present study indicate, for example, that imposition of a 20 percent ad valorem duty on lumber imports can result in a 0.75 percent (350MM BFt.) reduction in Canada's share of the lumber market in the first year. Such impact, however, is not likely to persist in future periods. The magnitudes of future period impacts also depend on price conditions in the U.S. For one thing, any such change in the delivered price of the Canadian 
lumber will also lead to increased average prices in the U.S. (and possibly some reduction in quantities demanded). We can therefore expect the initial period price disadvantage arising from the imposition of tariffs to be somewhat mitigated in the following periods so that the overall impact on market shares will not be very large.

\section{CONCLUDING REMARRS}

This research was motivated by an interest in exploring the mechanisms that underlie the geographical distribution of production in the lumber and wood products industry as a specific case in the broader context of spatial competition. The research is a further step in the ongoing efforts in regional modeling, and provides a framework for the explicit treatment of linkages between the national and regional economies. In addressing this problem, we opted for an econometric approach as a compromise between the oversimplicity of some conventional methods of location analysis and the complexity of mathematical programming.

The design of the model was guided by the three-fold objective of developing a model that accurately describes the behavior of the two industries and their spatial characteristics, can provide reliable projections of short term trends, and serve as a tool in simulation experiments.

The overall performance of the model bears witness to the fact that all three objectives were met, though with varying degrees of success. With respect to the approach 
adopted here, it has been shown that it is indeed a viable one. The findings provide ample evidence in support of the initial postulates of the study regarding the determinants of regional market shares.

In several areas, however, there is room for some refinements that can improve the effectiveness of the approach. There is, first of all, the specification of spatial units that can be better presented by further disaggregation. For example, more homogeneous spatial units can be created by separate treatment of the coastal and Inland parts of the Northwest region; and independent presentation of the southeast and southcentral regions. With further experimentation, and using more appropriate measures of product demand such as housing starts, alternative accessibility indexes can be constructed to better represent regional locational advatage.

Since a primary point of interest in this undertaking was development of the approach itself and testing of its validity, much emphasis was placed on the statistical properties of the model. This, combined with efforts to maintain theoretical consistency in behavioral relationships, led to certain rigidities in the structure that complicate the forecasting and simulation processes. A further problem in forecasting application arises from the frequent appearance of lagged endogenous variables in the model which can lead to efficiency problems in extended forecasts. 
Further extensions along the product dimension of the model are also possible. The pulpwood sector might, for instance, be included in the model so that a more complete picture of competition in regional stumpage markets is obtained. These and other extensions of the model are, however, contingent upon availability of data at the regional level, a persistent problem in all regional modeling efforts including the present one. 
Adams, D.M. (1976), "The Response of Softwood stumpage and Product Prices to Changes in National Forest Timber Harvest Schedules". Unpublished report, Pacific Northwest Forest and Range Experiment Station, Portland, Or., $13 \mathrm{pp}$.

Adams, D.M. (1977), Effects of National Forest Timber Harvest on Softwood Stumpage, Lumber, and Plywood Markets. School of Forestry, Oregon State University, Corvallis, or., Res. Bulletin No. 15.

Adams, D.M., R.W. Haynes, T.J. Mills, D. Shearer, and S. Childress (1979), Production, Consumption, and Prices of Softwood Products in North America, Regional Time Series Data. School of Forestry, Oregon State Univ. Corvallis, Or., Res. Bulletin No. 27.

Adams, D.M. and R.W. Haynes (1980), The 1980 Softwood Timber Assessment Market Model: Structure, Projections, and Policy simulations. Forest Science Monograph no. 22, $64 \mathrm{pp}$.

Adams, D.M. and R.W. Haynes (1980a), "U.S.-Canadian Lumber Trade: The Effect of Restrictions". in R.A. Sedjo (ed.), Issues in U.S. International Forest Products Trade. Resources For The Future, Research Paper R-23, Washington D.C., 1980.

Adams, D.M., R.W. Haynes, G.F. Dutrow, R.L. Barber, and J.M. Vasievich (1982), "Private Investment in Forest Management and the Long-Term Supply of Timber". Amer. Journal of Agr. Econ. 64, No. 2, pp. 232-41.

Adams, D.M. and R.W. Haynes (1986); "A Spatial Equilibrium Model of U.S. Forest Products Markets for Long-Range Projection and Policy Analysis". TIMS studies in the Management Sciences, North-Holland, pp. 73-87.

Adams, F.G. and J. Blackwell (1973) "An Econometric Model of the United States Forest Products Industry". Forest Science, 19, pp. 82-97.

Adams, F.G. and N. Glickman (1980), (eds.) Modeling the Multiregional Economic System. Lexington Books, Lex., Mass., pp.147-60. 
Alperovich, G. (1980) "Regional Elasticities of Substitution". Journal of Regional Science, 20, No. 4, pp. 503-11.

American Plywood Association, "Structural Panel Production by State". Bulletin FA-235, [annual].

Armington, P.S. (1969) "A Theory of Demand for Products Distinguished by Place of Production". International Monetary Fund staff Papers, 16, pp. 159-76.

Ballard, K.P., N.J. Glickman, and R.D. Gustely (1980) "A Bottom-Up Approach to Multiregional Modeling: NRIES". in Adams, F.G. and N.J. Glickman, (eds.) Modeling the Multiregional Economic System. op.cit., pp. 147-69.

Connaghton, K.P. and R.W. Haynes (1983) "An Evaluation of Three Simplified Approaches to Modeling the Regional Demand for National Forest Stumpage". Forest Science, 29, No. 2, pp. 3-12.

Deacon, R.T. and M.B. Johnson (1985) (eds.) Forestlands, Public and Private. Pacific Institute for Public Policy Research, Ballinger Pub. Co., Cambridge, Mass.

Dhrymes, P.J., E.P. Howrey, S.H. Hymans, J. Kmenta, E.E. Leamer, R.E. Quandt, J.B. Ramsey, H.T. Shapiro, and V. Karnowitz (1972) "Criteria for Evaluation of Econometric Models". Annals of Economic and Social Measurement, 1, No. 3, pp. 291-323.

Dorfman, R. (1953) " Mathematical or 'Linear' Programming: A Nonmathematical Exposition", in E. Mansfield (ed.), Microeconomics, Selected Readings. Norton, N.Y., 1979, pp. 137-65.

Dowdle, B. and S.H. Henke (1985) "Public Timber supply and the Wood-Products Industry", in Deacon, R.T. and M.B. Johnson (eds.), Forestlands, Public and Private. op.cit. pp. 77-102.

Engle, R.F. (1979a) "The Regional Response to Factor Supplies: Estimates for the Boston SMSA", in Wheaton, W.C., (ed.) Interregional Movements and Regional Growth. The Urban Institute, Washington D.C., 1979, pp.157-83.

Engle, R.F. (1979b) "Estimation of Price Elasticity of Demand Facing Metropolitan Producers". Journal of Urban Economics, 6, pp.42-64. 
Enke, S. (1951) "Equilibrium Among Spatially Separated Markets: Solution by Electric Analogue". Econometrica, 21, PP. 547-66. Reprinted in Dean, R.D., et.al. Spatial Economic Theory. The Free Press, N.Y. 1970, PP. 277-84.

Fehd, C.S. (1975) "Introducing Price Indexes for Railroad Freight". Monthly Labor Rev., (June 1975), pp. 19-24.

Fisher, F.M. (1965) "The Choice of Instrumental Variables in the Estimation of Economy-Wide Econometric Models". in H.M. Blalock Jr., Ed., Causal Models in the Social Sciences. Adline, Chicago, 1971, pp. 245-72.

Fox, K.A. (1953) "A Spatial Equilibrium Model of the Livestock Feed Economy". Econometrica, 21, pp. 547-66.

Garnick, D.H. (1980) "The Regional Statistics System". in Adams, F.G. and N.J. Glickman, (eds.) Modeling the Multiregional Economic system. op.cit., pp.25-38.

Ginsberg, A.I. and R.M. Stern (1965) "The Determination of Factors Affecting American and British Exports in the Inter-War and Post-War Periods". Oxford Economic Papers, 17, pp. 263-78.

Ginsburgh, V.A. and J.I. Waelbroeck (1981) Activity Analysis and General Equilibrium Modeling. North-Holland, Amsterdam.

Gregory, G.R. (1960) "A Statistical Investigation of Factors Affecting the Market for Hardwood Flooring". Forest science, 6, pp. 123-34.

Gregory, G.R., D. Hair, H.R. Josephson, V. Holopainen, K. Mantel, S.I. Pringle, P. Rilhinen, R. Saether, and H.J. Vaux (1971) "Forecasting in Forestry and Timber Economy". Folia Forestalia, 101, pp. 1-49.

Haynes, R.W. (1977) "A Derived Demand Approach to Estimating the Iinkage Between Stumpage and Lumber Markets". Forest Science, 23, No. 2, pp. 281-8).

Haynes, R.W., D.I. Holley, and R.A. King (1978) A Recursive Spatial Equilibrium Model of the Softwood Timber Sector. N.C. State Univ., School of Forest Resources, Technical Report No. 57.

Haynes, R.W., K.P. Connaghton, and D.M. Adams (1981) Projections of the Demand for National Forest stumpage by Region: 1980-2030. USDA/FS, Research Paper, PNW-282. 
Henderson, J.M. and R.E. Quandt (1980) Microeconomic Theory, A Mathematical Approach. McGraw-Hill, N.Y.

Holland, I.I. (1960) "An Explanation of Changing Lumber Consumption and Price" Forest Science, 6, No. 2, pp. $112-24$.

Holley, D.L., R.W. Haynes and H.F. Kaiser (1975) An Interregional Timber Model for simulating Changes in the Softwood Timber Economy. N.C. State Univ. School of Forest Resources, Technical Report No. 54.

Houston, D.B. (1967) "The Shift and Share Analysis of Regional Growth: A Critique". Southern Econ. Journal, 33, (April 1967), PP. 577-82.

Howe, C.w. (1979) Natural Resource Economics: Issues, Analysis, and Policy. J. Wiley \& Sons, N.Y.

Humphrey, D.B. and J.R. Moroney (1975), "Substitution Among Capital, Labor, and Natural Resource Products in American Manufacturing". Journal of Political Economy, 83, pp. 57-82.

Hyde, W.F. (1980) Timber Supply, Land Allocation, and Economic Efficiency. Resources for the Future, Wash. D.C., John Hopkins Univ. Press, Baltimore, Md.

Intriligator, M.D. (1971) Mathematical optimization and Economic Theory. Prentice Hall, N.J.

Isard, W. (1960) Methods of Regional Analysis. MIT Press, Cambridge, Mass.

Johansson, P.O. and K.G. Lofgren (1985) The Economics of Forestry and Natural Resources. Basil Blackwell, oxford.

Johnston, J. (1984) Econometric Methods. 3rd. ed., McGrawHill, N.Y.

Kennedy, M. (1974) "An Economic Model of the World Oil Market". The Bell Journal of Economics, 5, pp. 540-77.

Kloek, T. and L.B.N. Mennes (1960) "Simultaneous Equation Estimation Based on Principal Components of Predetermined Variables". Econometrica, 28, pp. 45-61.

Labys, w.C. (1973) Dynamic Commodity Models: Specification, Estimation, and Simulation. Lexington Books, Lex., Mass. 
Leamer, E.E., and R.M. Stern (1970) Quantitative International Economics. Allyn and Bacon, Boston.

Lindell, G.R. (1979) "World Softwood Lumber Trade: Patterns, Trends, and Prospects". Forest Products Journal, 29, No. 7, pp. 43-9.

McCarl, B.A. and R.W. Haynes (1985) "Exchange Rates Influence Softwood Lumber Trade". Journal of Forestry, 83 , No. 6, pp. 368-70.

McCarthy, M.D. (1971) "Notes on the Selection of Instruments for Two Stage Least squares and $\mathrm{K}$. Class Type Estimators of Large Models". Southern Econ. Journal, 37, pp. 251-8.

McKillop, W.L. (1967) "Supply and Demand for Forest Products: An Econometric Study". Hilgardia, 38, Univ. of Calif. Agr. Exp. Station, pp. 1-132.

McKillop, W.I. (1969) "An Econometric Model of the Market for Redwood Lumber", Forest Science, 15, pp. 159-70.

Merrifield, D.E. and R.W. Haynes (1983) "Production Function Analysis and Market Adjustments: An Application to the Pacific Northwest Forest Products Industry". Forest Science, 29, No. 4, pp. 813-22.

Merrifield, D.E. and R.W. Haynes (1984) "The Adjustment of Product and Factor Markets: An Application to the Pacific Northwest Forest products Industry". American Journal of Agricultural Economics, $66, \mathrm{pp} .79-87$.

Mills, T.J. and R.S. Manthy (1974) An Econometric Analysis of Factors Determining Supply and Demand for Softwood Lumber. Michigan State Univ., Agricultural Experiment Station, East Lansing, Research Report No. 238, 59 pp.

Milne, W.J., F.G. Adams, and N.J. Glickman, "A Top-Down Multiregional Model of the U.S. Economy". in Adams, F.G. and N.J. Glickman, (eds.) Modeling the Multiregional Economic system. op.cit., pp.133-45.

Nautiyal, J.C. and B.K. Singh (1985) "Production Structure and Derived Demand for Factor Inputs in the Canadian Lumber Industry". Forest Science, 31, No. 4, pp. 871-81.

Nelson, R.H. (1985) "Mythology Instead of Analysis, the Story of Public Forest Management". in Deacon, R.T. and M.B. Johnson (eds.), Forestlands, Public and private. op. cit. pp. 23-76. 
Nerlove, M. (1958a) "Distributed Lags and Estimation of Long-Run Supply and Demand Elasticities: Theoretical Considerations". Journal of Farm Economics, 40, No. 2, pp. 301-15.

Nerlove, M. (1958b) "Statistical Estimation of Long-Run Elasticities of Supply and Demand". Journal of Farm Economics, 40, No. 4, pp. 861-81.

Niedercorn, J.H. and B.V. Bechdolt (1969) "An Economic Derivation of the 'Gravity Law' of Spatial Interaction". Journal of Regional Science, 10, pp. 273-82.

Pindyck, R.S. and D.L. Rubinfeld (1981) Econometric Models and Economic Forecasts. 2nd, ed., McGraw-Hill, N.Y.

Polak, J.J. (1950) "Notes on the Measurement of Elasticity of Substitution in International Trade". Rev. of Economics and Statistics, 32, No. 1, pp 16-20.

Pringle, S.I. (1971) "Substitution as a Problem in Forecasting". in Gregory, et al. (1971) op. cit.

Richardson, H.W. (1979) Regional Economics., Univ. of Ill. Press, Chicago.

Robinson, V.I. (1974) "An Econometric Model of Suftwood Lumber and Stumpage Markets, 1949-1976". Forest Science, 20, pp. 171-9.

Robinson, V.L. (1975) "An Estimate of Technological Change in the Iumber and Wood-Products Industry". Forest Science, 21, pp. 149-54.

Samuelson, P.A. (1952) "Spatial Price Equilibrium and Linear Programing". American Econ. Rev., 42, pp. 283-303.

Samuelson, P.A. (1976) "Economics of Forestry in an Evolving Society". Economic Inquiry, 14, (Dec. 1976), pp.466-91.

Schallau, C.H. and W.R. Maki (1986) Economic Impacts of Interregional competition in the Forest Products Industry During the 1970's. USDA/Forest Service, Pacific Northwest Research Station, Research Paper PNW-350, $43 \mathrm{pp}$.

Spelter, H. and R.G. Anderson (1985) A Profile of Wood Use in Nonresidential Building Construction. USDA/Forest Service, Resource Bulletin FPL-15, 22 pp. 
Stanford Research Institute (1954) America's Demand for Wood. A Report to Weyerhaeuser Company, Tacoma, Wa.

Stier, J.C. (1980) "Estimating the Production Technology in the U.S. Forest Products Industries". Forest Science, 26 , No. 3, pp. 471-82.

Stigler, G. J. (1968) The Organization of Industry. Univ. of Chicago Press, Chicago, Ill.

Takayama, T. and G.G. Judge (1964a) "Equilibrium Among Spatially Separated Markets: A Reformulation". Econometrica, 32, pp. 510-24.

Takayama, T. and G.G. Judge (1964b) "Spatial Equilibrium and Quadratic Programming". Journal of Farm Econ., 44, pp. 67-93.

Takayama, T. and G.G. Judge (1971) Spatial and Temporal price and Allocation Models. North-Holland, Amsterdam.

Tinbergen, J. (1946) "Some Measurements of Elasticities of Substitution". Rev. of Economics and Statistics, 28, No. 3, pp. 109-16.

Tomek, W.G. and K.I. Robinson (1952) Agricultural product Prices. Cornell Univ. Press, N.Y.

USDA/Forest Service (1973) The outlook for Timber in the United States. Forest Resource Report No. 20, $377 \mathrm{pp}$.

USDA/Forest Service (1982) An Analysis of the Timber Situation in the United states 1952-2030. Forest Resource Report No. 23, 499 pp.

Uzawa, H. (1959) "Prices of the Factors of Production in International Trade". Economica, 27, pp. 448-68.

Western Wood Products Association, Statistical Yearbook of the Western Lumber Industry. (annual issues), Portland, Oregon.

Wilson, A.G. (1967) "A Statistical Theory of Spatial Distribution". Transportation Research, 1, pp. 253-68.

Zellner, A. (1962) "An Efficient Method of Estimating Seemingly Unrelated Regressions and Tests for Aggregation Bias". Journal of the American statistical Association, 57, pp. 348-68.

Zellner, A. and H. Theil (1962) "Three-Stage-Least-Squares: Simultaneous Estimation of Simultaneous Equations". Econometrica, 30, pp. 54-78. 


\section{APPENDIX A}

\section{DATA SOURCES}

1 - Adams, D.M., K.C. Jackson, and R.W. Haynes (1986) "Production, Consumption and Prices of Softwood Products in North America: Regional Time Series Data, 1950-1985". Unpublished Report, USDA/FS, Pacific Northwest Forest and Range Experiment station, Portland, Or.

2 - USDA-Forest Service, Pacific Northwest Research Station, Production, Prices, Employment, and Trade in the Northwest Forest Industries. Resource Bulletin, PNW-130, [quarterly issues]. Portland, Ore.

3 - National Forest Products Association, Fingertip Facts and Figures. [monthly], Washington, D.C.

4 - USDC, Business and Defense Service Admin. U.S. Lumber Exports: $1953-1966.1968$.

5 - USDC, Bureau of the Census, County Business Patterns. [annual issues].

6 - USDC, Bureau of the Census, "Iumber Production and Mill Stocks", Current Industrial Reports, Series MA-24T [annual].

7 - American Plywood Association, "Structural Panel Produuction by States". Bulletin FA-235, [annual], Tacoma, Wa.

8 - Economic Report of the President. U.S. Gov. Printing Office, 1985.

9 - USDL, Bureau of Labor Statistics, Employment and Earnings. [monthly].

10- U.S. Federal Reserve System, Federal Reserve Bulletin. [monthly].

11- USDC, Bureau of the Census, "Value of New Construction Put in Place in the U.S.", Construction Report Series c30-80s.

12- USDI, Bureau of Labor Statistics, Employment and 
Earnings, States and Areas, 1939-1978., and Supplements.

13- USDA, Forest Service, U.S. Timber Production, Trade, Consumption, and Price statistics, 1950-84. Miscellaneous Publication No. 1442 .

14- USDL, Bureau of Labor Statistics, Producer Price and Price Indexes. [monthly and annual].

15- USDC, Bureau of the Census, statistical Abstracts of the United States. [annual].

16- USDI, Productivity Measures for Selected Industries. Bulletin No. 2256.

17- USDC, Bureau of the Census, "Housing starts", Construction Report Series C-22.

18- USDC, Bureau of the Census, U.S. Exports, Schedule E Commodity by country. FT-410. [monthly and annual supplements].

19- USDA, Forest Service, "Volume and Value of Sawtimber Stumpage Sold From National Forests by Selected Species and Regions". [quarterly and annual]. 


\section{APPENDIX B}

\section{TABLE XVIII}

AVERAGE HOURLY EARNINGS IN MANUFACTURING AND LUMBER \& WOOD PRODUCTS (Current U.S. \$)

\begin{tabular}{|c|c|c|c|c|c|c|c|c|c|c|}
\hline \multirow[b]{2}{*}{ Year } & \multicolumn{5}{|c|}{ Manufacturing } & \multicolumn{5}{|c|}{ IC 24} \\
\hline & US & NW & so & SW & $I L$ & US & $N W$ & so & SW & IL \\
\hline 5 & .42 & 1.9 & 8 & 1.65 & 1.57 & 0 & .67 & 12 & 1.57 & .49 \\
\hline & & 1.9 & 7 & .77 & & & .83 & & 1.70 & .61 \\
\hline & 1.6 & 2.02 & .33 & 1.87 & 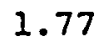 & 1. & 1.87 & 1.23 & 1.74 & 54 \\
\hline 195 & 1.77 & 2.07 & 71 & 1.97 & 6 & & 1.89 & 1.29 & 1.80 & .70 \\
\hline 195 & 1.81 & 2.13 & 1.45 & 2.03 & 1.91 & 1.63 & 1.91 & 1.30 & 1.83 & 1.72 \\
\hline 1 & 1.89 & 2.22 & 1.50 & 2.11 & 1.99 & 1.68 & 1.97 & 1.34 & 1.88 & 1.7 \\
\hline & 1.98 & 2.29 & 1.62 & 2.22 & 2.10 & 1.76 & 2.04 & 1.44 & 1.97 & 1.87 \\
\hline 1 & 2.07 & 2.34 & 1.71 & 2.32 & 2 & 1.81 & 2.04 & 1.50 & 2.03 & 1.90 \\
\hline 1 & 2.1 & 2.42 & 1.76 & 2.44 & 2. & 1.89 & 2.15 & 1.56 & 2.17 & .9 \\
\hline & 2.2 & 2.52 & 1.82 & 2.53 & 2. & 1.97 & 2.23 & 1.62 & 2.25 & .0 \\
\hline 1 & 2.2 & 2.59 & 1.89 & 2.62 & 2 & 2.07 & 2.34 & 1.70 & 2.37 & 2.1 \\
\hline 1 & 2.35 & 2.66 & 1.93 & 2.72 & 2.46 & 2. & 2.38 & 1.73 & 2.44 & 2.2 \\
\hline 1 & 2.38 & 2.74 & 2.02 & 2.80 & 2.54 & 2.14 & 2.46 & 1.81 & 2.52 & 2.2 \\
\hline & 2.46 & 2.76 & 2.05 & 2.86 & 2.62 & 5 & 2.41 & 1.79 & 2.50 & 2.2 \\
\hline 1 & 2.5 & 2.9 & & 2.94 & 2.67 & 2 & 2.48 & 1.83 & 2.51 & 2.2 \\
\hline 1 & 2.61 & 3.00 & 2.20 & 3.02 & 2.75 & 2.18 & 2.51 & 1.84 & 2.52 & 2.3 \\
\hline & 2.70 & 3.14 & 2.30 & 3.12 & 2.82 & 2.26 & 2.63 & 1.92 & 2.61 & .3 \\
\hline & 2.82 & 3.27 & .39 & 3.25 & 2.96 & & .76 & 02 & .74 & $\because$ \\
\hline 1 & 2.99 & 3.42 & 2.56 & 3.40 & 3.10 & 2. & 2.89 & 2.16 & 2.88 & 2.6 \\
\hline 1 & 3.18 & 3.65 & 2.72 & 3.57 & 3.23 & 2.72 & 3.12 & 2.32 & 3.05 & 2.7 \\
\hline 1 & 3.36 & 3.98 & 2.91 & 3.81 & 3.48 & 2.98 & 3.53 & 2.58 & 3.38 & 3.0 \\
\hline 97 & 3.55 & 4.26 & 3. & 4.06 & 3.68 & 3.12 & 74 & 2.70 & 3.57 & 3.2 \\
\hline 1 & 3.77 & 4.42 & 3.14 & 4.23 & 3.91 & 3.25 & 3.81 & 2.71 & 3.65 & 3.3 \\
\hline 177 & 4.04 & 4.75 & 3.47 & 4.45 & 4.13 & 3.61 & 4.24 & 3.10 & 3.98 & 3.6 \\
\hline 97 & 4.37 & 4.99 & 3.70 & 4.59 & 4.45 & 3.87 & 4.42 & 3.28 & 4.06 & 3.9 \\
\hline 1 & 4.78 & 5.52 & 4. & 5.10 & 4.88 & & 4.90 & 3.65 & 4.53 & .3 \\
\hline 1 & 5.15 & 6.01 & 4.43 & 5.46 & 5.30 & 4.66 & 5.43 & 4.01 & 4.94 & 4.8 \\
\hline 1 & 5.07 & 6.53 & 4.80 & 5.87 & 5.76 & 5.60 & 7.21 & 5.30 & 6.48 & 6.3 \\
\hline 1978 & 5.61 & 7.53 & 5.3 & 6.47 & 6.77 & & 8.15 & 5.84 & 7.00 & \\
\hline 070 & 6.67 & 8.19 & 5.84 & 7.10 & 7.04 & 6.15 & 7.55 & 5.38 & 6.55 & 6.4 \\
\hline & 7.18 & 8.85 & 6.35 & 7.60 & 7.68 & 6.55 & 8.07 & 5.79 & 6.93 & 7. \\
\hline 198 & 7.97 & 9.84 & 7.02 & 8.41 & 8.30 & 7.09 & 8.75 & 6.24 & 7.48 & .3 \\
\hline & 8.50 & 10.69 & 7.65 & 9.25 & 9.01 & 7.54 & 9.48 & 6.78 & 8.21 & 7.5 \\
\hline & 8. & 10 & & & 9. & & 9.7 & 7.13 & & 8.4 \\
\hline & & & 8.28 & 9.75 & 9.66 & 8.02 & 9.65 & 7.27 & 8.56 & $8.4^{\circ}$ \\
\hline
\end{tabular}

Source: Mfg, Appendix A, [9]; Lumber \& Wood Prod., 1972-84, App. A, [12], 1950-71 see page 80 of text for derivation. 
APPENDIX C

TABLE XIX

INDEX OF LABOR PRODUCTIVITY IN LUMBER AND PLYWOOD PRODUCTION $(1967=100)$

Lumber

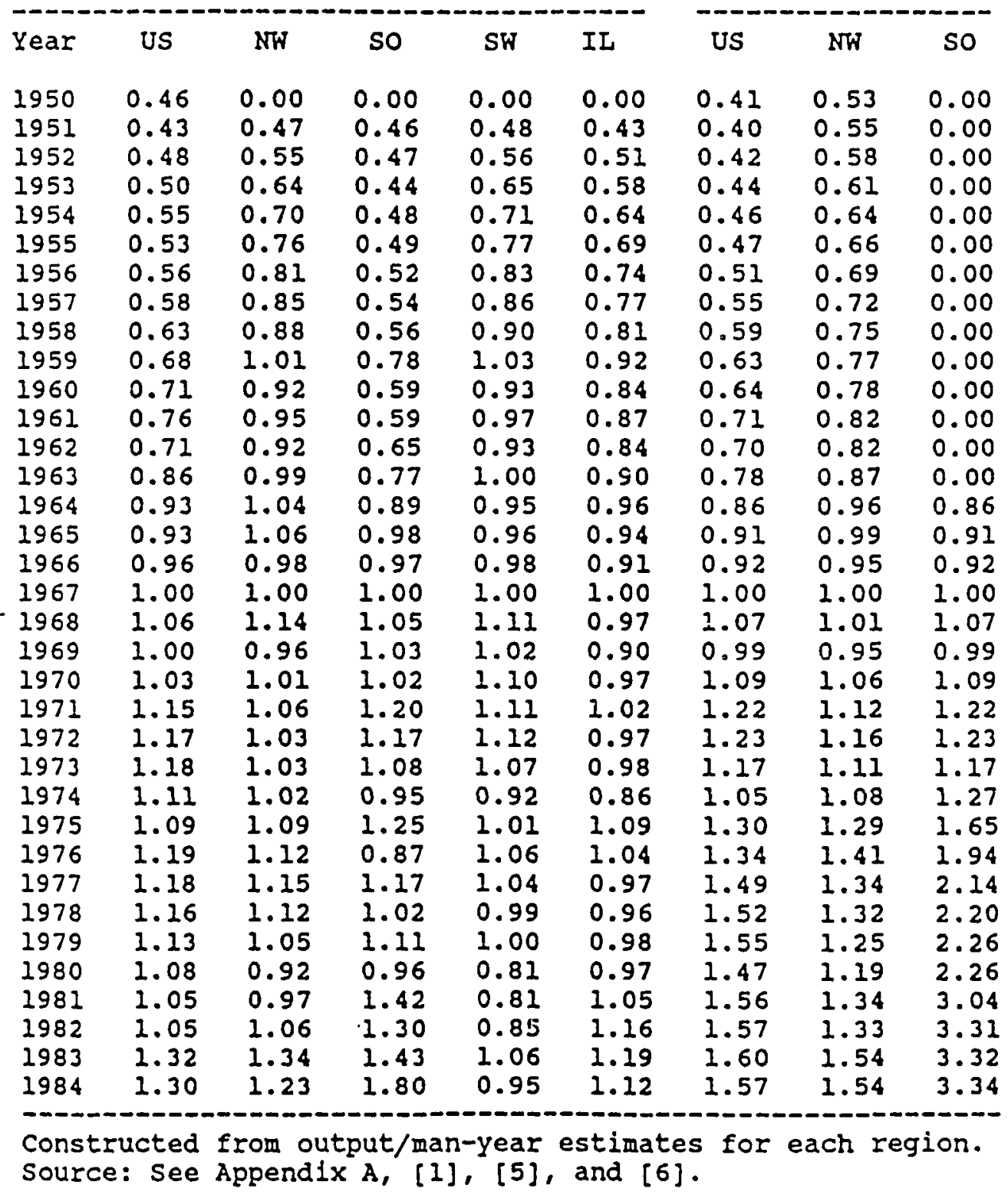

Plywood 


\section{APPENDIX D}

TABLE XX

PRODUCER PRICE INDEX: TRANSPORTATION SERVICES AND LUMBER \& WOOD PRODUCTS FREIGHT

$\begin{array}{lcc}\text { Year } & \begin{array}{c}\text { Trans. } \\ \text { Service } \\ 67=100\end{array} & \begin{array}{c}\text { Lum. \& WP } \\ \text { Freight } \\ 69=100\end{array} \\ & & \\ 1950 & 53.30 & 47.89 \\ 1951 & 58.30 & 52.38 \\ 1952 & 62.40 & 56.06 \\ 1953 & 66.40 & 59.66 \\ 1954 & 69.20 & 62.17 \\ 1955 & 69.40 & 62.35 \\ 1956 & 70.50 & 63.34 \\ 1957 & 73.80 & 66.31 \\ 1958 & 78.50 & 70.53 \\ 1959 & 81.20 & 72.96 \\ 1960 & 83.30 & 74.84 \\ 1961 & 85.30 & 76.64 \\ 1962 & 86.60 & 77.81 \\ 1963 & 87.50 & 78.62 \\ 1964 & 89.60 & 80.50 \\ 1965 & 92.90 & 83.47 \\ 1966 & 96.80 & 86.97 \\ 1967 & 100.00 & 89.85 \\ 1968 & 104.00 & 93.44 \\ 1969 & 111.30 & 100.00 \\ 1970 & 123.10 & 108.40 \\ 1971 & 133.00 & 119.00 \\ 1972 & 136.00 & 123.30 \\ 1973 & 136.90 & 127.40 \\ 1974 & 141.90 & 147.40 \\ 1975 & 152.70 & 163.60 \\ 1976 & 174.30 & 177.90 \\ 1977 & 188.40 & 191.70 \\ 1978 & 197.40 & 205.70 \\ 1979 & 212.80 & 233.80 \\ 1980 & 242.60 & 273.90 \\ 1981 & 271.60 & 320.50 \\ 1982 & 294.40 & 350.60 \\ 1983 & 303.60 & 355.00 \\ 1984 & 313.80 & 382.50\end{array}$

Source: Transportation Services, Appendix A, [14]. Lum \& WP Freight, 1969-84, Append. A, [14]; 195068 derived from regression PPIWPF $=-32.57+1.265$ *(PPI Transp. Services). 